\title{
Lahr, Germany, as a Microcosm of Urban Change examined through the Retail Sector
}

by

Nadine Newman, B.A. (Hons)

Submitted to Carleton University

in partial fulfillment of the requirements for the degree of

Master of Arts

Department of Geography and Environmental Studies

(c) Copyright

May 2006, Nadine Newman 


$\begin{array}{ll}\begin{array}{l}\text { Library and } \\ \text { Archives Canada }\end{array} & \begin{array}{l}\text { Bibliothèque et } \\ \text { Archives Canada }\end{array} \\ \begin{array}{l}\text { Published Heritage } \\ \text { Branch }\end{array} & \begin{array}{l}\text { Direction du } \\ \text { Patrimoine de l'édition }\end{array} \\ \begin{array}{l}\text { 395 Wellington Street } \\ \text { Ottawa ON K1A ON4 }\end{array} & \begin{array}{l}\text { 395, rue Wellington } \\ \text { Ottawa ON K1A ON4 } \\ \text { Canada }\end{array}\end{array}$

Your file Votre référence ISBN: 978-0-494-16435-8 Our file Notre référence ISBN: 978-0-494-16435-8

NOTICE:

The author has granted a nonexclusive license allowing Library and Archives Canada to reproduce, publish, archive, preserve, conserve, communicate to the public by telecommunication or on the Internet, loan, distribute and sell theses worldwide, for commercial or noncommercial purposes, in microform, paper, electronic and/or any other formats.

The author retains copyright ownership and moral rights in this thesis. Neither the thesis nor substantial extracts from it may be printed or otherwise reproduced without the author's permission.
AVIS:

L'auteur a accordé une licence non exclusive permettant à la Bibliothèque et Archives Canada de reproduire, publier, archiver, sauvegarder, conserver, transmettre au public par télécommunication ou par l'Internet, prêter, distribuer et vendre des thèses partout dans le monde, à des fins commerciales ou autres, sur support microforme, papier, électronique et/ou autres formats.

L'auteur conserve la propriété du droit d'auteur et des droits moraux qui protège cette thèse. $\mathrm{Ni}$ la thèse ni des extraits substantiels de celle-ci ne doivent être imprimés ou autrement reproduits sans son autorisation.
In compliance with the Canadian

Privacy Act some supporting forms may have been removed from this thesis.

While these forms may be included in the document page count, their removal does not represent any loss of content from the thesis.
Conformément à la loi canadienne sur la protection de la vie privée, quelques formulaires secondaires ont été enlevés de cette thèse.

Bien que ces formulaires aient inclus dans la pagination, il n'y aura aucun contenu manquant.

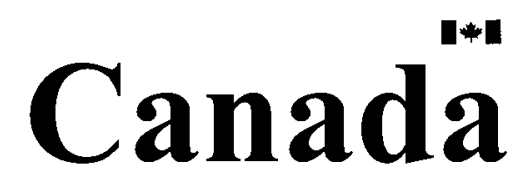




\begin{abstract}
$\underline{\text { Abstract }}$
This thesis examines contemporary urban change in Lahr, Germany, through the lens of the retail sector. Over the last 15 years, Lahr has faced a series of shocks, of which the one with the most impact was the closing of the Canadian Forces base located there. This took millions of Deutsch Marks out of the local economy and reduced the city's population by a quarter. The building of a shopping centre just outside the inner city has also had a severe impact on the core retailing by siphoning consumers away. The final factor examined is broader change in the German economy, specifically the impact of high unemployment and the perceived price increases brought on by conversion from the Deutsch Mark to the Euro. Finally, plans to revitalize the Lahrer inner city by attracting consumers are examined, with an emphasis on the Rahmenplan set out by the City of Lahr. They are meeting with some degree of success.
\end{abstract}




\section{Acknowledgements}

I would first like to thank all those who participated in my thesis, including anyone who agreed to respond to my surveys, City of Lahr employees and store owners who agreed to interviews, and everyone else who contributed to the success of my research.

I would also like to thank my German family and friends, who continued to motivate me to do my best, and who supported everything I did, regardless of the outcome. I would also like to thank my family in Canada for helping me through the process of taking my research and converting it into a thesis. I thank John Tunbridge, who was very friendly and supportive in the early stages of my thesis, donating much of his time to helping me develop the topic for this thesis. I would also like to thank Iain Wallace who assisted me through the later stages of the thesis, dedicating a lot of time towards editing the various drafts and helping to keep focus throughout. I would also like to thank the Ontario/Baden-Württemberg Exchange Program for admitting me as a candidate and handling all the administrative aspects of going on exchange to a foreign university.

Vor allem und besonders wichtig ist es für mich, dass ich mich bei Doris und Helmut Jülch bedanke. In den sieben Monaten, die ich in Deutschland gelebt habe, haben sie ihr Haus für mich geöffnet und mir ein Heim gegeben. Sie haben mir mehr Liebe und Unterstützung gegeben, als ich je hätte erwarten können. Dafür werde ich ihnen mein Leben lang dankbar sein. 


\section{Preface}

The original concept for this thesis was brought to my attention by a resident Lahr. Lahr, a city of 43000 , located in Baden-Württemberg, Germany, is my hometown and I lived there until 1993, which is why I still have close, personal connections to the area. I visit as often as I can and am quite interested in its development. During the time in which I was attempting to formulate a question for my thesis, I received a telephone call from a friend. During the course of our conversation, she mentioned that the city centre was becoming quite deserted, and that on my next visit I would not find it to be the bustling inner city that I remembered. This is the one phrase that essentially shaped my thesis. I decided that the decline in activity in the inner city would be an excellent starting point for a thesis. I had some theories as to why this might be so, but my three main factors were established only once I arrived in Lahr and began to assess the situation.

It is also because of my close connection to Lahr that I have elected to write this thesis in the first person. I find that it is difficult to separate myself from this body of work and therefore feel that the first person point of view in the most logical to use. 


\section{Table of Contents}

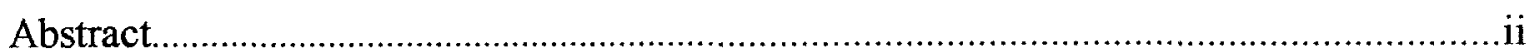

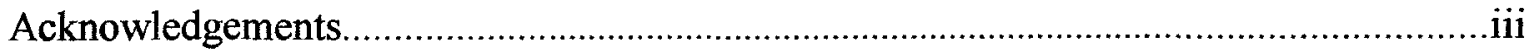

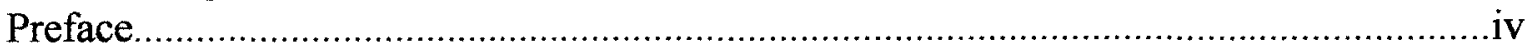

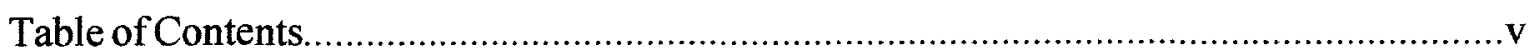

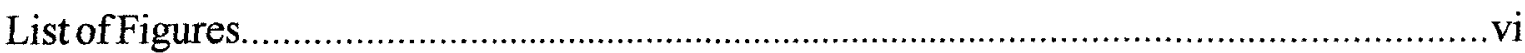

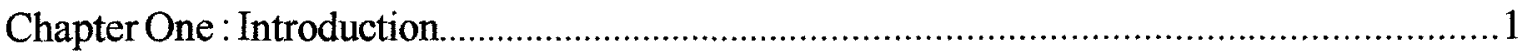

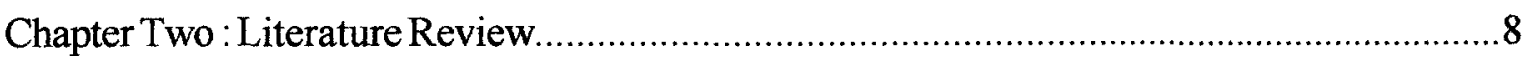

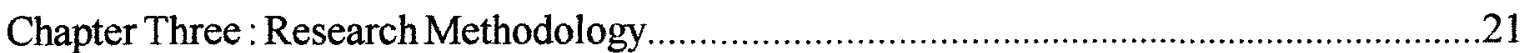

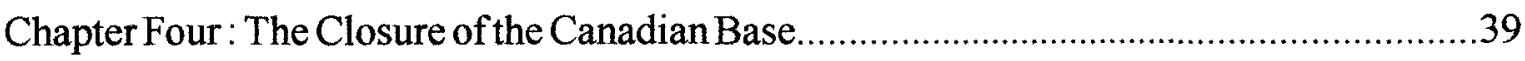

Chapter Five : Impact of the closure of the Canadian Base on the Retail sector in Lahr.......60

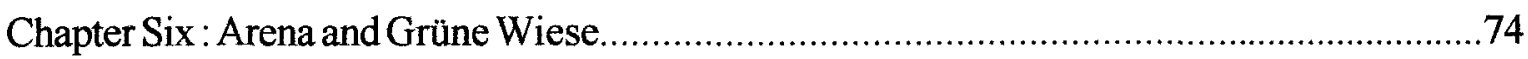

Chapter Seven : Effect of German Economy and Euro Conversion.............................92

Chapter Eight : Plans a nd Attempts to Revitalize the Lahrer Innenstadt..........................123

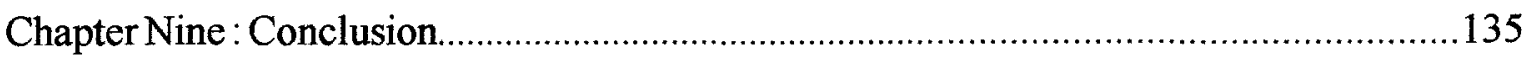

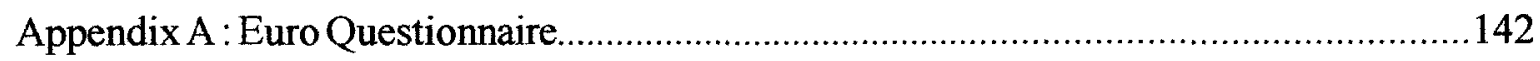

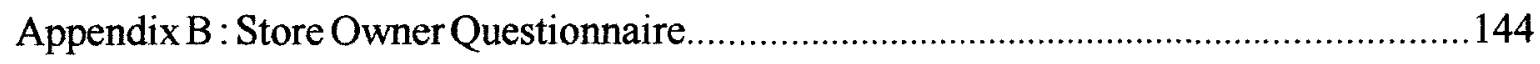

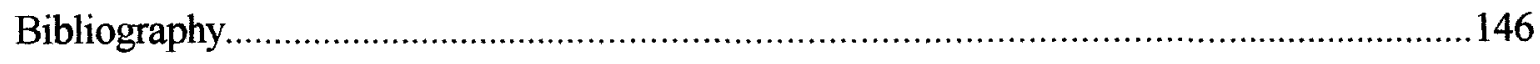




\section{List of Figures}

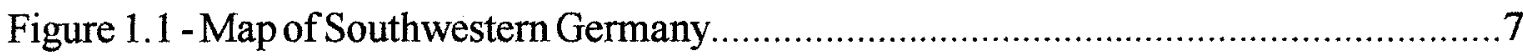

Figure 4.1 - Timetable for the pullout of Canadian troops from Lahr..............................50

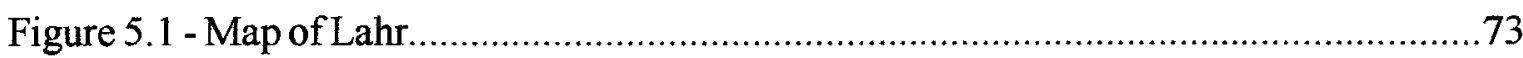

Figure 6.1 - Map of Arena in relation to the Innenstadt........................................90

Figure 6.2 - Map showing the Grüne Wiese in relation to the Innenstadt.....................91

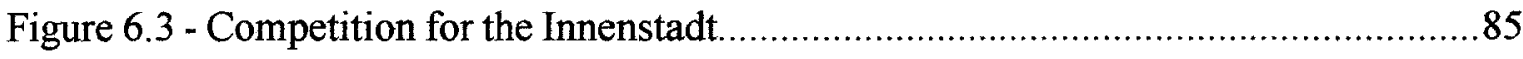

Figure 7.1 - Unemployment Rates in the German States June 2005 ............................97

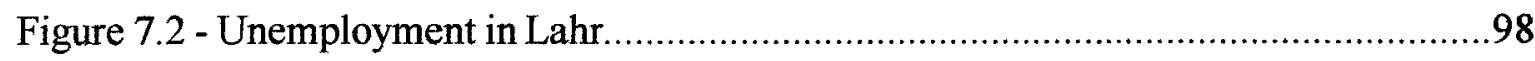

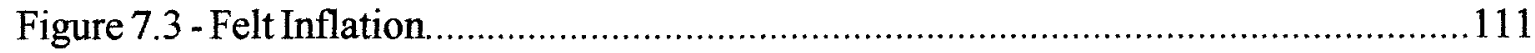

Figure 7.4 - Most important reasons for preferring Aldi to other stores........................116

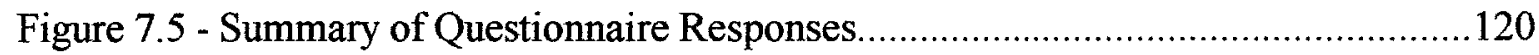

Figure 8.1 - Example of sign to encourage more side street patronage ..........................129

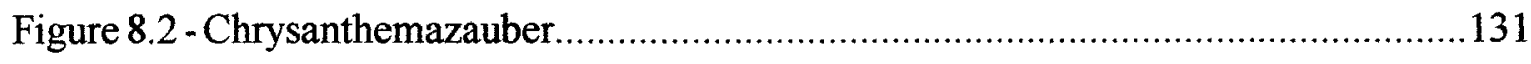

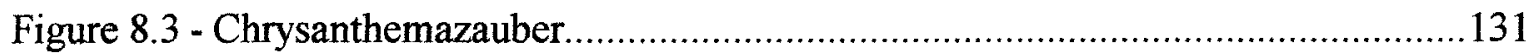

vi 


\section{Chapter 1: Introduction}

This thesis will examine the contemporary changes occurring in the central district of Lahr, in southwestern Germany (see Figure 1 on page 7). Many changes have occurred in this town over the last 15 years, including the pull out of a Canadian military base and building of a new shopping centre outside of the central area. This thesis will use the retail sector to examine the impact these changes have had on the town centre and how it has developed over this period. It is hoped this examination will help our understanding of how urban areas experience and manage change. The distinct combination of interacting factors makes this study unique, however, at the same time, it is hoped that the gained understanding can be applied to other areas.

Lahr was chosen because it has experienced an interesting mix of shocks at both the local, national, and international level. This mix of factors makes Lahr unique, yet at the same time, issues are being dealt with that apply to other European cities, and therefore, by examining these factors, light could be shed on other European cities facing similar situations. For example, the conversion to the Euro has had an impact on Lahr and what is discovered could be applied to other German cities, as well as cities in other countries that adopted the Euro as their currency and are experiencing similar problems.

Personal reasons also factored into the decision for choosing Lahr. The author grew up in this town, and therefore, when choosing a European city, there were simply many logistical advantages to having acquaintances locally and being familiar with some of its history and development. The fundamental reason for the selection of Lahr, however, was 
simply its distinctive mix of circumstances. The severe negative shock of the closing of the military base, and the fact that the shopping centre is relatively new provides an interesting opportunity to see how a city copes with these changes.

The retail aspect of the city is a very old and important part of the centre. Ever since stores have existed, they have existed in the city centres. This was where most of the people either lived or passed through, and therefore, when dealing with a fixed location, it just made sense to locate in the centre. The focus on retail as the lens through which the urban change is being examined was chosen because all the factors influencing Lahr have had a direct impact on the retailing situation. The local retail sector is experiencing much change as a result, making this an interesting time period for the town, and decisions stakeholders make now will influence Lahr's retailing future for many years to come. In North America, retail on the urban fringe is already well established. The city centres have much less ability to pull consumers out of the suburbs and into the inner city for shopping purposes. The suburbs are well equipped with stores and have supplied their consumers with so many shopping choices that there is no reason to leave them (Jordan-Bychkov and Domosh, 2001). However, in Europe for the most part, the city centre still appears to have some pull on the local residents. Perhaps as a result of not having as much open space to develop, planning regulations, or perhaps due to the longer history of the European city centres, residents still seem to find themselves pulled to the central areas of their cities for their primary shopping needs, as was traditionally the case. However, there is slowly some evidence of stores opening up and being successful in more fringe locations; stores that cannot meet the normally restricted space requirements of the inner city, or that wish to offer abundant free parking along with their 
products. More specifically, this thesis will examine the development of the retail sector in the centre over the last 15 years. What problems are arising in the city centre? Where is the competition coming from? Is anything being done to combat the problems? These all tie in with the development of the city centre, making them important questions for the local store owners and city officials, as well as being helpful reflections of how cities cope with change, and therefore, they will all be examined.

The main point of differentiation of Lahr from other towns is that since the end of the Second World War, Lahr has had a foreign military presence. An occupying force of French troops arrived on April 18, 1945. These troops remained in the area until 1967 when they withdrew as a result of a conflict between France and NATO (Nicks, 1992). In 1967, to replace the departing French troops, Canadian troops were sent into the area. This fact makes Lahr an interesting place for a Canadian to study because of this link. The closing of the Canadian base is also arguably the factor with the most influence on Lahr. These Canadian troops were to remain in the area indefinitely. However, with the end of the Cold War in 1990 , the need for NATO countries to maintain foreign bases severely diminished, and in 1991 it was announced that the Canadian troops would be pulling out of Lahr. The final Canadian troops departed in 1994, and as a result, over a period of about two years, the population of Lahr dropped by approximately 10000 , to approximately 35000 (Stadt Lahr, 2005, and Freeman, 1998). This did not leave Lahr a great deal of time to adjust and to introduce measures that would compensate for this loss. Arguably the greatest impact of the departure was economic. The troops and their families spent an estimated $400-500$ million Deutsch Marks annually in the region, and their loss was felt by all merchants 
(Freeman, 1998). Therefore, to fully understand the changing retail situation in Lahr's centre, the departure of the Canadians must be addressed as a factor influencing the area.

What impact did the closing of the base have on Lahr's city centre? Did the Canadians do a lot of shopping in the inner city? These are important questions that will help identify the Canadian role in the development of the Lahrer Innenstadt (city centre) over the last 15 years. The Canadian troop withdrawal is the main reason for selecting the time frame of 15 years. As the research was carried out in 2005 , this puts the last 15 years at 1990 , before there was any mention of Canadians pulling out, and during a time when the Innenstadt was said to still be flourishing, according to local residents. I personally was living in the area at the time, and there was never any mention about the Innenstadt being in any sort of competition for consumers. It was the place where people went to shop; that was taken for granted. This function began declining after the pull-out of the military, and it is therefore an important aspect that needs to be examined in this thesis.

The second reason that Lahr is an interesting town to study is that it is experiencing some of the first stages of contemporary change in the retailing pattern. As mentioned earlier, around 1990 it appeared that the inner city was still the main area for shopping. However, in 2000, a shopping centre, the Arena, was built just outside the inner city. This offers all the amenities of other shopping malls, most prominent being a controlled environment and lots of free parking. This shopping centre celebrated its five year anniversary during my time in Germany, and it appears to be a success. This is a sure sign that things are changing in Lahr as far retail patterns are concerned, as many people have begun to shop at the Arena at the expense of the inner city shops. So it is a challenging time for the stakeholders of the 
Innenstadt, store owners and city officials, to see how they can cope with this extra competition. This comes on top of competition for the Innenstadt from the Grüne Wiese, a type of 'big box' store complex, not connected like a mall, but where many large stores share a large parking lot. This complex is located further outside of the centre, but is still viewed as competition for the Innenstadt. It has existed since the mid 1980s but has certainly gained in importance in recent years. It is excellently located on the street that comes from the Autobahn, before one enters the city centre, giving it a competitive advantage for non-local consumers, as well as those from the Western portions of Lahr. The Arena is also located on this road, and so it represents an intervening opportunity before arriving in centre town. These two shopping complexes display characteristics quite similar to those of their North American counterparts, and being relatively new, it is necessary to examine the impacts they have on the Lahrer Innenstadt. One needs to explore why customers choose to patronize these complexes over the inner city.

The final factor that is influencing the development of the Innenstadt is the overall state of the German economy. A detailed examination of the German economy is not central to this thesis, and its specific impact on the Lahrer Innenstadt is difficult to isolate. But this study will focus on the two aspects of the economy with which German retailers appear to have the most problems: the conversion to the Euro, and the impact of high unemployment rates. At the beginning of 2002, many European countries converted their currency to the Euro in order to strengthen the bond of the European Union countries and make intraEuropean commerce easier. While this changeover has eliminated the need for exchanging money and being familiar with the value of foreign currencies, it also appears to have been 
used to increase prices of goods, or at least so the consumers appear to believe. In Germany there appears to be much popular discontent with the way the prices were converted, and complaints could still be heard in stores or even in everyday conversations three years after the switch. There has been much attention given to this topic by the media, although the opinion of experts presented suggests that prices have not increased, or at least not by much. However, the consumers steadfastly believe that goods have become more expensive, and have responded with a decrease in spending.

High unemployment is another problem in Germany, and many people do not feel they have job security. This encourages them to be more thrifty and to save more money than in previous times. This, coupled with the perceived increase in prices, appears to have resulted in consumers holding back or purchasing only the necessities. What has been the impact of Germany's slowing economy on the Innenstadt of Lahr? Or more specifically, what roles have the Euro conversion and job insecurity played in the development of the inner city of Lahr? An extension of this line of questioning could also include an examination of what the Innenstadt stores offer, and why people watching their wallets would choose not to go to there whenever they do go shopping. Where else are they shopping?

Finally, after examining all of these factors, it is worthwhile to examine what the municipal government and other retail stakeholders are doing to reinforce its centre. How is Lahr coping with these possible changes in consumer behaviour? What initiatives are being undertaken to revive the centre? And how do the store owners view the impacts of these changes? The way Lahr handles these changes will certainly define the conditions under which the inner city will continue developing. 
Figure 1.1 - Map of Southwestern Germany

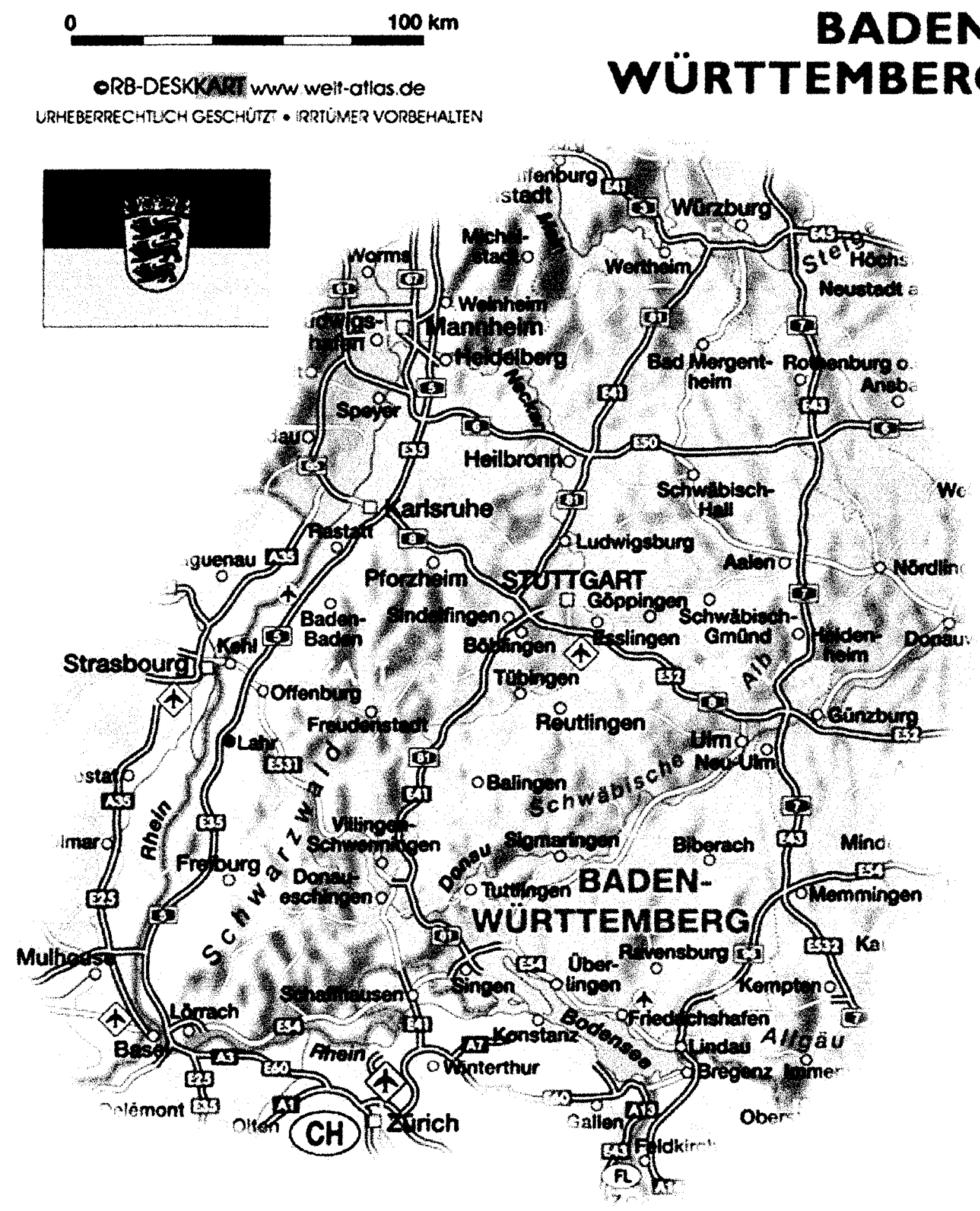




\section{Chapter 2: Literature Review}

This thesis draws on a variety of literatures to connect the various themes which range from base closings to retail patterns. However, these all intersect when examining urban change through the retail sector in Lahr, as all have had an impact on the city and its historical core.

Arguably, the aspect that makes urban change in Lahr unique, while at the same time being the factor with the largest impact, is the closing of the Canadian military base. For this reason the body of literature relating to base closures will be examined first. After the fall of the Berlin Wall and the end of the Cold War, there was no longer a need for NATO countries to keep as many bases open in Western Europe, and defence budgets were cut back in recognition of the reduced risk. As a result, many bases were selected to be closed down. A factor in the decision of which bases to close, was the strategic importance and location of the base (Warf, 1997). The base in Lahr was likely selected to be closed for strategic reasons, since it would no longer be important for Canada to have bases close to Warsaw Pact countries (the other Canadian base in Baden-Söllingen was also closed).

Base closures are considered a form of de-distributive politics. De-distributive policies generally impose a loss on a community, a region, or an entire country. Elected officials generally shy away from these types of policies because of potential electoral repercussions. But it is easier for governments to close foreign bases as opposed to domestic bases because the politicians making the decisions do not have to fear the electoral repercussions. Lahr certainly suffered the loss, in this case, at the hands of the Canadians (Goren and Lackenbauer, 2000). 
There are also a number of base closure characteristics that are drawn from the theoretical literature. While these are based on domestic base closures, they are still relevant to foreign base closures. The first assumption that can be derived is that the problems that result from base closings are highly concentrated geographically. There is a concentric ring of benefits that emanates from a dense core in the town closest to the base outward while it is still in operation. When the base closes, it is known that the loss imposition is highly visible and has a clear and delimited range of impacts (Goren and Lackenbauer, 2000). This is relevant to Lahr because some surrounding towns also benefited from the Canadians' presence, primarily through having shopping money spent in their areas. However, it is Lahr that suffered the greatest loss, as the base was located directly in the town. While base closures are certainly bad for the town affected, the politician can take some comfort in the idea that these policies affect only one specific area, as opposed to other policies that would affect the whole country. Essentially, with base closures, a small minority stands to suffer those who are forced to bear the costs in the short run - while a large, diffused majority stands to gain a little in the long run via the savings that are generated from closing the base (Goren and Lackenbauer, 2000, and Warf, 1997).

The second assumption that can be drawn from the theoretical literature is that large urban centres can recover quicker and more successfully than small towns and rural areas. This is largely because large urban centres have a much wider economic base (Goren and Lackenbauer, 2000).

Thirdly, losses suffered due to a base closing are primarily material in nature and include jobs, both military and civilian, the withdrawal of the economic stimulus of a city or 
region, and the reduced tax revenue generated for state revenues. Generally the level of resistance to a base closing is directly related to the size of the facility and consequently the impact it will have on the wider community (Goren and Lackenbauer, 2000). There is some evidence that the German federal government tried to keep the Canadians in Lahr for a while longer, demonstrating their knowledge that the area would suffer economically if the Canadians withdrew.

The final assumption is that any loss of revenues with such clear spatial delineations will be politically sensitive, either to the politician seeking reelection, or to the regional authorities which may perceive such closures as an attack on their region. Losses can be specifically identified with a political representative, and because political representation is organized spatially, this can be very politically sensitive, and lead to regional rivalries (Goren and Lackenbauer, 2000). Federal aid to communities affected by base closings is viewed as an essential part of defence adjustment in the United States, to help the communities make a transition successfully (Glassberg, 1995). The closed Summerside base in PEI provides a good Canadian example, in that when the base pulled out, the federal government built the GST Taxation Centre there to compensate for the lost jobs; and in other areas, the government usually supports a community-led redevelopment process (Bruce et al., 1995). However, as mentioned earlier, the Canadian politicians did not have to worry about voter backlash or providing financial aid in the case of Lahr, as the damages were suffered an ocean away. This certainly makes it easier to close foreign bases before local ones.

Bruce et al. (1995) have written a primer on base closures in Canada and how the community can recover. This publication identifies both negative and positive impacts of 
a base closing for the surrounding community. While this research is grounded in Canadian cases, the impacts would arguably be the same overseas. I believe that the negative impacts that the authors list, including lower salary levels in newly created jobs, excess housing stock, support and service industries losing customers, and the loss of an important tax base are accurate pointers to what happened in Lahr. However, the positive impacts of the closing of the base appear not to have materialized. It is recognized, however, that this primer was written about base closings in Canada, and does not appear to take into account the closing of Canadian bases in foreign lands. But it is also not clear whether this means that the positive effects are different for foreign bases. I believe that this thesis shows that the positive impacts can be completely discounted when dealing with a foreign base, as in Lahr's case. The positive impacts listed by Bruce et al. are as follows: minimal change in unemployment rate, minimal impact on retail sales, possible openings in the private sector, and a new supply of quality, low cost housing (Bruce et al., 1995).

To briefly explain why I think these are not applicable, although these factors will be discussed in more detail later, approximately 800 Lahrers were employed by the base, no small figure in a town of its size. Also, the retail sector does appear to have suffered greatly. Bruce et al. argue that most of the shopping is done on the base, however, in a foreign land there would definitely be more allure to shopping off the base. Due to language barriers it would not appear that too many Canadians would have had jobs off the base to supplement their income, so the third impact would also not be as important. And finally, the amount of low cost housing has attracted many low income Russian immigrants, which in itself is also changing the retail and social structure of the town. As these ideas are developed more fully 
it will likely become apparent that any positive impacts of base closings are rendered invalid when applied to foreign bases, and certainly when applied to the specific case of Lahr.

The Tourist-Historic City (Ashworth and Tunbridge, 2000) develops theory that relates to the historic core of cities. This book theorizes that any town (primarily European ones, however) will attempt to sell its heritage in order to become a tourist destination. It sees this development as a means of competing that is open to every town (Ashworth and Tunbridge, 2000). This competition would be particularly important for a town that has just lost a significant part of its economy. This theory is relevant because a vibrant downtown (where the majority of heritage buildings are located) is necessary for tourism, and perhaps another reason to improve the Lahrer Innenstadt area could be to help boost the tourism industry in order to improve the overall economic situation which has suffered since the troops pulled out of the region. There is certainly evidence of this with the Chrysanthema festival held in the fall, which has only begun since the Canadians left (see Chapter 8). In addition to this, Perks and MacDonald (in Koster and Randall, 2005) argue that culturalhistoric assets can be revived for economic reasons, but also as a way to enhance the livability of communities and strengthen their population retainability. This links the idea of a vibrant core with both tourism success and providing a better quality of life for all its residents.

Retail literature is also important to help situate the information about Lahr's retail patterns and situations. When considering retail environments there are two scales that are important. The first is the urban settlement scale, which encompasses national, regional, and urban markets. In this case the metropolitan area is treated as a unit, and is compared with 
other such units on the basis of size, growth and competition. The second type of scale is the metropolitan scale which examines patterns of markets and retail facilities within the urban area, breaking it down into communities and neighbourhoods, as well as non-spatial submarkets including the rich, the old, and college students. (Jones and Simmons, 1990). These types of scales are important to acknowledge as my study of Lahr will include both types. The urban settlement scale will be relevant when discussing out-of- town shopping, but the emphasis is on the metropolitan scale, as I examine how retailing in Lahr has shifted away from the Innenstadt.

At either scale, there are five types of boundaries that are relevant and will have an influence on the type of shopping that can be offered and that will be sustainable. The first type of boundary is institutional. This includes the rules and regulations of organizations including government (Jones and Simmons, 1990). This could play quite a role in Lahr as there are strict rules pertaining to when and for how long stores are allowed to be open in Germany.

The second type of boundary is natural, and includes the location of mountains and rivers. This boundary was historically more important than it is now, however with Lahr on the edge of the Black Forest region, the system of valleys and roads could prove to be a factor. The third type of boundary is the density of housing. This helps determine how much retail could be successful in a certain area, as settlements form distinct markets where boundaries occur between the two settlements. The fourth boundary type is the spatial decay pattern imposed by transportation costs. This essentially determines from how far away a store can expect to attract customers (Jones and Simmons, 1990). 
The final boundary is a result of the action of competitors. This is essentially based on how close they are located to you, and the boundary is the midpoint between the two stores. It is assumed that the consumer will go to the store that is closest to them, and not travel further to another store that sells the same merchandise (Jones and Simmons, 1990). Retail literature also helps establish some patterns of change (ie. Wrigley and Lowe, 1996, Heinberg, 2001, Popp, 2004, and Gerhard and Hahn, 2005). The large stores of the Grüne Wiese and the new Arena demonstrate that there are some retail changes occurring in Lahr, namely taking away the focus on the inner city as the main location of retail activity, which is occurring in many German cities (Heineberg, 2001). The main change described in the literature is the addition of huge, discount stores (for example the Walmarts and Home Depots). These types of stores have generally four effects : they cause market saturation, they drive retail prices lower, they give consumers many more choices, and they consequently make it more difficult for small businesses to operate profitably. These larger stores are also noted for appearing on heavily travelled roads and highways, as certainly is the case in Lahr (Stone, 1995).

The main method or mode of competition for the smaller stores of the downtown is to focus on quality. This is however, not strictly limited to the merchandise. It includes hiring good employees, training them well, adopting new and efficient technologies, having a user friendly store, having an attractive, functioning store layout, an easy return policy, and doing things correctly the first time (Stone, 1995). It would appear as though many of the stores in Lahr's Innenstadt understand that this is the niche they can exploit to their advantage as quality becomes an important discussion point when comparing themselves to the other 
stores outside of the downtown, as will become evident in future chapters.

There is also a body of literature about main streets and their general problems (Holdsworth, ed, 1985). The main threat to main streets and their success are the malls. Main Streets cannot compete with the abundance of free parking, the benefits of a climate controlled environment, convenient shopping hours, and popular anchor stores (Kalman, 1985 and Stone, 1995). Attempts to revitalize main streets have historically included modernizing store fronts (usually to the detriment of the historical buildings) and knocking down buildings for parking lots. This generally causes people to move out of the main street, resulting in run down and vacant upper floors of buildings, property values significantly decrease, other stores are forced to close, and eventually people do not go anymore and the main street loses its life blood (Kalman, 1985). While this Main Street Literature is based on the North American experience, it applies well to the Lahrer context as well. The issues being faced in Lahr are similar, and the competition is also coming from similar avenues. The difference would, however, be evident in the amount of desertion that has already occurred. While in Europe the downtown still seems to be an important location for retail activities, in North America this has not been the case for some time, already beginning in the post WWII time period, when the car became much more popular and accessible for nearly all families (Jordan-Bychkov and Domosh, 2001). It is stated that the downtown "is no longer the focus of retail activity; that role has been passed to major suburban shopping complexes" (Jones and Simmons, 1990, 243). My own experiences can certainly confirm this statement, as I live in the Ottawa suburb of Orleans, and never go downtown to shop, as I have everything I need in Orleans. In Lahr it would appear they are trying to make sure that the 
city does not develop in this fashion.

Methods of counteracting this are usually organizing merchants on main street into a collective effort to change the appearance of the core, including changing it by fixing the store fronts, by catching the consumers' eye with tasteful signs, and building store fronts sympathetic to the historical fabric of the buildings. It is important for the group of merchants to work together because if only a few merchants participate, it could hurt them due to the high costs of renovations; but if everyone participates, then the whole ambience of the street is changed and consumers are likely more willing to return. Unfortunately it is oftentimes difficult to get all the merchants to agree due to individual competitiveness as well as the high cost involved. The marketing then needs to be improved in order to re-attract the consumers into the area (Kalman, 1985). There is certainly evidence of increased marketing in Lahr and clear attempts to draw people back into the Marktstrasse. Merchants are also working together in the Lahrer Retail Promotion Organization (LRPO).

The National Main Street Center in the United States organizes Main Street programs all over America with their four-point approach. While Lahr is not following this specific program, there are still some similarities that could help determine whether their efforts will be successful or not. The first point is Organization, which includes raising funds, developing communities, recruiting members and building partnerships (Robertson, 2003). In Lahr's case, it appears to be mainly the city and the LRPO who are concerning themselves with getting more people into the Innenstadt. The second point is Design, which involves enhancing the downtown's physical assets and visual qualities, something the City of Lahr is definitely very involved with: however, it is often hampered by budget dilemmas. The third 
point is Promotion, clearly referring to the marketing and publicizing the downtown with the goal of improving its image, as well as sponsoring events occurring in the downtown and attracting people to them. Both the city and the LRPO again are very involved in this aspect. The final point is Economic Restructuring, which refers to strengthening and adjusting the downtown's economic base and business mix (Robertson, 2003). There is definitely evidence that the City of Lahr is attempting to attract larger retail stores to the Innenstadt to make it more of a magnet. It would appear as though Lahr is, for the most part, following a strategy determined to be successful in the United States, whether consciously or not. However, the attempts of Lahr to revitalize its downtown core will be examined further.

In Germany in particular, there appears to be a trend towards helping the inner cities by developing shopping centres in inner city locations. It is believed that this will improve the situation for the retail locations in the town. However, those opposed "see direct competition as a dangerous trend that could lead to (further) decline of the town centre" (Popp, 2004, 107). With this notion, however, come very many variants, including the distance between the town and shopping centre, the difference in size of the two locations, the space that connects the two, and so on (Popp, 2004). This idea is still being contested, but as it originated as an idea to help declining inner cities it is relevant here. In addition to this, the fact that the City of Lahr approved this location for the shopping centre very close to the town makes this idea very pertinent in this thesis. This idea will be discussed more in depth in Chapter 6.

A very popular notion in German cities is that of the Fußgängerbereiche, or Pedestrian Zones in the city centres. These areas are closed to cars, and pedestrians have sole authority over the streets. These areas help make the downtown areas more attractive. In a survey, $42 \%$ 
of respondents believed that the Pedestrian Zones were very good, and 39\% said good, with only $5 \%$ of respondents saying they were bad (Monheim, 2000). Overwhelmingly, German shoppers like these areas of their inner cities. The development of these areas started during the rebuilding phase after the Second World War. By 1960, 31 cities in West Germany had Pedestrian Zones, $71 \%$ of these in big cities. In the 1970 s mid to small sized towns began catching on to the ever growing trend, and at the beginning of the $21^{\text {st }}$ Century nearly every German city boasts a Pedestrian Zone (Monheim, 2000). These areas were purposely built with the goal of making the city more attractive to consumers, as well as to the retailers of these zones. It led to a changing use of the downtown area, becoming more popular during periods of free time, and in the 1990s the use of the downtown as an area of promoting culture gained prominence. These zones are often used by City Marketers, to help foster identity and quality of life amongst those who visit the area (Monheim, 2000). This could help explain the importance of the Lahrer Innenstadt, as most of it is designated as a car-free zone. Lahr's inner city was declared to be a pedestrian zone in the $1970 \mathrm{~s}$, and does offer many cultural events, as Monheim suggests is an important function of the German Pedestrian Zone.

As this thesis focuses upon a certain area in southern Germany, it could be considered under the category of regional studies, shedding light on issues in this area. While Lahr is being viewed as a region in context, it should also be noted that this exact combination of factors can only be found here, and this combination also makes Lahr unique. The specificity of place is viewed as an important part of geography, and appears to be reasserting itself in the discipline. Massey speaks of a non-parochial view of place which relates to a "view of locality which stresses its linkages with the wider world" (Massey, 1993, 144). Clearly Lahr 
is a locality with plenty of links outside of its physical area. Its links with Canada were strong when the base was in operation, and even now it claims a partner town in Belleville, Ontario, as well as one in Dôle, France. Other questions Massey raises include, how do the actions of local people affect the global? And how they are affected by the global? (Massey, 1993)

Lahr is certainly a town greatly affected by global actions. The end of the Cold War had a tremendous impact on the town, the most immediate effect being the reunification of Germany. Following that, it led to the closing of the Canadian base, removing a vital source of economic prosperity in the town. With the increase in vacant apartments afterwards, many Russians with German heritage were attracted to Lahr to fill these vacancies, as they took advantage of Germany's right of return laws. On a European level, the euro conversion also had a strong impact in Lahr. Clearly Lahr is very impacted by these global happenings.

This literature review demonstrates how many different influences are at work when considering the development of Lahr's downtown. The base closing and retail literatures were given priority here because these relate to the local factors of the Canadians and the development the retail sector has faced in Lahr. The base closing literatures help set in context the losses that Lahr has experienced, and the types of repercussions this has on a community. The retail literature helps identify and where problems arise for inner city retailers as they primarily focus on quality merchandise. It also examines how placing malls close to city centres was believed to be beneficial for the centre, but as time passes, this notion is being called into question, setting up an important avenue of exploration with regards to the Arena. Inner cities have often looked towards heritage to revive a slowing economy, which in this case would be caused by losing the Canadians and the construction of the Arena, and so this 
was briefly examined as well. Clearly any examination of the Lahr region needs to focus on a wide variety of themes as they all intersect and are relevant to Lahr despite their surficial dissimilarities. 


\section{Chapter 3: Research Methodology}

Most of the research undertaken for this thesis is qualitative. Due to the nature of the topic, the research involved interviewing people with expertise in the area, as well as researching newspapers and other documents. The limit of my using quantitative analyses will be discussing percentages from the questionnaires, counting, and comparing statistics. Participant observation will also play an important role as I was in the field observing activities in the Innenstadt and other shopping complexes for seven months. The research methods I had planned prior to leaving, however, were quite impacted by the response I received once I arrived in Lahr, forcing me to adjust as I went along.

During the initial stages of my time in Germany, field reconnaissance was crucial in order to determine if the research question I had developed in Canada regarding the urban change occurring in Lahr, manifesting itself in lower visitation levels of the stores in the Innenstadt, was a viable angle. This essentially required that I visit the Innenstadt during different times of day and different days of the week to see how full or empty the streets were. The focus here was on the main street, the Marktstrasse, and the smaller side streets. In addition to this, I visited the Arena and the stores of the Grüne Wiese to establish how well they were being patronized during different time periods. This was essentially determined by the sheer mass of people in the area, cars parked in the parking lots, and nothing else. This included how many rows back the cars went, how full the streets and stores were, were they easy to manoeuver or very full, and so on. This was not quantified in any other way as it was regarded as preliminary research simply to assess if I could go ahead with my thesis as planned, and since the data would not be used in my analysis, this method was deemed 
adequate. Since I am familiar with the area, I also used this time to walk through the downtown and see which stores had closed since my last visit, what were the new types of stores, and which stores were still there from when I used to live there, 12 years ago.

This was also the time where I had to make changes to my initial outline that I had written in Canada. For example, at that time, instead of investigating the Arena and Grüne Wiese, I had planned to examine the combined impact of the stores that had moved to the vacated base. However, upon my arrival it was very clear that the base stores were not much of a factor. This area is more filled with businesses and other odd buildings, including a hostel, a nightclub, and a Jehovah Witness building. The main shopping attraction in this area is a huge furniture store (but clearly furniture is not something one buys everyday), and a flea market every two weeks. Prior to my arrival in Germany, I was not aware of exactly what types of buildings were on the base, just that there had been a lot of development in the area, and I had heard from other sources during previous visits that the city wanted to develop a retail sector in that area.

However, when I arrived, it was clear that the base posed no threat to the inner city, both on account of the content as well as that it is so far away from the core: this was not the kind of retail development that consumers visited on a daily basis. What really posed the threat was the Arena and Grüne Wiese. The Arena is a new shopping mall that was built in 2000 , close enough to town to be central, but far away enough from the core not to be considered part of it. The Grüne Wiese is a somewhat older development, dating from the 1980 s, similar to a strip mall that offers about 10 relatively large stores with lots of parking, directly off the main road into town. These are really the places having an impact on the city 
as they contain the type of retailing that is frequently patronized, including grocery stores and clothing stores. So this initial period of observation was very valuable in adjusting the thesis to the situation on the ground. Fortunately, what I had assumed to be on the base was the type of developments that are at the Arena and Grüne Wiese, so making this substitution did not create any problems in my methodology because I had already planned for investigating this type of development. The only other changes from my original outline that had to made were reducing the number of people I had originally planned on interviewing, but this will be addressed below.

The fact that I am conducting research in my hometown and have a longer family history in this area likely has an influence on my research. This alone will influence the types of things I take for granted or some assumptions that I make. It is difficult for me to know now exactly how much this has influenced my research, but I have kept it in mind when formulating questions and have attempted to be as objective as possible. However, as England argues, "fieldwork is intensely personal, in that the positionality and biography of the researcher plays a central role in the research process, in the field as well as in the final text" (England, 1994, 87). So clearly the fact that I conducted the research, and not someone else, will have a strong bearing on the results. As Stanley and Wise build on this idea, "our consciousness is always the medium through which the research occurs; there is no method or technique of doing research other than through the medium of the researcher" (quoted in England, 1994, 84). Reflecting upon one's position is a necessary step in identifying the fact that it is impossible to create completely neutral knowledge, and to recognize that the type of knowledge that is created is largely dependent on who is creating that knowledge (Rose, 
1997). For this reason a discussion of my personal biography is imperative to understand the lens through which I conducted my research.

The types of things that constitute positionality include gender, race/ethnicity, class, age, as well as the researcher's own biography (England, 1994). In my case I will have a somewhat similar background to the people I am interviewing. I am from the same town that they currently live in, and I am of German nationality, so there are some similarities. However, I do have a dual identity as a German-Canadian, and this is something that not many other people will have. One important factor related to this is that my university education is from Canada, so I will not be familiar with how Germans generally conduct research or other academic pursuits, and I will do them the way I was taught to, which could be quite different. Other factors that may prove to be notable in my interactions with my interviewees could be my age, gender, and my status as a student.

There are some clear strengths and weaknesses about having a personal background in the research context. The most obvious weakness would be that I look at Lahr favourably, not unusual feelings to have for one's hometown. So clearly I have a bias: however, I do not feel this is a topic that can really be greatly compromised by my liking the town. In addition to this, it is highly unlikely that any researcher can remain completely neutral and not have any personal feelings regarding their research topic since they likely chose it due to a personal interest. As Fuller argues, it is a false assumption that the researcher is "inert, detached, and neutral;" and therefore, I am trying to identify my personal connections in order to identify where any feelings I have come from so I can deal with them accordingly, or at the very least, simply be aware they exist (Fuller, 1999, 224). 
I believe that the strengths of doing my research in my hometown far outweigh any weaknesses. Firstly, as a result of having lived there and visiting often after leaving, I have a good awareness of developments that have occurred over the last two decades, which gives me some valuable insight and background information before even starting my thesis. I also speak the local dialect, which certainly helped me gain acceptance as an insider. Associated with this, having a history in the area certainly helped me when dealing with interviewees. They would ask where I lived before, or ask if I remembered when a certain store was still around, and these types of connections seemed to put the interviewees at ease because they were dealing with a person with a similar background, and who was familiar with the same things they were, sharing much common ground. Others would even ask for my mother's maiden name, original address, trying to place me in the fields of Lahrer history. When dealing with people with associations with the Canadians, they would often prove to know both my mother and father, telling me to say hello to them when I returned. This really helped me to gain the confidence of my interviewee, and I feel that as a result of this, I was able to get honest and reliable information from the participants, much more than some other foreign researcher.

This leads to an issue that I was faced with while conducting my research, and that was insider/outsider relations. Again, since this is my hometown, it would be incredibly difficult to distance myself from my surroundings; nor would I want to. I may have been there to do research, but when not conducting my research, I was behaving in the same manner as anyone else who lives in this town going about their daily lives. I was living with a German family who also have long roots in the city, and whom I have known since birth, 
and I was included with them in the community and introduced to their friends as their new daughter for seven months. All this truly made me feel like any other person in the town, and a part of it. As a German citizen I also had the opportunity to do my civic duty and vote in the federal elections, as well as in mayoral elections that were held in Lahr that year as well. Since my stay was for a period of seven months, it would be have been impossible to remain distanced from the community, especially under these circumstances.

I definitely feel as though my being an insider was incredibly helpful in this thesis. The one obvious advantage is that as a result of being an insider, I speak the language. I would have been extremely limited if I did not speak German, and would have had to limit myself to conducting interviews only with people who spoke English. Even if I had learned German in school, there is still an obvious difference in capabilities of learned languages versus first languages, especially when it comes to expressions and colloquial language use. Here, knowing the local dialect, was extremely helpful. And clearly being able to communicate with participants is a vital aspect of doing research.

Overall, being viewed as an insider is considered an advantage because it is argued that it leads towards a more balanced or in-depth view of the people who were being studied, and insiders could view things in a different light than outsiders might be able to (Wolf, 1996).

However, there are some problems that arise with the notion of my being an insider. For one, I have a dual identity as a German-Canadian, and Wolf discusses how other researchers felt that their position, with regard to their own dual identities, meant that they were considered neither an insider nor an outsider, but both simultaneously. She states that 
this could be due to the notion of having dual nationalities, or because of their position as an academic (Wolf, 1996, 16). So while I may have considered myself an insider, and I certainly did, especially as more time went by, others may not have, simply because I do have a Canadian side to my identity, I was conducting research, or even simply because I have been living in Canada for the last twelve years. However, having my outsider status be connected to Canada was likely advantageous because Lahrers already have much experience dealing with Canadians. They are not unfamiliar to them. Lahr has the obvious connection via the base, which has led to many other connections. There were many mixed marriages between Germans and Canadians, resulting in many German-Canadian children, many Canadians stayed behind in Lahr when the base closed, and there were various other relationships, either through friendships, through renting houses, through being neighbours, etc. It seems every Lahrer knows someone who lives in Canada, who has been to Canada, or knows Canadians still living here. On top of this, Lahr has a German-Canadian Friendship Club, so if I am to be classified an outsider, it seems Canadian is a good one to be, as the city obviously cultivates its unique relationship with Canada. However, I have no control over how other people perceive me, only over how I present myself.

Positionality, however, has the added complication that it is not a fixed attribute. Mullings takes this idea to point out that "the binary implied in the 'insider/outsider' debates, however, is less than real because it seeks to freeze positionalities in place, and assumes that being an 'insider' or 'outsider' is a fixed attribute" (Mullings, 1999, 340). Mullings is clearly stating that a researcher's status as either an insider or an outsider is dynamic, and I believe this could be especially relevant in my own case. Certainly in the early portion of my field 
work, I was still getting accustomed to being back in Germany, and during this time, could have been perceived more as an outsider than an insider. However, by the end of my seven months, I certainly felt like an insider. I have the appropriate local accent, had been living with a German family, made local acquaintances, and essentially completely re-integrated myself into the community.

After establishing that my research question was viable by visiting the various sites and speaking informally with local residents, my next step was to interview employees of the city. I decided upon this because, from reading the local newspaper, Die Lahrer Zeitung, the municipal government (primarily in the city planning and city marketing departments) appeared to be quite involved with, and interested in, drawing people back into the downtown. There seemed to be either city-sponsored events or showings of some kind almost every weekend, and I felt that that would make city officials a good starting place. In addition to this, it seemed it would be good preparation for dealing with store owners, whom I assumed would have less disposable time to give me and whose opinions were quite important for this thesis, resulting in my wanting to optimize any time I received from them. I felt that if the city officials could direct me to important issues that I may not have considered, it would make my interviews with store owners much more channelled and specialized.

Unfortunately, this is where the troubles began as far as not getting much help on the ground. I began by emailing officials in city departments that I believed would be relevant to my thesis, including city planning, city marketing, economic growth promotion, city archives, the culture bureau, and the bureau of internal organization. My many email requests 
were either unanswered, or were answered with a "I sent your mail to someone else who deals with this kind of stuff," which eventually led to my email being sent from one person to the next, eventually ending up back to the original person I mailed it to, with no one wanting to give me any time. Eventually one Stadt Lahr (City of Lahr) employee mentioned to me that everyone was busy writing new website pages for their respective departments as Stadt Lahr was launching a new internet site at the end of the summer (at the time it was late April, early May), and if I could possibly call back after July (at this time I had changed my approach to calling, although not with much more success). The new internet site ended up being launched only in mid August, but after that I was able to get a few interviews with city employees. Some of the passing around still happened, but I imagine that is unavoidable.

In the meantime, still not wanting to lead unprepared interviews with store owners, I decided to conduct archival research. I started at the city archives, which unfortunately could not assist me because my topic was too recent, as they have nothing younger than 30 years old. However, this meeting was useful as it introduced me to the city archivist, Thorsten Mietzner, who proved to be very helpful throughout my turbulent search for information. I next decided to move to finding archived newspaper articles on the topics. I decided that if I could not find people to talk to me, then perhaps I could at least find articles about them. The archivist suggested that for this part of the thesis I should consult the archives at Die Badische Zeitung, as opposed to Die Lahrer Zeitung, where I had originally planned to go. He informed me that they both had very similar articles, but that Die Badische Zeitung had an electronic search engine whereas Die Lahrer Zeitung did not and I would have to manually search through the newspapers. However, at Badische Zeitung offices, I 
again encountered some difficulty because the only way to search through the newspapers was on an employee's computer, and she was quite busy. As a result, I did not feel I had sufficient time to search as thoroughly as I would have liked to. The two topics that I researched here were those regarding the Euro and the Arena.

To supplement the material on the Euro, I also conducted a survey to discover the feelings people had about it. The Euro is a very contested topic in all of Germany, and there is so much hearsay surrounding it I just felt that it would be necessary to do my own probe (see Appendix A). This questionnaire asked whether respondents felt in general prices had increased or decreased. It asked for specific examples of products that had been marked up, and also if the respondents knew of any products that became cheaper after the conversion. I also asked respondents to respond to a quote stating that the Euro conversion did not cause an overall increase in prices, as many people believe is the case. This questionnaire was seen as important simply to gain some opinions that would be considered more than hearsay. Hearing people complain about the Euro in Germany is about equivalent to hearing people complain about the cold during an Ottawa winter; it is widespread and heard everywhere. I wanted to be able to turn the rumblings I heard everywhere into data that I could use in my thesis, and this seemed the best way to do that. This questionnaire cannot be considered representative because there are not enough numbers involved to capture the thoughts of all Germany or even just Lahr (total number of surveys conducted was 63). However, the questionnaire results definitely capture the feeling on the ground and the mood that surrounds the Euro as a Teuro; teuer being the German word for expensive. The respondents were chosen mainly at random from locations in the Innenstadt and at the Arena. The only 
deviation from "pure" randomness was when I surveyed some people that I knew, or guests of the people I was living with. I felt that while maybe it did not fit the pattern I had started with, it was still a way to gain opinions and that those people should not be excluded from my questionnaire on the basis that we are in the same circle of acquaintances. After all, a sample stops being random when one purposely chooses or rejects potential respondents based on certain qualities they possess. This strategy was almost more useful as I felt that the people I knew took more time to answer carefully and truthfully, whereas the people I asked on the street were generally more hurried in their responses.

For information on the Canadians I went to another source - the Canada Haus. The Canada Haus is the former building of Der Kanadier, the weekly newspaper of the Canadians, which is now the official clubhouse of the German-Canadian Friendship Club. Here they had copies of all newspaper articles that I was able to photocopy, from any newspaper, that was relevant to the topic of Canadians and German-Canadian relations in Lahr.

I obtained more archival material on the Canadians when the city archivist brought to my attention an Akte (dossier) on the Canadians. This Akte consisted of letters exchanged between German politicians and Canadian politicians or base commanders and summaries of meetings of the city council or other affected parties, regarding the closing of the Base in Lahr. However, due to the sensitive material in the file, I needed to request permission from the current mayor of Lahr, Hr. Müller, to see it. The archivist assisted me in composing a letter to the mayor, and I was later granted permission to photocopy most of the file. The information I was not allowed to copy was deemed to be too sensitive. It was my hope that 
these files would add insight to how the people of Lahr were feeling about the prospect of the base closing during the time of announcement, and then during the time the troops were pulling out.

After conducting some interviews with city employees (from departments of city planning, city marketing, economic growth promotion, and internal organization) and gaining some insight into the problems and developments going on in Lahr, my next step was to interview store owners who had been in the Innenstadt for 15 years or more. This time frame was chosen in order to capture the changes that occurred over the entire time period that my thesis is covering. Newer stores would obviously not recognize differences between the current situation and that of the early nineties. I began with the head of the Lahrer Retail Promotion Organization (LRPO) who I thought would likely offer interesting insight in addition to having a long standing store in the Innenstadt himself. While receiving an interview with him via a phone call, I was not so fortunate with other stores. I was forced to adapt my approach, and instead began working on a questionnaire for the stores of the Innenstadt (see Appendix B), deciding that I would then ask the people from older stores who seemed more interested whether they would consider giving a longer interview. I also thought that perhaps a questionnaire would be seen as less taxing on their time, and therefore they would be more likely to participate in the questionnaire as opposed to a longer interview.

The purpose of the questionnaire was multi-faceted. First off, I wanted to determine whether older store owners felt that there were more, the same, or fewer people in the Innenstadt than 15 years ago. For the younger stores, I wanted to know the same thing, just instead of 15 years ago, the time frame was simply from the time they moved in. In this 
section I added a question about why they chose to move into the Innenstadt and not elsewhere in Lahr. I felt that this would help indicate what strengths the Innenstadt had from a retail perspective. I also inquired about changes in the consumer to detect whether people were shopping differently than they were previously. Then I asked whether the conversion to the Euro had an impact on their profits. This, combined with the first question, would help determine whether the Euro truly was an important factor for the retail sector of the Innenstadt. Finally, I asked what the retail owners felt was the main competition for the Innenstadt. Knowing what I believed I saw in the field, I wanted to get the opinions of the people who spent everyday in the Innenstadt to validate my own findings. I felt that an insider's opinion into what could be drawing consumers away would be very important. Since I was having difficulty finding people interested in talking to me, I had to make this questionnaire cover as much ground as possible, while still being of a reasonably short length to convince people to do it in the first place (total of 47 completed surveys). For this reason it covers all of the main factors I believe to be playing a role in the desertion of the inner city. And again, as mentioned earlier, I had hoped that it would provide a more successful platform for getting longer interviews.

There was one situation, however, that garnered me the greatest success getting interviews, and that was an introduction via a family member. She knew a man who worked in the city planning department of the city of Lahr, and he, likely as a result of this connection, spent a great deal of time with me. He also led me to two further employees, one also from city planning and the other from the archives, who would be of assistance, and actually went with me to meet them to ensure that I was successful after hearing about my 
previous troubles getting appointments with other employees of the city. In this case I would again assume that I was perceived as an insider, being the niece of someone he has known for decades.

Positionality is something that certainly came into effect while I was conducting the qualitative research. As alluded to earlier, the only thing I could really control was how I presented myself. However, how I presented myself was largely dependent on or affected by the type of research I was involved with at the time; different situations led to my presenting myself in different ways. I think it is useful to examine how the different views garnered different reactions from potential respondents during the different research stages of this thesis, now that these stages have been fully examined.

When e-mailing people for interviews, I would always include that I was on exchange from a Canadian University doing a thesis on Lahr. In these instances it would not be obvious that I was from the town as it did not seem relevant to include the information and they did not hear me speak and therefore could not hear my local dialect and assume so for themselves. In such a case, the outsider impression would likely have been more prevalent, and perhaps contributed to my getting either no answer or simply passed on to someone else.

In most situations when I met people face to face, without them having any prior knowledge about my thesis, I would usually drop the Canadian part and just say that I was a geography student doing a thesis (Arbeit) on the Lahrer Innenstadt. This would occur during, for example, the questionnaires, when it seemed much more appropriate to be brief as one certainly got the impression the respondents did not like to be held up for a long period of time. Perhaps in these types of situations I would have been viewed more as an 
insider. In this case I was met with more willingness to participate, but that could very well have been as a result of the nature of my demands on their time as opposed to being a result of being perceived as an insider.

I believe that the most important factor while conducting my research was that of power relations. However, my experiences contest the common notion that the researchers are the ones with the power. Granted, they are the ones who decide on the research topic, how to conduct the research, decide which questions should be asked, who to ask, how to interpret the responses as well as any field observations made, and finally how to write up the results (Wolf, 1996, 19, and Sarah McLafferty, quoted in Rose, 1997, 307). However, all of this is useless if the researcher cannot find anyone to agree to an interview! The questions to ask will be useless, there will be no data to interpret, and no results to write up. This leaves the researcher with a shadow over the finished work as it cannot claim to be as representative as the researcher had hoped it would be during conception of the project. I had what later were proven to be very optimistic expectations of who I was planning to interview for this thesis. I adapted as best I could, thankfully having arranged a long stay in the field. This resulted in most of my interviews coming as a result of snowballing from informed sources knowing other people who could be of use to me and willing to talk with me, some even going so far as to set up the interview themselves. For these occurrences I could be nothing other than grateful.

The general reception in the field, however, was much different than I expected. When I had sent emails to city of Lahr employees before leaving Canada, I had always been responded to in a polite and helpful manner. I was mailed information or simply told that 
when I arrived in Lahr they would be happy to meet with me. As a result of these experiences I naturally expected help and interest. However, instead of being interested in the project as it involved something potential respondents were closely related to, I was often questioned regarding my age, and upon hearing it, why I did not have a job yet, and what kind of a job would a thesis on the Lahrer Innenstadt get me? I certainly got the impression that I was not being taken very seriously.

There were certainly many instances in the field when I felt powerless to improve the outcome of my research. Cotterill writes that "the majority of research projects are peculiarly dependent on respondents who provide source material. Without them and their trust the research cannot proceed, and therefore, I believe, the onus is on the researcher to make what she can of poor interview conditions and adapt" $(1992,602)$. I can only hope that the adaptations I made to my research project and the way in which data is collected is adequate to make up for the lack of assistance in the field.

However, the traditional notions of the researcher having the power still applies when one does eventually get that interview. As mentioned earlier, the researcher chooses the questions, interprets them, and writes up the final report (Wolf, 1996). This does leave a lot of power in the researcher's hands. Also when doing field observations, I interpret what I see and write down what I believe I saw. Others may not see it the same way as a result of different positionalities, but because it is my thesis, my interpretation is what the readers will see. In order to reduce this type of power I ended all of my interviews with open ended questions, asking whether there was something I did not mention that should be included in a discussion of the Innenstadt, or otherwise anything they wanted to add to the discussion. 
I also tried to act as neutral as possible, and to make sure I did not show any preference to a certain answer, or lead questions in such as way as they would favour a certain predetermined answer. Capps (2001) writes that it is important to monitor one's own actions in order that one's own views stay covert to avoid respondents simply mimicking my own thoughts or giving me answers they think I want to hear, and I certainly did my best to avoid this.

The rest of the information that I needed to supplement the primary research came from written sources: books, newspapers, and relevant internet sites. I had hoped to get more information from the city, but was informed by the city archivist that Lahr did not keep many statistics, and from city officials that, surprisingly, even minutes from city meetings were not recorded. There were a few meeting summaries in the Akte, but perhaps this was due to the extenuating circumstances of the base closure and they needed to keep a record of certain meetings. This is probably a disadvantage of doing research in a smaller town. However, as Lahr grows as a city some kind of transition is likely necessary and records will need to be kept, especially if it wants to learn from past experiences.

An added complication where mistakes could be made in this thesis is in the translation. Almost every aspect of the primary research for this thesis was carried out in German, and therefore, has had to be translated. For the bulk of the thesis this is not an issue: however, with all translation, instances arise where sometimes one cannot find a word in another language that means quite the same thing. I do have the advantage that I do speak the local dialect, and therefore can understand nuances or sayings that even other native speakers from different parts of Germany would not understand. If there are still tricky instances 
despite this, I could even ask my mother, who is a local speaker and has experience working as a translator for a number of years, and would therefore understand the importance of choosing the right word. Hopefully this will help to eliminate any mistakes that could occur during the translation.

The focus on qualitative research really set the tone for this thesis. The emphasis on interviews and survey results was in part necessitated by the lack of statistics and other quantified evidence that could be found. The store survey essentially came about as a direct result of there not being much information kept about the Innenstadt, as well as my having difficulty finding willing participants for longer interviews. In the end, however, the surveys do strengthen the thesis, the Euro survey being particularly necessary to capture the sentiments associated with its introduction, and they fit well with the interviews. The newspaper articles add to the overall texture of the thesis and provided excellent information that appeared to be unattainable elsewhere, and was clearly accurate as it did correspond to what little official information I did get from the city files. In the end, it is unfortunate that I did not receive as much assistance on the ground as I had anticipated prior to leaving for Germany, but this forced me to make alterations that I believe, in the end, made up for this lack of support and in fact deepened the overall examination of Lahr and its development. 


\section{Chapter 4: Closure of the Canadian Base}

On November $9^{\text {th }}, 1989$, the Berlin Wall fell, ending a long and sombre chapter in German and world history. A year later Germany was officially reunified, and a year after that the Warsaw Pact was officially dissolved. This had far reaching impacts in the entire world, including on NATO, whose continued existence was called into question (Phillips, 1996). While NATO was left intact, there was certainly less pressure on the organization to uphold such a strong military presence in Europe. After all, the Communist front was no longer in existence, and there was no longer a potential threat beyond the boundary of the Iron Curtain. Many governments used this opportunity to reduce military spending, and the Canadian government was no exception. Foreign bases are especially expensive to support, and the decision was made that it was no longer necessary to keep the Base at Lahr open, due to the fact that its location was no longer strategically vital after the disintegration of the Soviet Union.

For Lahr this was a big change; it would be the first time in 100 years that Lahr would not be a garrison town (MP, Nov. 6, 1990). The Canadians, of course, also played an important role in the Lahr community during the almost three decades that they were stationed there. As the Canadians took over after the French troops left, it appears that they were viewed less as an occupying force, and instead as NATO stationed troops. After the collapse of communism in Europe, it was anticipated that at some point in time the Canadians would reduce their overseas presence, or perhaps even completely pull out, but I believe in the end, as I will illustrate, the Lahrers were surprised at how quickly it occurred. 
The period of withdrawal seemed to be shrouded in mixed messages and was generally confusing, and I believe that Lahr was somewhat unprepared for life after the base.

The earliest evidence I have in my possession of the city government acknowledging the possible withdrawal of military troops is from October 1990. This information comes from an Akte (dossier) obtained through the city archives which was described as containing all the material on the handling of the military pull out (Heizmann 24). The dossier begins with a letter from Stuttgart, the seat of the state government, addressed to all cities with military forces stationed in them, both foreign and domestic. It states that due to the recent political developments in Eastern Europe, a reduction of military troops is very likely and should be expected, and that cities should begin planning possible civilian uses for the vacated land as soon as possible in order to be prepared (Hauser, 12 Oct, 1990). The somewhat belated Lahrer response was to assure the state government that they had been planning some strategies to cope with a possible reduction of troops (although none are mentioned) and an invitation to discuss these ideas (Dietz, 28 March, 1991).

During a city council meeting in April 1991, German officials discussed a possible life after the military presence, and what could be done on the current military lands to benefit the town. The topic of a civilian use of the airport came up, something that will never leave the discussions. It was mentioned that the city would really like to develop a civilian use of the airport. The runway at Lahr was quite well known for being one of the longest (3400 metres) and best kept runways in Europe, and even the heaviest transport airplanes were able to land on this runway. For these reasons the city of Lahr really wanted to develop the area because they felt that it would be the key to their success in a post-military economy. 
This would help attract companies to settle in Lahr as an excellent mode of transportation would be in their midst, as well as the free space to develop factories, buildings, and whatever else would be needed. It was also hoped that commercial flights might be possible. However, there is continued mention that the Canadians have not yet decided anything concrete, and that Canada has made declarations that it does still intend to have a continued presence in Europe, arguably displaying signs of hope that the Lahr base will not be completely abandoned. At this point in time, the plans for the airport were also referred to as "Mitnutzung," or a shared use of the airport, perhaps a signal that they thought they were only dealing with a reduction in troops and not a complete withdrawal (22 April, 1991, Akte).

Before the announcement from Ottawa was actually made, there was further speculation about the joint future of Lahr and the Canadians. In an interview published in the local paper in May of 1991, the state elected representative for Lahr, Walter Caroli (SPD Socialist Party of Germany, stated that there are no indications from the Canadians that they even intend to leave, and adds later a rhetorical question, "but who knows what will happen in 10 or 15 years?" (LZ, May 4/5, 1991). Clearly by this point government officials had not yet received any official news about a closure of the Lahr base. However, in the earlier mentioned meeting there was some discussion about Hr. Caroli, stating that he was either wrong or better informed than they were, which clearly displays, if nothing else, a lack of clear communication between different levels of government regarding this issue (22 April, 1991, Akte).

Later, as the Warsaw Pact was officially dissolved and Soviet troops were moving out of Eastern Europe, it was reported that Canadian Prime Minister Mulroney assured the 
elected officials who covered the Lahr region, that the Canadian troops would not be completely pulling out of Germany, but that some decisions on reductions would be made shortly. In response to this, the federally elected official for Lahr, Rainer Haungs (CDU Christian Democrat Party), thanked the Canadians for their help in establishing safety in his region and stated that he hoped Lahr would continue to be the host town to a Canadian base. Chancellor Kohl added that he hoped Germany could remain host to Canadian troops (LZ, 20 June, 1991). In June 1991 it was announced that 1400 soldiers would be leaving the two Canadian bases in Germany, but it was then added that other than this announcement, further decisions regarding possible reductions in 1992 were not yet made (LZ, 28 June, 1991). At this point in time it would appear Canada was sending the message that it would reduce its troops, but no indication was yet made that it was considering any complete closures. However, based on the above mentioned comments, the German government does appear to be getting the message out that they would like the Canadians to stay.

In a follow up interview, Caroli stated that a complete withdrawal of Canadian troops would only be bearable if it was done in steps to allow Lahr to adjust, and added that his goal in the next period of time would be to create a plan so that Lahr would not fall into a hole if the Canadians do leave (LZ, 3 Aug, 1991). However, these are clearly vague goals, as he has no time frame to build his plan around, and also no guarantee that such a plan is even necessary. There is clearly some exasperation being felt in Lahr, as an article from September 1991 writes that "it is high time that Ottawa ends this frustrating guessing game and finally says a clear word regarding planned troop reduction so that Lahr can make arrangements for its future" (LZ, 6 Sept, 1991). 
Another example of what type of announcement was expected is revealed in an interview with Roland Hirsh, the head of the SPD in the region. He stated that he anticipated the announcement that another 1000 troops would be moved out of Lahr. He then added that in the future the Lahr base would likely be so "radically reduced" that only 2000-3000 soldiers would stay in Lahr (LZ,17 Aug, 1991). Once again this demonstrates that many people did not believe the Canadians would fully pull out of Lahr. His language also reveals that leaving Lahr with only 2000-3000 soldiers (one would also have to add to this figure their families and supporting civilian personnel) would be troublesome (the total Canadian population at that time was about 12000 , including families), only foreshadowing the anxiety officials must have felt when the complete pull out was finally announced.

The announcement Lahrers were waiting for was finally made by Canadian Cabinet on the $12^{\text {th }}$ of September 1991 ; the Lahr base would be completely closed by 1995 . The Mayor was informed on the $17^{\text {th }}$ of September. The reasons given for this announcement were the ailing finances of the Canadian government, which needed to save money, and the changing world politics reduced the need for bases in Europe, and presenting them with an opportunity to do so. Closing the Lahr base would save them 525 million Deutsche Mark (DM) per year (LZ, 18 Sept, 1991, und 17 Sept, 1991, Smith). According to the average exchange rate of September 1991, this is about 350 million Canadian Dollars (1 CAD bought 1.5 DM, Oanda, 2006). Immediately the whole gambit of problems and affected people came to the fore. What would happen to the German civilians working for the Canadians ( 800 at this time)? The landlords renting to Canadians? The tradespeople and companies who did contracts for Canadians? The restaurants they patronized? The stores? The city, with less tax 
money? After all, Lahr was losing almost $25 \%$ of its population (LZ, 18 Sept, 1991).

At this point the mayor, Werner Dietz, stated the financial effects of the Canadians leaving would be enormous. He stated that it would have to be made up for in higher fees for electricity, water, sewage, kindergarten, and other essentials. He stated that the Canadians leaving would be the greatest challenge in the city's history, adding that the city was not counting on receiving any financial assistance from the state or federal governments (LZ, Sept. 18, 1991). Financial figures were later announced; the states with troops leaving (also from American bases) requested 20 billion DM spread over 10 years. The federal government, however, only offered 500 million DM spread over 5 years (BZ, 21 Oct 1991). The amount of money that Lahr would have to make up for was estimated to be around 450 million DM at that time, certainly a daunting figure for a town of Lahr's size (LZ, 19 Sept, 1991).

Surprise appeared to be the first reaction. Headlines read "the news of a total withdrawal of Canadians surprised everyone," and "Even in Bonn they were surprised (LZ, 18 Sept, 1991)." Apparently many Germans were of the opinion that of late the Canadians had put so much money into the base (in addition to maintenance fees, the Canadians had just built a new hospital on the Casern) they simply did not expect them to completely abandon their investment (LZ, Sept. 20, 1991).

In a letter to the Ministerpräsident (premier of Baden-Württemberg), Mayor Dietz asks for some support in dealing with the conversion period. During the time of the announcement that the Canadians were pulling out of Lahr, it was also stated that Canada would keep a contingent of 1100 troops in Europe, most likely in Germany. In this letter, 
Dietz states that he hopes the State will consider Lahr as a station for these soldiers. $\mathrm{He}$ admits that he is not entirely sure how Lahr will handle the financial effects of losing the base (Sept. 19, 1991, Dietz). From the tone of this letter it seems obvious that he is unclear about the successful future of Lahr, and that despite previous discussions regarding a pullout, he is worried and somewhat unprepared for a future without the military. While the announcement is still new at this point in time, it could not have been a complete surprise, and perhaps the Mayor's apparent worry shows that they were not prepared. However, it may very well have also been a ploy to gain some extra assistance from the State.

However, the argument of unpreparedness gains some support when looking at a summary of a Lahr city council meeting held in October, 1991. There appears to be some criticism made that the Mayor could have anticipated, since mid 1990, that some sort of change would occur regarding the Canadian troops. Clearly some unhappiness is expressed here. The Mayor continued to argue that perhaps the left-over contingent of Canadians could be stationed in Lahr. He also stated that he expects an announcement for 1992 of similar proportions to that of 1991 regarding the rate of reduction, being around the 1000-1500 mark. He also expects the first buildings to be free in 1993, and their plans should be for such a time frame. Problems with the economy are brought up, including the loss of purchasing power that will be experienced once the Canadians leave. Mayor Dietz states that in the case of Lahr, it should not be considered a typical garrison town. He argues that because over $20 \%$ of the population is Canadian (at its high point in 1990, there were 17000 Canadians in Lahr) and $25 \%$ of all the surface area is in the hands of Canadians, representing more than is usual in a garrison town, this will be a much tougher conversion than is usual. In this 
summary there are further mentions of how surprising this complete pullout of Lahr was, for both the federal government as well as the municipal. Discussions are made about the usual airport matters, the apartments housing the Canadians, and uses for these buildings, but again nothing concrete or new appears to be developing (7 October, 1991, Akte).

In December of 1991 there was a further city council meeting discussing the topic of the Canadian troop withdrawal from Lahr. However, this evidence, some notes on a meeting that took place, says little more than that a plan is necessary. It states the need to prepare for an appointment of an experienced conversion and development office to make a plan of how the city of Lahr could use the vacated military spaces. A few points were outlined as to what should be included in any proposal, as well as that they cannot expect help from the state without such a plan (16 Dec, 1991, Akte). Clearly this is not much of a development from the last city meeting.

The next step in the timetable for Canadian troop withdrawal was then made public. First it was announced that 1300 more troops will be leaving Lahr in 1992 (LZ, 19 Oct. 1991). Unfortunately by this point in time there is still no plan to deal with the conversion period, and on the $19^{\text {th }}$ of November the Mayor received a letter from the municipal members of the CDU requesting that a plan be made regarding the development of the land that will be left behind by the Canadians. They add that this could be an important stage of the city's development, but in order to use any chances they need a well developed plan for future uses, and request that this all be discussed during the next council meeting (Rieger, 19, Nov 1991).

The final meeting summary that was included in the dossier was dated the $16^{\text {th }}$ of December 1991. Clearly the issue of the Canadians was not finished by this date, but this 
dossier was presented to me as the complete dossier on the departure of the Canadians. (Gaining access to this information was very difficult, and I certainly got the impression that the city was not too pleased to be releasing this information to me. So perhaps there is more information out there, but no more was given to me, nor was I made aware of its existence.) Based on the content of these meetings I believe that the overriding feeling in Lahr is that the city council did not handle the conversion period very well, for whatever reason, and they do not appear anxious to share the relevant information with others. However, up to this point the newspapers had been extremely accurate and in synch with everything in the dossier, so I am very comfortable with a reliance on these sources. In the final city council meeting summary that I possess, it is stated that they are preparing for a contract to an experienced planning bureau to develop a plan for the conversion of the military land and buildings. What this should include was covered, and it consisted of issues such as the airport, the Casern (an area where the Canadians had office buildings, one of their schools, some stores, and recreation complexes), the schools, and their open spaces (16 Dec, 1991, Akte).

However, while Lahr was planning a strategy to cope with losing the Canadians by 1995, Ottawa surprised them once again by speeding up the departure. In February of 1992, it was announced that the Lahr base would be abandoned one year earlier than planned, in 1994. The reason given was again that money had to be saved (LZ, Feb 26, 1992). In March came the revised timetable for troop withdrawal which included that 1200 troops would be leaving in two weeks to serve in Slovenia for the UN, 1900 leaving Lahr in total for the year. They also stated that the majority of all other personnel, military and otherwise, would be removed by the fall of 1993 , leaving only 600 personnel to close the base from 1993-1994 
(LZ, 16 \&17 March, 1992). Essentially this meant that Lahr would be losing the bulk of the Canadian population within one year, much sooner than was expected, and certainly nothing they were prepared to cope with. The reaction in the town was not good; headlines read "Unrest and apocalyptic feelings in Lahr," or "Canadians burst last bubble of hope in Lahr" demonstrating the uneasiness that the town was feeling at this time (LZ, 26 Feb \& 16 Mar, 1992). This abrupt announcement of the accelerated departure of the Canadian troops was clearly met with anxiety on the part of the Lahr citizens. It was also eventually announced that Canada would not keep a contingent of 1100 in Germany after all, as they had previously said they would do (Blume, 2000).

The reaction from the Lahrer Retail Promotion Organization (LRPO - Lahrer Werbegemeinschaft) was also one of worry. For one the membership fees for being in the LRPO were going to be increased by $51 \%$. These increases had to be made to invest in things such as Christmas lights in order to make Lahr more competitive with other towns, and also work on the attractiveness of the downtown area. These types of measures needed to be made in order to make up for the huge loss in purchasing power that would be experienced when the Canadians leave (LZ, 16 Mar, 1992). However, this appears to be the closest that anything comes to being a plan for coping with the closing of the base. While it often states that Lahr needs a plan, there is no mention of what this plan should include or what areas it even will cover. Even by July 1993 nothing appears to have been solved. With the large portion of Canadians gone or in the process of moving, the FDP (Free Democratic Party) Faction leader Alfred Klausmann complains that everything has been over-discussed, but that nothing has been solved (BZ, 24 July, 1993). 
Officially the stay of the Canadian forces in Europe came to an end on the $13^{\text {th }}$ of July, 1993. Many ceremonies were celebrated during this time to say good bye as well as thank you to the departing troops. The papers are absolutely filled with images of marching soldiers, marching bands, many German spectators as the Canadians make their final processions through the streets of Lahr, as well as many ceremonies including prominent German and Canadian figures exchanging plaques and thanking one another for the great times and great friendships made (July, BZ, LZ). The Canadians were also honoured in that one of the largest PMQ (Private Married Quarters) districts where the Canadians lived was going to be renamed "Kanadaring" (LZ, 19 May, 1993). Clearly during this time period, the last time period Lahr would ever face with a large contingent of Canadian forces, the general mood points to one of sadness due to the loss, and lots of reminiscing of good times between the two cultures. For a summary of the important dates regarding the Canadian troop withdrawal see Figure 4.1.

With the loss of the Canadians a reality, Lahr finally released what it titled the "Masterplan." This plan was to explain how Lahr would handle the conversion from a garrison town to a civilian town without falling into an economic hole. It was planned by two companies simply addressed as the Karlsruhe and Freiburg Planning Groups, possibly as a result of the CDU's demands for a plan in November of 1991. This plan was presented on the $30^{\text {th }}$ of June, 1993. The most important point of the Masterplan was a civilian use of the airport. The runway on the Canadian base was well known as one of the longest and best maintained runways in all of Europe, and Lahr wanted to make good use of it. It was stated 
Figure 4.1: Timetable for the pullout of Canadian troops from Lahr

\begin{tabular}{|c|c|}
\hline $\begin{array}{l}\text { Date of decision } \\
\text { or publication }\end{array}$ & Action \\
\hline $9^{\text {th }}$ Nov, 1989 & Fall of Berlin Wall \\
\hline 20 June, 1991 & $\begin{array}{l}\text { Mulroney says Canadians will not completely pull out of Germany, } \\
\text { but there will be reductions }\end{array}$ \\
\hline $28^{\text {th }}$ June, 1991 & $\begin{array}{l}1400 \text { troops leaving both German bases (Lahr and Baden } \\
\text { Söllingen), } 1992 \text { will see further reductions }\end{array}$ \\
\hline $12^{\text {th }}$ Sept, 1991 & Lahr will be completely closed in 1995 \\
\hline $19^{\text {th }}$ Oct, 1991 & 1300 troops leaving Lahr in 1992 \\
\hline $26^{\text {th }}$ Feb, 1992 & Lahr will be closed one year earlier - in 1994 \\
\hline March 1992 & $\begin{array}{l}\text { Revised timetable for withdrawal } \\
1200 \text { in two weeks } \\
1900 \text { for total of } 1992 \\
\text { Majority removed by fall } 1993 \text {, leaving } 600 \text { personnel to close up } \\
\text { the base from } 1993-1994\end{array}$ \\
\hline $13^{\text {th }}$ July, 1993 & Lahr base officially closed \\
\hline Summer 1994 & Remaining personnel leave Lahr \\
\hline
\end{tabular}

that the runway was Lahr's key asset. The State of Baden-Württemberg was supporting Lahr on this point, agreeing to help pay a portion of whatever developments needed to be made. The Masterplan also included converting the newly constructed Canadian hospital into a heart clinic, bringing in a psychiatric department along with it. A new advertising school was 
hoped for, and a better working relationship with the rest of the Ortenaukreis ${ }^{1}$ in order to help the whole region cope with this loss (BZ \& LZ, 1 July, 1993). The use of former military lands was a very important factor at this time as the Canadians occupied $25 \%$ of the land in Lahr.

However, this 'Masterplan' clearly does not live up to its name. The document was described in the newspapers as being 80 pages long, hardly enough to cover a conversion of this magnitude (LZ, 1 July, 1993). There are also obvious holes; no mention of the Canadian PMQs is made, nor who will fill the vacated apartments, there is no discussion of the price for which the city will buy the vacated Canadian properties from the German federal government, and the Casern is not covered at all in connection to the Masterplan. The Casern was on the agenda for a symposium on both the Airport and Casern (Casern was in small print) on the $30^{\text {th }}$ of July, but any developments that may have been made regarding the Casern were not reported on; those concerning the Airfield took precedence. All of this is clearly a case of Lahr putting all its eggs into one basket. Practically the entire future of Lahr was framed as being dependent on whether the airport was going to be used or not, and in hindsight it certainly would have proven more useful to develop a more comprehensive plan of conversion, with the thought in mind that perhaps the airport redevelopment would not be successful. It should also be noted, however, that after this initial reportage on the Masterplan, there is no further mention of it, and nothing to indicate that they stuck with the

1

The Ortenaukreis is the region, within Baden-Württemberg, to which Lahr belongs. It covers an area of 1860 square kilometers and has a total population of 450000 . The most prominent city in this region is Offenburg. 
plans that were conceived for this plan.

Two more developments not listed in the Masterplan, perhaps because they had been handled beforehand, were the development of a Post Secondary institute for art in one of the buildings previously owned by the Canadians (although the final decision had not been made by this point in time), and the development of a Freight Post Office on the former base (LZ, 26 June 1993, and BZ, 7 Oct, 1992). These two developments actually materialized quite quickly after the Canadians left - the post-secondary Art Institute decided upon the Officer's Mess as their building, however, while originally it had been hoped it would occupy a few buildings on the Casern. The heart institute mentioned above also came into development and is quite well known, however, without the psychiatric department. Its staff in 2006 numbered almost 400 (Our Hospital, 2006).

Another issue that was also not addressed in the Masterplan, but was clearly raising concerns amongst the population as it did receive coverage in the local newspapers, was that of who was going to replace the Canadians? The PMQs account for 1271 homes that will be vacated, 870 owned by the German federal government, the rest private investors, and approximately 3290 homes were rented all across the region from local landlords (BZ, 6 Nov. 1991). Clearly new people were needed to fill these vacancies as they are numerous. As word got out that Lahr had lots of vacant apartments to fill, people known in Germany as Spätaussiedler, or simply Aussiedler - ethnic, repatriated Germans who come primarily from Russia and Kazakstan, generally do not speak any German, and require social assistance in many cases - flowed into Lahr, hoping to get an apartment. The central department responsible for these people, located in Bonn, would essentially direct them to areas where 
there were vacant apartments. The departure of the Canadians clearly provided an opportunity for the Aussiedlers in the way of available housing (Stegna, 2006). These people are allowed into Germany under their right of return laws, which provide citizenship for anyone "who has been admitted to the territory of the German Reich within the boundaries of December 31, 1937 as a refugee or expellee of German ethnic origin or as the spouse or descendent of such person" (Right of Return, 2006).

Financially speaking, the city was not able to purchase all of the federally owned apartments and had to partner with other organizations (599 were eventually purchased for 28.7 million DM - LZ, 31 Aug, 1996), and the renovations that had to be made in order to bring the apartments up to German standards as well as specifications were quite costly $(\mathrm{LZ}$, 11 Nov, 93). In 1994, the city went into debt for 10 million DM as a result of this conversion process, and house taxes, sewer fees, water fees, graveyard fees, and kindergarten fees all had to be increased just to keep it at this number (LZ, 10 Nov, 1993). The city also had to borrow 40 million DM from the state due to their dire straights (BZ, $10 \mathrm{Feb}, 1994)$.

The situation during open houses was described as having queues 20-30 metres long of Spätaussiedlers, and so many of them came that they had to create pamphlets in Russian explaining how the division of apartments would be decided upon. This resulted in many Germans being discouraged when arriving to look at the apartments and consequently leaving, although the government was encouraging them to come as they wanted to avoid the creation of a ghetto-like area (BZ, 28 Jan, 1995).

Another problem associated with this influx of people from former Soviet states was with regard to the schooling system. The Canadians had always taken care of their own 
children, but now there was a huge increase in the number of students, and many of these students needed special attention as they did not speak the language. As a result the city had to invest heavily to create more school spaces as well as hiring some new staff who could speak Russian (MP, 11 June, 1996). By 1998 the number of Spätaussiedlers that had moved to Lahr numbered 8000 (Freeman, Feb 6, 1998). However, while the number is certainly close to that which was lost with the withdrawal of the Canadian troops, there was a marked difference in the purchasing power of the groups (LZ, 6 Feb 1999). As mentioned earlier, the Spätaussiedlers rarely spoke German upon arrival, and therefore had difficult times finding work and had to rely on social assistance. Clearly someone in such a position would have much less disposable income than the Canadians did (BZ, 27 March, 1999). Years after the Spätaussiedlers arrived, an article looking back depicted Lahrers as having tried to help these people integrate, but when it either did not go fast enough, or they encountered people who simply did not want to try to integrate, Lahrers simply lost interest in helping them (BZ, 27 March, 1999).

As alluded to earlier, the Casern was not covered in the Masterplan, which likely contributed to the fact that, when visited in 2005 , it was in total ruin, with only one building being used as the seat of the head of administration for the Ortenaukreis. The rest of the buildings were falling apart - every window had been smashed, weeds are growing 6 foot tall between the cobblestones, and the sport track resembles a jungle. The issues with the airport were also still going when I left in November 2005, the latest possibility being that perhaps an Australian billionaire was interested in buying it to develop it commercially, but this was also unsuccessful. At this time the airfield is rarely being used: for example, special permits 
are given when the München soccer team comes to play against Freiburg. The next developer that is interested in the airfield is Europa Park, the largest amusement park in Germany, only a 15 minute drive away from Lahr. They wish to develop packages that include air and hotel to visit their park. The main factor hindering all these ventures are surrounding airports, who do not wish to have the added competition of Lahr's airstrip (Stegna, 2006).

Also not mentioned in the plan were the Aussiedlers, who were moving into the majority of the vacated apartments. As mentioned earlier, it was hoped that these areas would not become dominated by the Spätaussiedlers as a ghetto-like settlement was not desired. However, perhaps as a result of lack of planning, this appears to be exactly what occurred, and by 2005 many of the former PMQ areas were completely dominated by the Aussiedlers.

In 2001 there was a discussion between the federal candidates of the Lahr riding regarding how well Lahr handled its conversion period. While many of them continued on the airport promotion, the Green Party candidate, I believe, summed the situation up quite realistically. He stated "the conversion in Lahr did not advance as we had hoped. The onesided fixation on the airport, which never came to fruition... hurt the conversion process," and added that "the situation on the Casern is more than sad" (BZ, 15 March, 2001). Unfortunately, however, his counterparts in the CDU, SPD and FDP were still fixated on the airport as solving all of Lahr's problems, which as mentioned earlier, is still an unresolved issue up until this day. There are currently some businesses on the airport, but actually using the airport for flights has never materialized. All parties agree, however, that something must be done with the Casern.

Clearly the most dramatic effect of the Canadians leaving Lahr was the lost money 
in circulation, early on estimated at around 450 million DM. However, after the Canadians were gone, and the full effect was noticed, and many estimated it to be higher, around the 500-600 million DM per year mark (LZ, $6 \mathrm{Feb}, 1996)$. The way that this translated into revenues for the stores of the Innenstadt was clearly an important factor for those businesses, as will be explained in Chapter 5 .

But more than that, this loss reverberated through the whole region, as was reviewed in Chapter 2 as a characteristic of base closings. Clearly Lahr felt the primary effects, but there is a concentric ring of loss that is emanating around Lahr. Apartments became free, which meant that even the landlords had less money to spend (Albrecht, 30 Aug, 2005). Werner Beck, an economic development officer for Stadt Lahr, stated that even those landlords who were able to rent out their apartments suffered, because the prices came down drastically after the Canadians left, so they still had less disposable income (Beck, 17 Aug, 2005). So even the purchasing power of the Germans was affected by the withdrawal of the Canadians. Walter Blum, also an economic development officer at Stadt Lahr, stated that the withdrawal of the Canadians hit not just the Innenstadt hard, but the entire region as well (30 Aug, 2005).

Ulrike Starr, the head of advertising for Der Kanadier, the newspaper for the Canadians stationed in Lahr, stated that many outlying businesses felt the loss of the Canadian departure. She stated that one sector that really suffered were the car dealerships. European cars were very popular with the soldiers, she stated, and car dealerships in and around Lahr benefited from having many Canadian customers. She also stated that one of her biggest clients was actually from Triberg, $50 \mathrm{~km}$ away from Lahr. This city is famous for its 
cuckoo clocks, and the largest clock store advertised quite a bit in Der Kanadier as Triberg proved to be a favoured location for short trips, and a popular souvenir would be a clock. Her husband, Colin, even joked that "you couldn't get on the plane [to go back to Canada] without a cuckoo clock" (25 Oct, 2005). This highlights that indeed, the entire region would have felt the loss of the Canadians, albeit stronger in Lahr.

One main reason the Canadians had so much purchasing power was that the military troops received extra pay for being overseas. The idea behind this was as sort of a "hardship supplement," officially the foreign service allowance, for being away from their family and friends and in a non-English speaking country (Cornforth, 11 Oct, 2005). This supplement would increase the more years one spent abroad, and generally ranged from about 500-700 DM per month. In addition to this, those soldiers that lived off the base in local German housing, received an "on the economy" supplement to help them pay their rent. This was a flat rate based on their rank, usually averaging around 500 DM per month (Newman, 13 Feb, 2006). Clearly this is quite the boost from a usual pay level, and the Canadians were surrounded by European flavour at a time when they had more wealth than other times; it seems only natural they would spend it. And the beneficiary of this was definitely the town of Lahr and its inner city shop owners. Naturally the whole region prospered alongside the Innenstadt.

In addition to the pay bonuses, Canadian soldiers were not required to pay the Mehrwertsteuer, or sales tax, on items over $50 \mathrm{DM}$. So any large purchases were automatically cheaper for Canadian soldiers. As Hr. Beck explains, Canadians had much more disposable income, allowing them to spend much more of their money on hobbies, 
food, or anything else they desired. "Lahr was certainly a special case in that regard" (Beck, 17 Aug, 2005). Moreover, the Canadians were paid in dollars, and at that point in time the Canadian dollar was worth much more than the Deutsch Mark, so again the Canadians had the financial advantage, and spent that money in Lahr (Albrecht, $30 \mathrm{Aug}, 2005$ ). All these factors contributed to the Canadians having an enormous purchasing power.

There was some opposition to the military presence in Lahr. There were those who opposed the military presence because they were simply anti-militarists and therefore against war and things relating to it. Others who lived near the airport (especially in Hugsweier, see Appendix $\mathrm{C}$ for location) were against the amount of noise it generated, and that is, to this day (2005), still an issue with regard to finding a civilian use for the airport. However, on the whole, and especially from a simply economic viewpoint, the Canadians were a huge advantage for Lahr, and many people wish the Canadians had never have left.

Throughout the process of the Canadian military pull out there seem to have been many instances where Lahr could have done things differently. First, there could have been some anticipation of what was to come, be it a complete or partial withdrawal, once the Berlin Wall had come down. Delayed reactions are again evident with the late response to the State government who warned of possible closures in October of 1990, but Lahr only reacted the following March. The Masterplan only coming out in summer 1993 is also problematic. Had it come out earlier, the city could have begun implementing plans while the Canadians were still in the area. The Masterplan is also problematic due to all the omissions that were discussed. However, the issue was made more complicated by the Canadian government changing the dates and moving up the departure of the military 
personnel. Finally, if Lahr was not prepared to change its century old status as a garrison town, perhaps the city should have simply tried to continue it, albeit on a smaller scale. The facilities that were left behind were in excellent condition, so perhaps there could have been some exploration of moving some German military forces to the base at Lahr to make use of the runway, airplane hangers, and other facilities. This type of a decision was undoubtedly out of the scope of a city government, but there is no evidence that this was even suggested to other levels of government. The economic hole left by the Canadians was immense. With their departure, the Innenstadt retailers lost some of their best customers, customers who could afford to pay for the quality of specialty stores located in an area where stores are of a smaller size. The specific impact the closure of the base has had upon the retail sector will be examined in the following chapter. 


\section{Chapter 5: Impact of the closure of the Canadian Base on the Retail Sector in Lahr}

While the Canadian base and Casern had a few stores to service the military population, the Canadians very often went off-base to do their shopping. The stores on the Casern and base were not equipped to supply an entire population. There were essentially five stores; a grocery store, a toy store, a sports store, an electronics store (although the equipment was made for 110 voltage, whereas Germany has 220 ), and a small clothing store. Clearly this was not enough to support a population of about 10000 , especially because these stores were not very large, and did not offer large selections.

Another reason Canadians would shop off base was that most people lived closer to the German stores (see Figure 5.1, page 73, for location of PMQs). Trisha Cornforth, a reporter for Der Kanadier, the newspaper of the Canadians, radio host for the Canadian station, the cultural go-between person between Canadians and Germans, and currently the president of the German-Canadian Friendship Club explained this. "They did like going downtown, I mean, that was one of the things that made Lahr, or the German town, so interesting for the Canadians was the fact that they weren't full of cars. But they were places to wander around in and enjoy the atmosphere and see some beautiful old buildings" (11 Oct, 2005). She said that many Canadians would mention to her that they all got cricks in their necks from always looking upwards at all the lights, historic buildings, flower arrangements, and general nice scenes (Cornforth, 11 Oct, 2005). Thomas Bickel, the head of the Lahrer Retail Promotion Organization (LRPO) and owner of a kitchen accessories store in the 
Innenstadt, simply states that they loved the flair, the atmosphere, and found the historic core beautiful and interesting (31 Aug, 2005). I remember, from my time there, until 1993, that the Canadians really enjoyed being able to shop in a European town in their daily lives. It was so different from their Canadian shopping experiences, and to them it was almost like being on vacation every single day. They soaked up the atmosphere of being in Europe, they wanted to make the most of their few years abroad, and shopping in the historic core was a part of that experience.

For these reasons, the stores in the Innenstadt benefited greatly from the presence of the Canadians. As mentioned earlier, figures indicate anywhere from 400-600 million DM were brought into the Lahrer economy each year by the Canadians. This is a huge amount of money for a town of this size - about 35000 at the time of the Canadian withdrawal (Canadians not included). The population of Canadians was about 12000 shortly before closure. When I asked Hr. Bickel what he felt were the biggest differences between the Innenstadt today (2005) and 15 years earlier, he immediately stated, unprompted, that the Canadians were missing. He believed that this was, above all others, the most important difference (Bickel, 31 Aug, 2005). Eugen Himmelsbach, a former store owner in the Innenstadt, when posed the same question, answered that there was a loss of purchasing power, which is simply another way of stating that the Canadians are gone (5 Oct, 2005). Manfred Spinner, the owner of a jewellery store in the Innenstadt, took this notion even one step further, stating that the main difference was the stores simply were not as good as before, indicating that there has been some major changes in the type of retail that is presented in the Innenstadt ( 3 Nov, 2005). This is very likely due to the fact that many stores 
could simply no longer stay in business once the Canadians left, resulting in this change in the types of retail offered. Gerhard Albrecht, an official from the City Planning Department, stated that it is a huge economic factor that 10000 people are missing. "That of course, brought a certain degree of death to the stores of the Innenstadt" (30 Aug, 2005). A second Jeweller added that the Canadians left very much money in their cash registers. They rented apartments, shopped in our stores, and went in local restaurants. They added much money into the system, and once the money was in the system it brought further revenues as it circulated, and through that it brought life. They brought 550 million DM of fresh, new money into the system (13 Oct, 2005). All these comments point to how vital the Canadians had become to Lahr's economy. Their influence was felt in many sectors, but retail suffered greatly when they departed.

Ulrike Starr was the person in charge of advertising at Der Kanadier for the last 15 years it was in circulation prior to the Canadians leaving. She discussed with me all the different stores that advertised with Der Kanadier hoping to catch the eye of the Canadian consumers. She stated that the Canadians did do a lot of shopping in the Innenstadt. She spoke of all the stores that were regular advertisers. She also knew of many stores that really suffered once the Canadians left. One example involved a popular toy store that I know I, and many other Canadian children frequented, Donner, was a good advertiser. She also mentioned that their profit margin fell drastically when the Canadians left, and as a result they closed down a year to two years after the Canadians left. She also mentioned that the head of the LRPO was a very prominent advertiser, and that he also suffered when the Canadians left. While he was not driven out of business, he used to fill the entire building he 
owns in the inner city, and now only fills the back portion of it, giving the front part up for rent to another store (Starr, $25 \mathrm{Oct}, 2005$ ). Clearly many stores recognized the benefits of advertising in the Canadian newspaper, but also suffered when the Canadians left.

When discussing with the remaining shop owners who had their stores when the Canadians were still in Lahr, it is obvious those were good business days. It seems they all have stories about what made the Canadians special customers to them. A long standing employee at Rödel, a shop specializing in handicrafts, refers to the time period when the Canadians were in Lahr as "heavenly." They would buy cross stich patterns, always of Schwarzwald motifs. They were a huge portion of our business, she stated (Rödel, Sept 29, 2005).

Hr. Bickel also had many stories, but his clear favourite seemed to be about a Canadian doctor who was posted to Thailand, but whose wife stayed in Canada. They decided to get a house in Lahr, which would then be their meeting place because as a result of the base, one could get cheap or sometimes even free flights into Lahr, especially if it was not important what type of plane you travelled in. This doctor commissioned Hr. Bickel to essentially fill the entire kitchen, everything brand new - glasses, dishes, pots, and everything else. Another interesting occurrence he described involved a NATO general stationed in Belgium, who would come down to the Canadian base in Lahr, but would always stop by his store, Saettele, with a wish list. Six weeks later he would come back and pick up the merchandise. These are merely a few examples of things that would never have happened without the base being in Lahr. He also added that at this time it was simply more fun to be in the retail business. One could order a very high value assortment of products because one 
knew the public would want to buy something really great. That went for all types of stores, he added; clothing stores, furniture stores, everything. For this reason Hr. Bickel describes that time as "simply wonderful," and expressed regret that it would never be like that again (Bickel, 31 Aug, 2005).

Hr. Himmelsbach used to have a leather store in the Innenstadt, but he closed it in 1998. He too, had some memories of good business done with the Canadians. His prime business dealings, he stated, mostly happened around Oktoberfest, when the Canadian parties were taking place. During these times, he said, it seemed every soldier wanted to buy a complete set of traditional German lederhosen. He stated that those who came early got a good selection, but those that came a day before it started were not so lucky. He laughed as he remembered Canadians trying to fit into lederhosen that were anything but their size, and if they could get into them, they bought them. It did not matter what they looked like, he needed lederhosen for the Oktoberfest. Hr. Himmelsbach also added that once he got a contract from Canada to do the lederhosen for a whole group of people for their own Oktoberfest festivities in Canada, and that that was a huge deal because of the number of people, and also because they chose him to do it, when they could have chosen any company from anywhere (Himmelsbach, Oct 5, 2005).

There are doubtless countless more stories about doing huge business with the Canadians. The only trouble is finding the people to tell them. Since the Canadians have left, many of the stores which were in the area closed down. Many of the stores I remember are gone, more and more disappearing with each visit over the years. Many other stores have had changes in ownership, meaning that while the store itself has a history in Lahr, the owner 
does not understand what it was like when the Canadians were stationed here. This also means they do not qualify as interviewees for stores that have been here during the time of the Canadians. All the store interviews I conducted were with people who were with the store during the time when the Canadians were in Lahr.

Another factor that is very important when determining the spending pattern of the Canadians was the duration of time that most of them were in Germany. Due to the nature of the job - a military posting to a foreign base - the terms of posting were never very long. There were of course exceptions; one could apply to get the term extended, as was done in the case of my father, who would apply and get extended primarily on account of him having a German wife. But it was more common for the soldiers to be there on terms of two, maybe three years at the most. And this limited amount of time really affected their spending patterns. As Hr. Blum, an economic development officer for Stadt Lahr, stated, there was always a fresh group of people to go shopping. The rotation of troops was very good for the stores (Blum, 30 Aug, 2005).

Fr. Cornforth detailed this situation quite well :

I think the Canadian factor is mainly based on the fact that when the Canadian were living here, it was always for a limited amount of time. It was always whatever their posting was. And they regarded it like being permanently on holiday. And your spending behaviour is very different when you are only here for a short time, you have to make the most of it while you can. (Cornforth, 11 Oct, 2005)

She added that when one is staying for a long time, one's consumer behaviour is completely different and you are not prepared to spend as much money because you are there for a long time. That is what really made a difference in Lahr, there was a constant turnover (Cornforth, 
11 Oct, 2005). Clearly the duration of stay played an important role in determining the spending patterns of the Canadians in Lahr.

There is a stark contrast between the Canadians and the Aussiedlers that came after them. The Aussiedlers do not have anywhere close to the same amount of purchasing power at their disposal as did the Canadians. In fact, in many instances, the Aussiedler are being supported by the government, which clearly makes a difference in spending power (Jeweller, 13 Oct, 2005). However, people certainly were needed to fill the vacant apartments and to try and fill some of the void left by the Canadians. Hr. Bickel stated that he believed that having the Canadians in Lahr helped them handle the adjustment to an increase in population of a primarily Russian culture. He said that due to the Canadians we were used to always hearing foreign languages in our town, and used to the mixing of cultures (Bickel, 31 Aug, 2005). He also stated that he can understand that they do not need as much stuff, certainly not enough to fill the void left by the Canadians. He adds that if they come from Kazakstan, there is clearly a huge difference in lifestyle. They do not go to him and buy a whole set of dishes, and he understands completely. However, he states, that does not bring me anything. He continued by stating that they seem to prefer the shopping on the outside of the city where the discounters are located (Bickel, 31 Aug, 2005, discounters will be discussed further in Chapter 7). Hr. Blum corroborated this when he stated that they rarely do their shopping in the Innenstadt, although he believes that as they become more accustomed to the German culture and way of life and begin to earn more money that this will change, especially with the younger generations (Blum, Aug 31, 2005). But clearly this demonstrates a marked difference between both the purchasing patterns, as well as the purchasing power of these two 
cultures.

The others stores all agreed that the Canadians represented a large portion of their customers and that profits were affected shortly thereafter. Then, they added, they simply had to try and attract new customers, some from the Aussiedler group, and simply more of the native Lahr population. The success of these attempts certainly varies, however (Jeweller, 13 Oct, 2005, and Spinner, 3 Nov, 2005).

Clearly the economic reasons for wanting the Canadians to stay are obvious. Fr. Starr said that when the announcement was made, Lahrers realized the problem; realized that nothing was coming afterwards. She describes it as a very sad moment (Starr, 25 Oct, 2005). Hr. Himmelsbach stated that after the fall of the Berlin Wall, when it was announced that the Canadians were leaving, the faces of many people fell down. He said everyone was sad they were leaving. They did leave a lot of money behind, that is for certain. And he stated that since then the profits have not been the same for the specialty stores of the Innenstadt (Himmelsbach, 5 Oct, 2005). Fr. Starr added that since the Canadians left many stores have closed down and very few remain from the time of the Canadians, and she names many stores that were largely dependent on the business of the Canadians and suffered terribly once they left. She also mentioned the many owner changes, illustrating an unstable retail situation (Starr, 25 Oct, 2005).

In order to determine to what degree the Canadians improved business for the retail stores of the Innenstadt, I conducted a survey of the stores in the Innenstadt. This survey was multi-faceted, but included a question regarding whether, for the stores that had been open during that time, the Canadians were a large portion of their clientele. It should be noted here, 
that where there was a store with an owner change, they answered with what they learned from the previous owner in discussions during the change of owner period (often explained as one reason why the previous owner wanted to sell - sales not as good as previous times with the Canadians). Those who did not know were not included in this category. Out of the 14 stores that were around long enough, 10 of them stated that the Canadians were a big part of their customers. In discussion with the other 4 , they simply stated that did not feel they were really a 'big' part, but they certainly shopped there. I also had a question regarding their general profit margin, whether it had increased, stayed the same, or decreased over the last 15 years. Of these 14 stores, 11 stated that their profits had sunk over this time frame. The other three stores said their profits had stayed the same. No one said their profits had increased. Certainly not a good indication of the successes of the Innenstadt. The final question pertaining to the Canadians was whether they believed there were now more or fewer people in the Innenstadt than during the times of the Canadian presence. This question was included as an indicator of pedestrian traffic as well as a degree of life or culture in the inner city. 13 of the 14 stores stated that there were less people in the Innenstadt, and only one store said it was the same as before. These are pretty stark figures because if the number of people is drastically down, it of course relates to their decreased profits. This survey definitely points to the fact that the Canadians were an integral part of shopping in the Innenstadt.

The German federal government did try to encourage the Canadians to stay. As mentioned earlier, Chancellor Kohl made some statements trying to promote a stay in Germany. Hr. Albrecht describes this as a natural reaction, despite the fact that it was pretty 
much impossible to change their (Canadian) minds. The Canadians were like a monopoly in Lahr and that was a financial bonus for the federal government. The Canadians left a fortune behind (likely referring to the 450 million DM per year); they spent like crazy, he added. Canada invested here trying to make their base a success, and invested millions. Unfortunately, the government could not do anything to keep the base. The decision came from Ottawa, and it started and ended there. With the fall of the Berlin Wall and with that the end of the Cold War, in addition to Canada's low finances, there was simply no reason to keep the base open (Albrecht, 30 Aug, 2005). Hr. Bickel, however, did criticize the handling of the Canadian withdrawal by the local government. He stated that at that point in time, Lahr had a leader who did not fully understand the economic hole Lahr was falling into, and it took them much too long until they finally started working on the problem (Bickel, 31 Aug, 2005). Hr. Blum added that usually, as a host city, you have some kind of say in the matter as it greatly concerns you, but in this case there was no chance (Blum, 30 Aug, 2005).

So while attempting to keep the base open for economic reasons, many feel there were also other benefits to having the Canadians here, that being a richer town overall. When I asked Fr. Cornforth whether she thought that Lahr missed having the Canadians she replied "Oh yes. I think they miss them not only because they were generous in the sense that they spent lots of money. But because they were cheerful, friendly on the whole, that they were casual and cheerful, and generally provided a good atmosphere" (Cornforth, 11 Oct, 2005).

Hr. Bickel added credence to this idea when he discussed what Lahr was like before the Canadians left. He described the city as being full of people. "The Canadian dealings attracted others," he continued, 
you had Italians, Belgians, and goodness knows what else. And you heard everything on the streets. It really was like the smallest metropolis in Europe. And every year or two about half of them were changed for new ones, so we always had a new public walking through. I mean, one cannot adequately describe what it was like, what a wonderful flair Lahr had back then, when one has the feeling that you are in the middle of the world. From my point of view, that was the best time period for this city. It really blossomed during this time, it was absolutely wonderful. They could all come back tomorrow! (Bickel, 31 Aug, 2005)

Furthermore, he added that the revenues of the Canadians are definitely missed, but also the joy of life that the Canadians brought with them...it just takes life away. When the Canadians were here, it was indescribably good for us. Especially in a town the size of Lahr, everything was exaggerated - blown up. And then the bubble burst, and it was all gone (Bickel, 31 Aug, 2005). The Jeweller added to the idea of Canadians elevating life in the city when she stated that the Canadians also celebrated local festivals alongside the Germans, that whenever there was an event, the Canadians were there (Jeweller, 13 Oct, 2005). Clearly this demonstrates just how much the Canadians brought to the inner city of Lahr. Not only did they leave a lot of money behind, but it put Lahr on the map in a sense, bringing more awareness to a small town that otherwise would have gone largely unnoticed. Certainly having an international base in such a small town brought much attention to it. And flourishing life and culture is certainly a very important factor for having a thriving downtown core.

Clearly the withdrawal of the Canadians was an important factor in the development of Lahr over the last 15 years. Through the retail sector one becomes very aware of the changes that are occurring in the city. The retail sector was quite impacted by the loss of the purchasing power the Canadians possessed due to their unique situation. The loss of the base is truly a factor that defines Lahr's development and makes it stand out from other examples 
of urban change. As Hr. Beck, an economic development officer, stated "Lahr is a special situation. You cannot simply say that Lahr's problems are due to the Grüne Wiese or due to the Arena. 450 million DM of purchasing power are missing" (Beck, 17 Aug, 2005). When discussing the development of the shopping outside the Lahrer Innenstadt, Fr. Cornforth stated that the growth of malls and such, which happened decades ago in North America, happened seriously about 10 years ago in the UK, and was now happening in Germany. It is simply unfortunate for Lahr, that both [the loss of the Canadians and building up of shopping outside of the core] are happening at the same time (Cornforth, 11 Oct, 2005). Hr. Bickel added that he would love to be able to go over and get the Canadians back, but that he must face the reality of the situation and attempt to adapt (Beck, 31 Aug, 2005).

The Canadians clearly patronized the Innenstadt extensively. It was a very different shopping environment than they were used to, and they wanted to make the best of their time in Germany by soaking up as much of this atmosphere as possible before they were sent back. The military families were also very well paid, and this meant that they were in a better position to be able to afford the merchandise that was offered in the Innenstadt, as stores that focus on quality and expertise, and who generally do not have large stores (in this case due to the architecture of the historic buildings) have to reflect this in their prices. Clearly the stores of the Innenstadt were in a position to lose revenues when the Canadians withdrew.

As mentioned many times, the decision to pull out of Europe was largely based on the fall of the Berlin Wall and the consequent end of the Cold War. A comment that I heard often during my time in Germany was 'if only the wall didn't fall,' or something to that effect. Reunifying Germany has certainly come at a cost, and West Germans were indeed 
prospering prior to the end of the Cold War. And perhaps this particular thought is occurring in Lahr because the fall of the Wall is also associated with their losing the Canadians. So while I heard this comment quite a few times, I only once managed to catch it on tape. I will conclude this chapter with a small excerpt from my interview with the head of advertising for the Canadian newspaper, Ulrike Starr, and her husband Colin, a Canadian who stayed behind in Lahr, because I feel it captures the underlying sentiment of many Lahrers, and perhaps demonstrates why Lahrers are having a difficult time moving forward; an 'if only' attitude coupled with nostalgia for this time period in Lahr's history.

Colin They all wish the Canadians were back.

Nadine Yes, that is what I hear all the time.

Ulrike If the wall wouldn't have dropped!

Nadine Exactly. I hear that too all the time.

Ulrike The cold war would still be on! Everywhere.

Nadine Yes, I hear that. Keep that wall up and everything would be fine.

Colin Keep the wall and make it three feet higher! 
Figure 5.1 : Map of Lahr

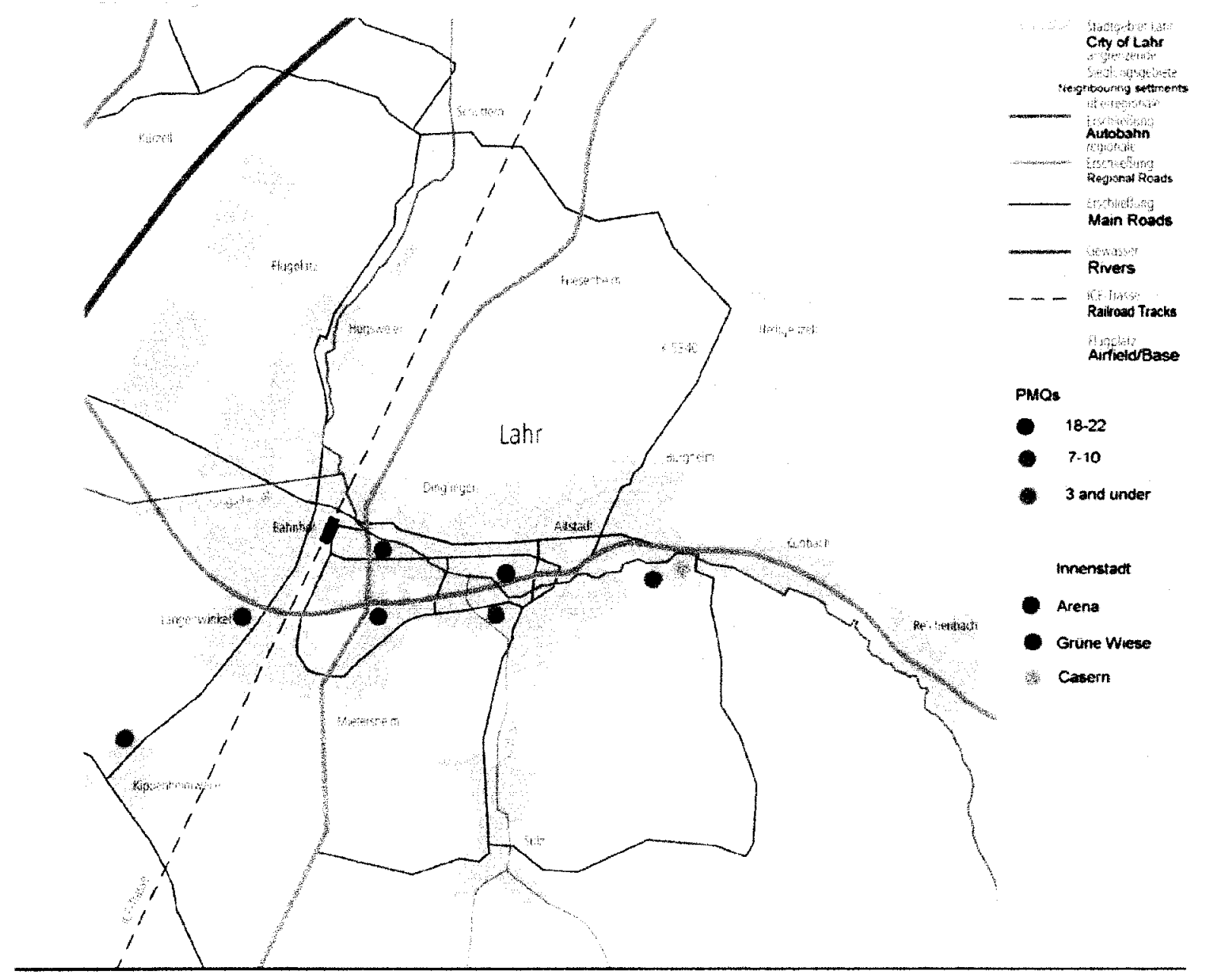

Source : Pesch und Partner. Rahmenplan. 2003. Modified by author.

Note : PMQs - Canadian Private Married Quarters 


\section{Chapter 6: Arena and Grüne Wiese}

On the $24^{\text {th }}$ of May, 2000 , a new shopping mall, the Arena, opened its doors for the first time in Lahr. Since opening day, this mall has been a source of competition for the stores of Lahr's inner city. This is the first mall of its type in Lahr, and it consequently has had quite a noticeable impact on the shopping patterns of consumers. Unlike in North America, where malls are commonplace, this phenomenon is relatively new in Germany, where the primary emphasis of shopping has historically been in the city centres. The Grüne Wiese is an older complex of large stores, similar to a strip mall, that is also quite popular with Lahrer consumers. It has relatively recently had some redevelopments done, and has also been quite a pull for shoppers. Both of these areas are locations that are considered competition by the Lahrer Innenstadt, and their impact will be examined.

When the Arena opened in the summer of 2000 it added 6400 square metres of shopping to Lahr. The Arena has a wide variety of stores, but these stores are also very high quality. It has a very large grocery store, a huge book store (the first of its kind in Lahr), a music store, a hardware store, some clothing stores, a flower shop, a travel agency, a pharmacy, a jewellery store, and a bakery. In total there are about 18 stores in this complex. Its location was decided upon in conjunction with the prime investor and the City of Lahr. Prior to this development, another mall had been proposed on the vacated lands of the airfield, but rejected on account of the fact that it was too far away from the city centre. By building this mall close to the centre, it was hoped it would translate into an attraction for the whole city, and not just an attraction solely for the mall itself(BZ, 24 May, 2000, Kohlmeyer 
1). Figure 6.1 shows a map of Lahr displaying the Innenstadt area and the Arena. The Innenstadt is highlighted with yellow streets, and the Arena is the red box to the left of the map. The Arena certainly delivered in this respect. On the $26^{\text {th }}$ of May it was found that $54 \%$ of its clients were coming from outside of Lahr, and naturally the Innenstadt was hoping to benefit from the pull the Arena was creating (BZ, 26 May, 2001).

However, there is a problem with the notion of the Arena and the Innenstadt being connected. Despite the fact that the Arena really is not far away from the Innenstadt (about a 10 minute walk), it seems that this notion is not getting across to consumers. There definitely appears to be an 'either/or' attitude where the Innenstadt and the Arena are concerned, and stakeholders are having a very hard time convincing consumers that the distance between the two is not great, and that one can easily patronize both of these areas in the same shopping trip. However, the perceived distance is evident in the language people use when they discuss this issue.

"They said you would only need five to six minutes to walk there. I walked it, I needed 10 minutes - and I did not even take a break...how can you tie the two together? After all, it is hundreds of metres away" (Himmelsbach, 5 Oct, 2005).

"Nobody walks from the Innenstadt to the Arena or vice versa" (Bickel, 31 Aug, 2005).

"I think it is because of the Arena out there," [why the Innenstadt is empty], and when discussing connecting the two, "that won't work. It is too far away, too far over," (Rödel, 29 Sept, 2005).

"We need to develop a clear transportation link between [the Arena and the 
Innenstadt]. A pedestrian link will not work with such a large distance," (Bickel quoted in BZ, 18 Feb, 2003).

"The decision [to build] the Arena should not be seen as a decision against the Innenstadt," the feelings of the Mayor of Lahr as written in Die Badische Zeitung (BZ, 20 April, 2002).

These are simply a few examples of how the people of Lahr speak of the connection between the Arena and the inner city. Clearly, despite the fact that the current location of the Arena was chosen to not damage the Innenstadt, it is doing so. There is still perceived to be an almost insurmountable barrier between the two locations, regardless whether it be perceived or real.

However, intentions were likely good at the outset, which certainly makes the Mayor's quote believable. A study conducted in southern Germany (Popp, 2005) showed that when deciding on locations of shopping centres, it was thought that by placing them close to the inner cities, it would help to improve the retail situation in town. However, as time passes, opinions are splitting on this notion, and some believe that locating shopping centres near town centres actually leads to the further decline of the core. The initial logic behind the idea was to avoid the shopping centre becoming a 'town within a town,' and that if it were linked to the core, retailers there would benefit from coupling effects (people that shop at both areas in one trip) as the two locations merge into one. It was believed to be a "quick and effective means to combat the decline of town centres" (Popp, 2005, 108).

One presumed benefit of the mall was to increase the ability of the city to attract consumers from out of town, increasing the city's attractiveness on the urban settlement scale 
(refer to Chapter 2). This certainly corroborates what is occurring at the Arena, as was earlier mentioned. However, the problem begins when the shopping centre creates a large enough market for itself without needing the coupling potential from the town centre (Popp, 2005).

This notion leads to one of the main factors deciding the success or failure of the merging of shopping centres and inner cities into one successful area, and that is the distance between the two locations. Clearly, if the shopping centre is far away, it is more likely to create its own market independent from the town centre. In Popp's study, the towns with shopping centres less than 100 metres away from the town centre showed the highest amount of coupling between the two locations. These numbers decreased the further away the shopping centre was. The furthest any mentioned shopping centre was, was 1500 metres, which displayed very low levels of customers who would visit both locations (Arena is located approximately 1000 metres away from the southern-most portion of the Innenstadt, Popp, 2005). Clearly distance between the two locations is of paramount importance when attempting to encourage any kind of a connection between the two locations, and the conclusion that Popp came to, was that "at distances of more than 250 metres, it generally becomes difficult to establish significant exchanges of visitors" $(2005,119)$. This highlights perhaps the most important obstacle to a successful connection between the Lahrer Innenstadt and the Arena, as the separation is four times this distance. The other main factor, the attractiveness of the connection between these two locations, will be discussed later on in this chapter.

The Grüne Wiese has a similar effect on the Innenstadt. The Grüne Wiese has a prime location just off of the road that comes off of the Autobahn. Figure 6.2 displays the location 
of the Grüne Wiese, indicated with a star at the left of the map, with relation to the Innenstadt. It is located before the city centre, and therefore, consumers who do not wish to deal with inner city traffic, in particular those coming from the Autobahn or the western portions of the city, can merely turn off and do their shopping without going anywhere near the city centre (see page 73 for map of city). In fact, the Lahrer Innenstadt is at an extreme disadvantage as far as location is concerned; the Arena is also located on this road into town, also right before the inner city, so twice the consumer may be tempted to turn off before reaching the city centre. The Grüne Wiese is definitely a separate entity from the Innenstadt, at a distance of roughly three kilometres from the centre, or a good 30 minute walk. So unless there is a specialty item that is needed from a particular location, this would likely also be an 'either or' situation, nor would one even dream of the possibility of a connection between the two.

As mentioned earlier, the Grüne Wiese is a slightly older development, built about 20 years ago, consisting of 34000 square metres (Fischbach, 2004). While it has been an attraction for a number years, it was recently redeveloped and expanded upon, making it even more of a magnet than before. Not to mention that earlier the Canadians were still around, who patronized the Innenstadt quite well (but who would have also visited the Grüne Wiese). In 2001 it was announced that the Kaufhalle, a large building consisting mostly of a grocery store - a total of 4500 square metres of space - was closing. The replacement of this grocery store would be a branch of a Germany-wide chain, Edeka, owned by the Kohler family, the same family who primarily funded the building of the Arena. They would open up a grocery store of 2000 square metres in this building overtaken by the "Oviesse Gruppe," a leader in 
the Italian textile market, who took over 99 of the abandoned Kaufhalle locations Germanywide (BZ, 25 July, 2001). On the $18^{\text {th }}$ of September the re-developed building opened, its two prime attractions being the Edeka and the clothing store (BZ, 18 Sept, 2001). This brought extra attention to the Grüne Wiese, which currently consists of, in addition to this development, two drug stores, two shoe stores, an electronics store, and a hardware store. As this development is quite similar to a strip mall type of development, it should be noted that these stores are essentially built in a warehouse style and are quite large.

The stores in the Innenstadt are generally smaller, however, there are certainly exceptions, and there is quite a variety of sectors represented. The Innenstadt consists of 37 300 square metres, with about 60 retail stores. From the interview sources it is already known that there are jewellery stores, a hobby handcraft store, and a kitchen accessories store. In addition there is a new, very large, drug store (other smaller ones as well), a department store, a bed store, bicycle stores, cell phone stores, shoe stores, a book store, a toy store, and clothing stores covering all demographics. In fact, over the last few years, Lahr acquired the clothing chains of Orsay and H\&M, quite impressive feats for a town of Lahr's size, and stores that are mentioned as magnets to the Innenstadt. In addition to the retail possibilities, there are hairdressers, restaurants, food stands, ice-cream dealers, and cafés, as well as a farmers market twice a week. There is truly a plethora of stores in the inner city offering a variety of retail options. However, the one portion of the market which is not very well covered is that of groceries.

The Kohler family have also opened an Edeka chain in the Arena. The fact that both the Arena and the Grüne Wiese have large Edeka stores, which are known for their good 
quality, is a large disadvantage for the Innenstadt. As alluded to in the previous chapter, the inner city is experiencing difficulty holding on to grocery stores due to problems with transport trucks and limited space in the older buildings. With Arena and Grüne Wiese having these stores, they have huge advantages over the Innenstadt as far as being a factor for one stop shopping. It does not help that the Kohler Edeka stores are excellent. Hr. Bickel, head of the Lahrer Retail Promotion Organization (LRPO) describes the store in the Arena as such : "one's heart is just filled with joy when one sees what that store offers... what they have in the way of fish, cheese, and meat and deli. From this regard, it certainly is enriching to the city" (Bickel, 31 Aug, 2005). He is not the only one that thinks this way. This Edeka store won the "Golden Cheese Knife" prize in 2003 for best cheese selection (over 300 kinds) and best service in Germany (BZ, 7 June, 2003). This store also won the "Edeka-southwestcup 2003" prize - a competition between all Edeka stores in southwestern Germany based on profits, spectrum of products, store organization, customer service, employee leadership and fresh produce display (BZ, $19 \mathrm{Sept}, 2003)$. Clearly steep competition for any grocery store, and then especially for the Innenstadt which is currently in possession of only two very small grocery stores.

There is certainly evidence that the Arena essentially chased those grocery stores remaining in 2000 out of the Innenstadt. In 2001 it was announced that two grocery stores would be closing in the Innenstadt. One was an Edeka store which had been in the basement of a prominent Lahr store, the Kaufhaus Kraus (KK), which has had a grocery store in its basement since 1969. This store could no longer stay, regardless of the fact that five years prior the KK had cut its rent in half - an indication of both how important groceries are to the 
Innenstadt and to the dire straights the grocery store must have been in. However, it was stated that the opening of the other Edeka store in the Arena created an enormous loss in profits for the Innenstadt location. The other grocery store closure was based on a new Germany-wide corporate policy to close all stores that did not have at least 80 parking spaces attached with it (BZ, 25 Oct, 2001). Claudia Dalm, a city planning official, stated that grocery stores have a hard time staying in the Innenstadt because of the parking issue. Not only do people believe it will be difficult to find a spot, they simply do not want to have to carry the heavy groceries from the store to where they parked. This is especially complicated by drinks, which Germans buy regularly by the case of 1 litre bottles; clearly no one could be expected to carry these across town (Dalm, 19 May, 2005). This loss of grocery stores in the Innenstadt was described as being an "absolute loss of centrality for the Innenstadt"(BZ, 25 Oct, 2001). Clearly without any major grocery store magnets, the Innenstadt is weakened as a location for covering all angles of the market, groceries naturally being a vital part of the 'whole picture.'

This difficulty faced by the Lahrer Innenstadt with regard to parking is a problem that afflicts all downtown cores. Obviously when the inner core was being built, a place to leave cars was not considered, and parking spots have to be created where there is space, or go underground. There are both underground and above ground parking places in Lahr, however, they are all pay parking spaces, as in all downtown cores. However, the consumers are quite vocal in their disapproval of this system, and often complain that the prices are much too high. Hr. Bickel explained that at the time the underground parking garage was being built, because they are awfully expensive, the city cut a deal with a developer to build the parking 
garage, and one of the conditions was that the developer would decide upon the rates that would be charged. At this time though, the Canadians were still around, and the situation was still a very profitable one, so Lahr did not foresee any problems with this. However, years later, they are still stuck with this deal, and he feels that this is hindering the inner city's ability to compete with areas like the Arena and Grüne Wiese (Bickel, 31 Aug, 2005). These two locations offer large amounts of free parking, the Arena alone having 420 spaces for its shoppers (BZ, 24 May, 2000, Kohlmeyer 2).

Hr. Bickel adds that measures have been taken to try and make parking cheaper. For example, stores of the LRPO will pay a portion of one's parking fees if something is bought in the store. Also, the city of Lahr has made all above ground parking free on weekdays after five in the afternoon, and after noon on Saturdays (Bickel, 31 Aug, 2005). Consumers can make good use of this, as the regulations regarding store openings were relaxed about three years ago. Since then, the LRPO has tried to establish fixed opening times. On average the stores are open until 19.00 on weekdays (20.00 at the Arena) and about 16.00 on Saturdays. Hr. Bickel admits, however, that not everyone follows these guidelines. He stated that some of this depends on the type of store one has. For example, a butcher will open earlier (general openings are 10.00) and therefore close earlier as well. These parking regulations also encourage consumers to take advantage of the non-retail aspects of the Innenstadt, such as visiting cafés, going to restaurants, or visiting any of the cultural events that may be taking place (Bickel, 31 Aug, 2005).

These measures certainly indicate that efforts are being made to correct the parking problem, but it does not appear to be enough. When I asked the Jeweller what the factors are 
that make consumers choose the Arena over the Innenstadt, she stated that parking played a huge role in the decision making, especially for those who come from much further away and are less familiar with all the dispersed parking opportunities spread throughout the downtown core. She stated that you have to also add parking fees to whatever it is you come to the city for, and to some it is just not worthwhile to go, have a coffee and cake, pay for that, and then have to pay to leave your car somewhere as well. She stated that one can most often find parking spaces, it is not a problem of supply, but the cost of it (Jeweller, 13 Oct, 2005). This certainly appears to be the case, as the Innenstadt boasts more than 2000 parking places (BZ, 18 Feb, 2003).

Hr. Himmelsbach, who used to own a store in the Innenstadt, stated that the problem also lies on the fact that people want to drive a lot, as opposed to taking public transportation, and naturally get angry when they park somewhere and end up with a parking ticket on their car after they are done shopping. Another problem is that parking is always difficult to develop in a small town like Lahr. However, he points out that it is a given that when one drives to Offenburg or to Freiburg to do their shopping, that they pay for parking. Yet for some reason, in Lahr they complain about it. Then they do not go into the parking garages, leave their car on the road somewhere, and then get mad when they get a ticket. It is a double standard (Himmelsbach, 5 Oct, 2005). I can only imagine that this problem lies with the fact that Lahr is a small town, because it really is a fact of life that one pays when visiting larger towns, and perhaps that is why people resent it in Lahr, although really it should be just as expected as when dealing with any other location. Added to this, the parking in Lahr does not even appear to be that expensive. The prices range from the cheapest being $0.50 €$ for an 
hour (roughly 70 cents), to the most expensive being $0.50 €$ for a half an hour (Parken in $\underline{L a h r}, 2005$ ); certainly not a terrible price. Hr. Bickel pointed out that one could go poor parking in Freiburg, and yet people still do that. And in Lahr one can even park right in the town centre, he adds, as the underground garage is located directly under the market square (Bickel, 31 Aug, 2005). However, no matter how simple Lahr makes its Innenstadt parking, it will never be as simple as huge lots where parking is always free as it is by Arena and Grüne Wiese. Hr. Albrecht, a city planning official, stated that this certainly encourages the consumers to simply go goal-oriented towards these points to minimize stress or complications (Albrecht, 30 Aug, 2005).

When conducting my survey of retail owners, it was clear that these two areas were perceived as strong competition. Of the owners that gave answers, $57 \%$ stated that the Arena was among the biggest competition for the Innenstadt, $38 \%$ stated that the Grüne Wiese (it should be noted multiple answers were allowed). Also, as mentioned in the previous chapter, $30 \%$ of respondents stated that the discounter stores were competition. What is interesting to note is that some store keepers would list faults of the Innenstadt as being their biggest competition, I imagine in a sense, their biggest hurdles to get over. For example, 3 respondents stated that there were no grocery stores in the Innenstadt, and that is why people were not shopping here. $17 \%$ of the respondents mentioned that parking was the prime issue, and that the Innenstadt simply could not compete with the stores that offered free parking. Only three stores stated that the Innenstadt had no direct competition, and all stated something similar to, if you have a good store, then you do not have to worry about competition. There were a few other unique answers, and these included shopping on the 
internet or in catalogues, and bad weather (See Figure 6.3).

Figure 6.3 : Competition for the Innenstadt

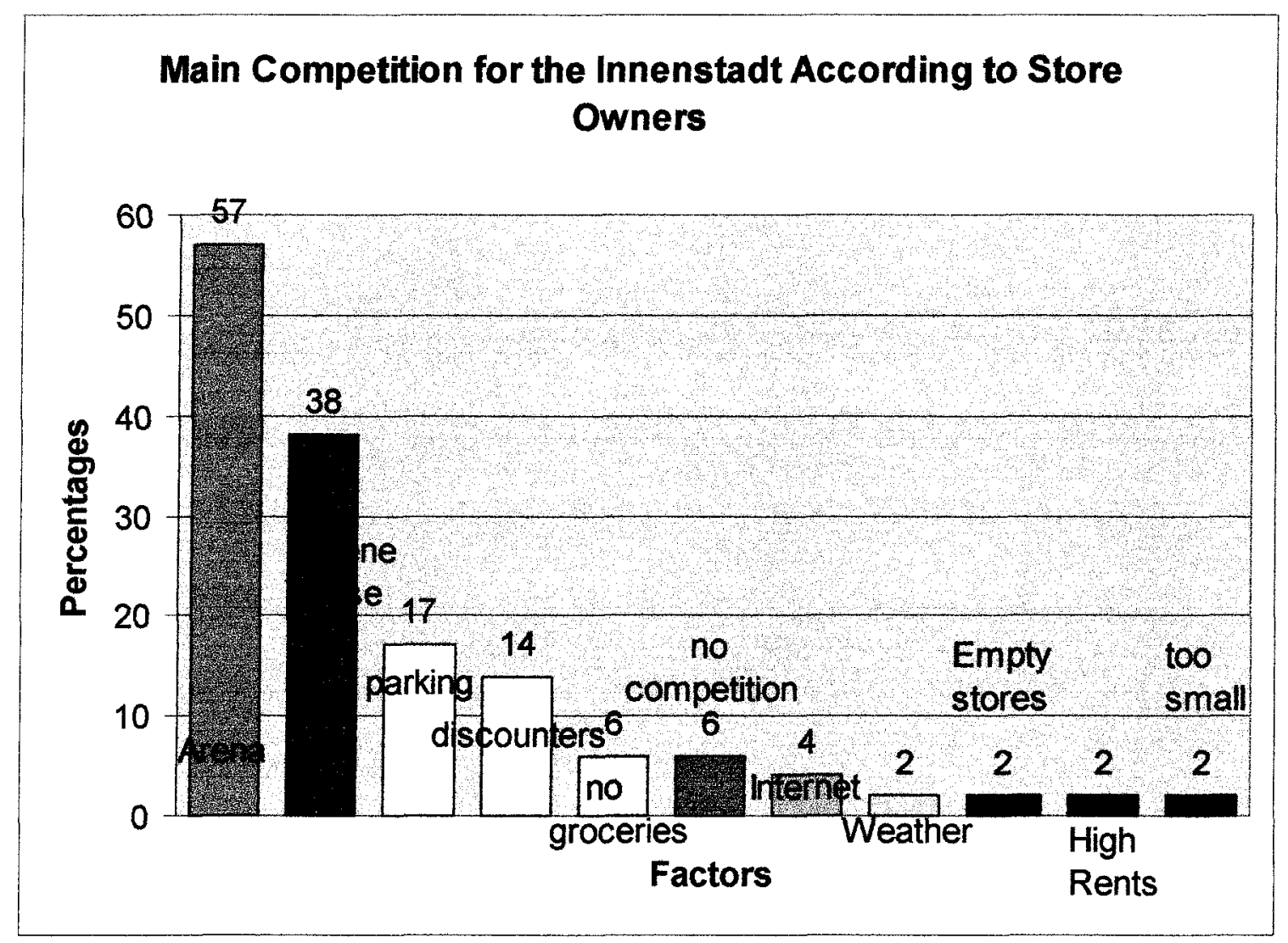

Source : Author's survey, 2005.

The City of Lahr and the LRPO are trying to attract shoppers into the Innenstadt over going to the Arena or the Grüne Wiese. It can be largely assumed those coming from parts of Lahr and its surroundings other than those directly next to these complexes, are coming primarily by car. One can argue that the attempts at improving parking are a way to try and get these consumers to choose the Innenstadt over these other locations. Those that do not come by car, will largely come by bus. In recent years the city has made attempts to improve the public transportation routes, making the Innenstadt the central location through which 
all buses pass, and a prime location for those who need to switch buses. On top of this, the bus routes entering the inner city from the south have been improved - the direction from which people who live around the Grüne Wiese would enter - and now people can reach the inner city even faster from this area (BZ, 7 Dec, 2004).

With the Arena so close to the Innenstadt, Fr. Dalm explained to me that the city would really like to have the Arena better connected to the historic core. She brought up the idea that the consumers simply view it as being too far away and therefore, do not walk there from the Innenstadt, or vice versa, creating this 'either/or' dynamic. She states that the pedestrian connection is in place, but the problem lies with the mental connection (geistige verknüpfung). She believes that it does not help that it is a small town and people are not used to walking long distances, and also feels that because there is not anything particularly attractive between the two places, it does not encourage consumers to walk between them (Dalm, 19 May, 2005).

This leads to the other important factor in the success of inner cities and inner city shopping malls alluded to earlier, and that is the attractiveness of the connection between the two locations. This is crucial when attempting to encourage consumers to walk between the two retail locations. Many of the successful case studies Popp examined had either pedestrian bridges, or a revitalization of the path connecting the two places (Popp, 2005). In contrast, the walk between the Arena and the Innenstadt is certainly anything but attractive, nor is there any sort of a visible path or other type of connection linking the two. One can either walk down the Tiergartenstrasse, a very busy road, or walk through some small streets to reach Goethestrasse, also a very busy road. One must then cross this road, and then walk 
through an unattractive park (where many transients often gather and drink) and open space to arrive at the Arena (see Figure 6.1). The walk is not exactly inviting, and a visitor to Lahr would likely not even think of taking it when starting from the Innenstadt, as there are no signs encouraging one to do so. (Neither are there from the Arena to reach the Innenstadt). The Arena is not even within sight. Fr. Dalm believes, however, that the lack of mental association is the true barrier to overcome, and said that the City of Lahr has to work on this, and accept that it will simply take a long time to change the attitudes of the consumers (Dalm, 19 May, 2005).

Fr. Dalm stated that for these reasons the city was currently working on a connection via transportation routes. She states that many improvements have been made on the roads between the two locations, including more roundabouts to keep traffic flowing (Dalm, 19 May, 2005). Bus stops have also been added at the Arena, and these go between the Arena and the Innenstadt directly, resulting in a very short driving time, less than 5 minutes, between the two (BZ, 7 Dec, 2004). Fr. Dalm also added that they were considering creating a shuttle bus that would simply go between the two locations all day long, to encourage people to view the two as connected and that they could easily visit both locations in a single shopping trip (Dalm, 19 May, 2005).

Hr. Bickel also agreed that it is the mental association between the two locations that needs to be improved. He states it is not an Innenstadt against the Arena type of situation. He adds that they cannot get rid of this building, they must make the best of it and work together. The Arena is a member of the LRPO, and he says they offer very much support. He talked about how they funded and organized many special events together, in the hopes that people 
would see the two as connected. However, he stated that the Grüne Wiese never participates and appears to have no interest in demonstrating a connectivity or partnership with the Innenstadt (Bickel, 31 Aug, 2005).

However, many people still remain sceptical as to whether such a connection can be made. After discussing some of these options with the former store owners, they still doubted the successes of such actions. Hr. Himmelsbach thought that it was a good idea in principle, but he feared it would never work. The obvious problem with the shuttle bus, he stated, was that of who would finance it? It would likely fall to the stores and the city, but the people that go there, have their shuttle busses with them - their cars, he added (Himmelsbach, 5 Oct, 2005). Fr. Himmelsbach, his wife who ran the store with him, added that it was simply too far away. If it were in another location, then perhaps such a plan would work. But she added, the Innenstadt is simply the Marktstrasse, the Schlossplatz, and the Marktplatz, and that is it. For these reasons, they both agreed, it simply would not work (Fr. Himmelsbach, 5 Oct, 2005).

Rödel also doubted the successes of such actions. She had already known about the ideas to connect the two with a bus, but stated "I would like to know who plans to do that" (Rödel, 29 Sept, 2005). She added that the city tries to convince people to walk the distance, but that no one does it. Here surfaced the argument again that the Arena is simply too far away, and she went as far as to say that it cannot be connected to the Innenstadt, and trying to do so would not bring any results (Rödel, 29 Sept, 2005).

So while the City remains hopeful that such connections can be made, the store owners are less so. I personally often walked back and forth and had no problem doing so, 
however, it can be argued that due to my time in Canada, I have a different perception of what a long distance is, as was often pointed out to me whenever discussing issues of distance. However, there certainly is something behind the argument that for people carrying heavy bags, whether from regular shopping or specifically from groceries, the distance is a deterrent. Also, the Arena is four times the distance that Popp (2005) suggests is the furthest away a mall can be from the town centre and still be considered part of it - 250 metres. So when comparing the situation in Lahr to the Popp study, it certainly conforms with the trend. The lack of grocery retailing definitely appears to be hurting the Innenstadt, because the two small stores that remain have an extremely limited selection due to the size of building they are in. As mentioned earlier, this situation will only get worse because one of these stores will be leaving the Innenstadt shortly. This is currently a locally unique problem, as the other cities in this region all still have grocery stores in their city centres. The result of this will likely be that when people have multiple things to purchase, they will be more likely to go to the Arena or Grüne Wiese because they have grocery stores, and this increases their chances of getting everything they need in one place. The free parking of shopping centres is certainly an issue for inner cities of the entire developed world, and the climate controlled environments of the centres would certainly give them an advantage when there are inclement weather conditions. For all of these reasons, the two developments create quite a challenge for the stores of the Lahrer Innenstadt, and it will be interesting to see whether or not the City and the LRPO will be successful with their attempts at forging a mental connection between at least the Arena and the Innenstadt, as this was likely their intention from the moment they agreed to the building of the Arena in its current location. 
Figure 6.1 : Map of the Arena in relation to the Innenstadt

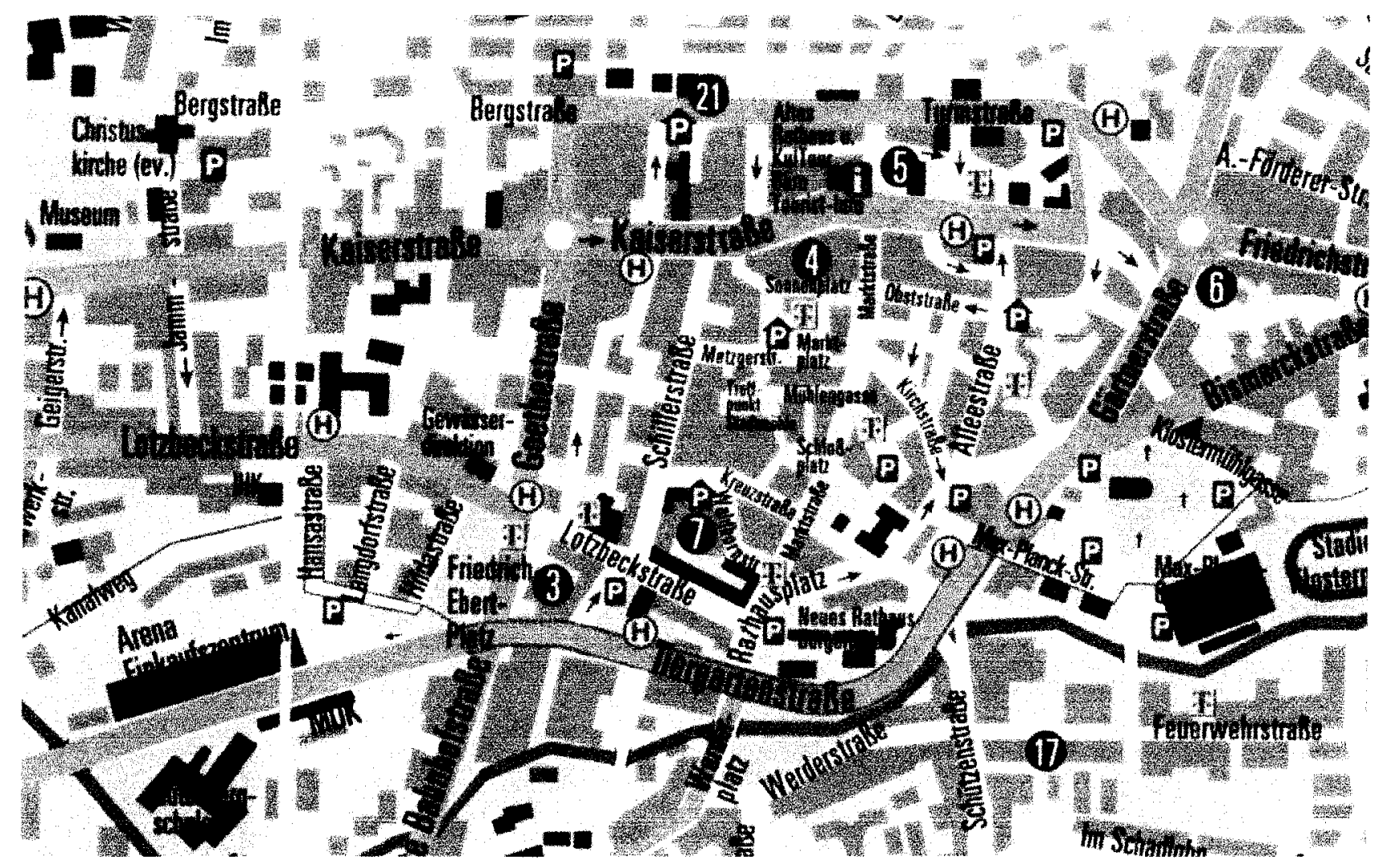

Scale: $1 \mathrm{~cm}$ roughly equivalent to 125 metres.

Source : Das Schuttertal Map. 
Figure 6.2 : Map showing the Grüne Wiese in relation to the Innenstadt

Scale :

$1 \mathrm{~cm}$ roughly

equivalent to

300 metres

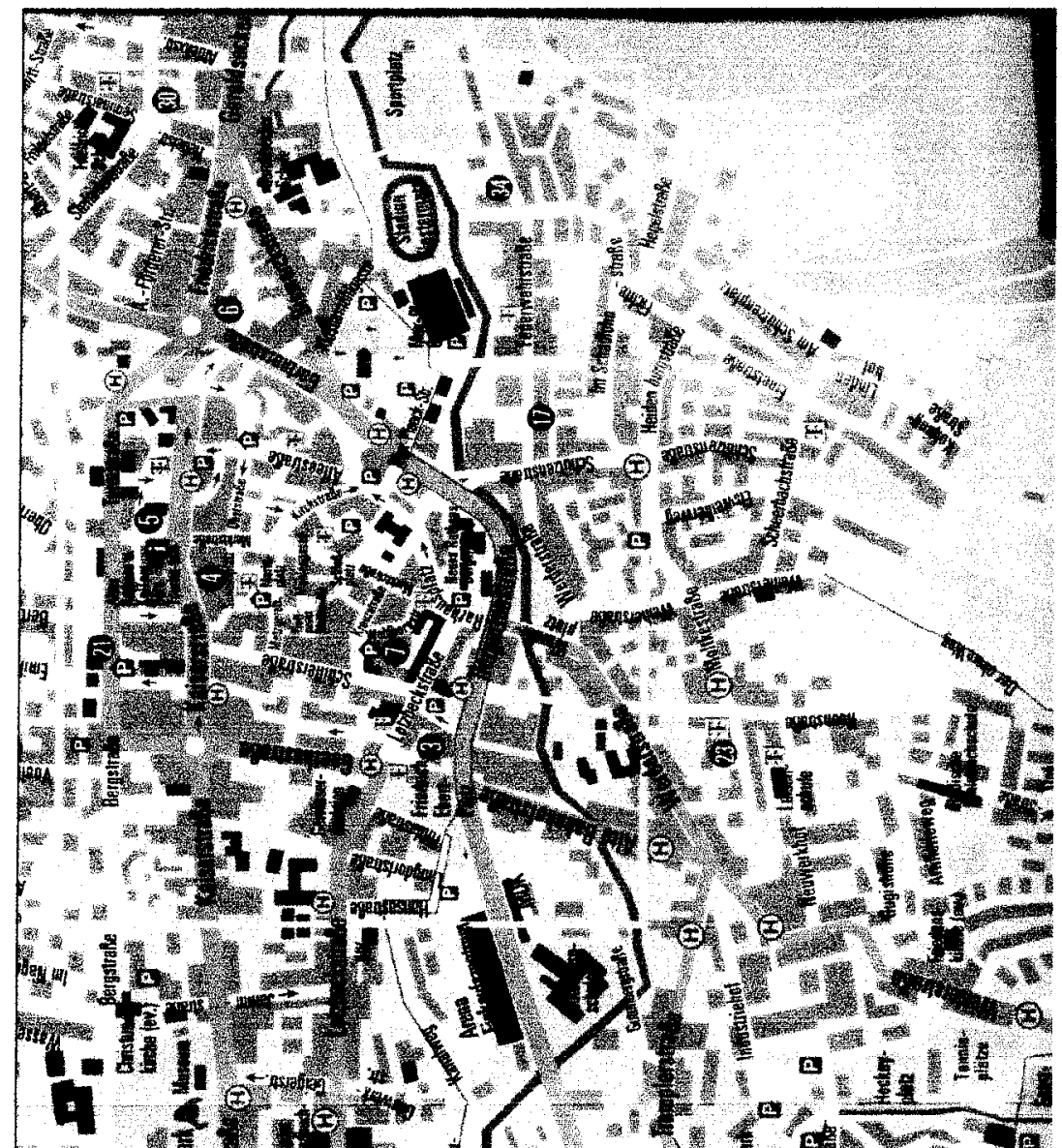

Das Schuttertal Map.

Source :

(f.
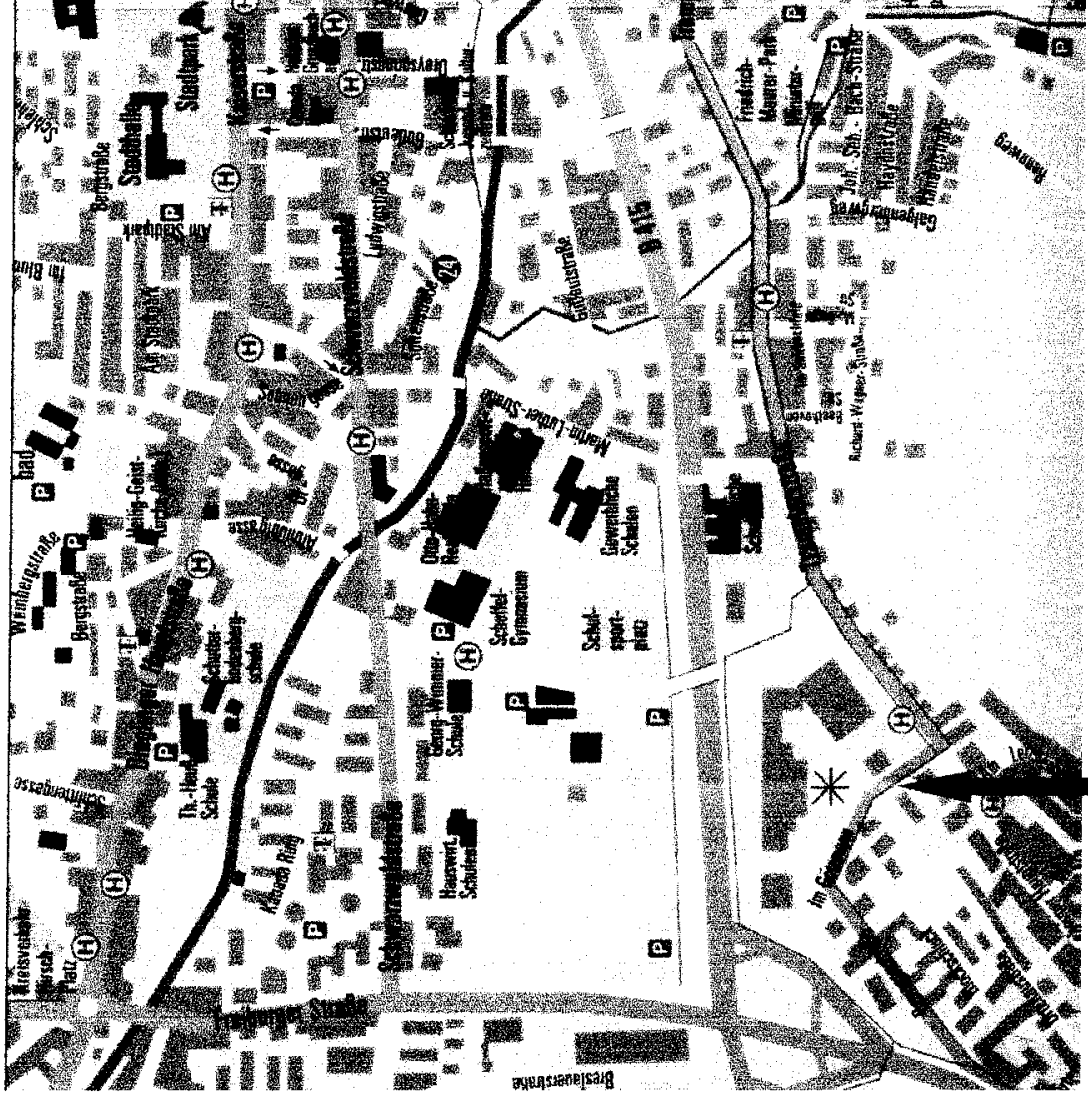


\section{Chapter 7: Effect of German Economy and Euro Conversion}

On the $9^{\text {th }}$ of November 1989 , the Berlin Wall came down. East Germans streamed into the western part of Berlin, overjoyed to be mingling with the fellow countrymen they were separated from for nearly three decades. After this momentous occasion, it was clear that it was only a matter of time until the two Germanies were reunified. One year later it was official, and the task of rebuilding the East after a devastating period of Soviet rule had begun.

There was plenty of work to do in Eastern Germany, and the West was more than happy to fund the developments. West Germany had set itself an ambitious goal in that it aimed to make living standards in the East exactly the same as they were in the West. That would cost money, and the West was exceedingly generous, believing that this money would produce the results they so desired (Berg et al, 2005). Government funds were primarily used to bring the failing infrastructure of the East up to par - roads, bridges, railways, airports, telephone services, and power stations were all heavily funded. Income maintenance was also targeted by paying for unemployment compensation, social security, and other social costs (Gordeeva, 2006). After heavy initial investments, government transfer payments to the East settled at around 100 billion Euros per year. In total it is estimated that the costs of reunification on the West total over 1.5 trillion Euros (German Reunification, 2006). This absolutely colossal number more than demonstrates the good intentions of the West in trying to get the former East Germany up to the standards of the West. However, there are still large 
discrepancies between the East and West.

What is the cause of these discrepancies between the two regions? One major problem in the East are levels of productivity. While the West worked hard to achieve wage equality in the public sector, despite its high costs, there was a mounting productivity deficit between the two former Germanies (Berg et al., 2005). In 1992, the Eastern states contributed only 7.7\% of Germany's total gross domestic product (Gordeeva, 2006). A prime reason for this, as was discussed informally a few times during my stay in Germany, were the work conditions. Many Germans simply believe that the East Germans had a very hard time adjusting to working in a capitalist economy. Under communism there was extreme job security, and there is a feeling that the East Germans had a hard time understanding that they needed to compete for their employment position, that they had to work fast and for regular hours, otherwise the employer would simply replace them with someone who would. This appears to be what many Germans believe, although it should also be pointed out that none of this was ever discussed with any malice; it was understood that they simply came from a different system so it is only natural that it take some time for them to adjust.

Another big problem in the East is that many young people are emigrating to the West. Due to high unemployment in the East (sometimes reaching as high as $20 \%$ ), many young people feel that they cannot have a successful future in the East, and move to the West to find work. This results in an extraordinarily high proportion of elderly people in the East. Many towns close to the former West German border are also deemed as bedroom communities, where many people simply live in the East, and commute to jobs in the West. It is currently estimated that there are over 1 million empty apartments in the East (Berg et 
al., 2005). In addition to this, it creates more job competition in the West because more people are competing for the same jobs.

However, with this many people moving to the West from the East looking for work, it results in work being less available in the West as well. I have decided to focus attention on the issue of unemployment because it is certainly a hot issue in Germany today. It seems everyone who has a job is worried about their job security, and the unemployed appear to be having a difficult time finding work. It can really only be described as an desolate mood in Germany - and the area I was living in was considered to be better off than many other parts, bringing me to the conclusion that if people here were worried, they were worried everywhere. Because this mood does appear to be so prevalent, I wanted to examine it because "in Germany there is a close relationship between fear of unemployment and consumer confidence" and is therefore having a negative impact on the Lahrer Innenstadt (Ready to motor?, Aug. 20, 2005, 58).

On September $9^{\text {th }}, 2005$, an article in the Lahrer Zeitung discussed this feeling of anxiety Germans feel about their futures. Topping the list of worries was found to be increasing prices, deterioration of the German economy, and increases in unemployment. This study began in 1991, and states that since the last examination (no date given but I would assume the year prior) the anxiety of losing one's job has increased 12 points (LZ, 9 Sept, 2005). The study describes the Germans to currently be so worried as never before (“ängstlich wie noch nie"). With regards to unemployment, it states that unemployed people are no longer a fringe group, instead unemployment is something that is quite widespread and could only be a matter of time until it 'gets you' (LZ, 9 Sept, 2005, Frädrich). Another article 
in The Economist states that "consumer spending seems stifled by lack of confidence in the future" (Germany's surprising economy ${ }_{2}$ Aug. 20, 2005, 9). This is certainly an indicator of how well the German economy has been coping over the last years, and it would seem that the citizens do not feel it has been entirely positive. One can certainly not blame East Germany itself for this, however, perhaps the politicians could have handled the unification better. Although in the former West Germany, it would appear as though some people do hold reunification responsible for some of the economic problems that Germany is currently facing, as the interview excerpt in the previous chapter indicates.

In Lahr itself there was much discussion about unemployment. It certainly did not help that over the summer of 2005 two of Lahr's major firms experienced financial difficulties. The first was Roth-Händel, a tobacco manufacturer. Tobacco has been an essential industry to the Lahrer economy for almost the last century, and they have already been forced to reduce their workforce drastically in the past. This year, Roth-Händel was facing trouble from the European Union regarding how their most important product - West Single Packs - would be taxed. If the reforms came through, their product would no longer be able to compete (LZ, 3 May 2005). This caused much worry in Lahr.

The other major firm that faced serious economic hardship was Grohe, a company which produces faucets. Profits had been decreasing, and a study contracted to try and improve their internal structure suggested they needed to cut back on employees. In May there was much discussion and many demonstrations in Lahr regarding these possible job losses. At this point in time it was estimated that up to 1500 jobs could be lost (LZ, 25 May 2005). When the decision came in Lahr, it was settled that 384 people would lose their jobs. 
However, this was not necessarily the end of it, and Grohe employees still worry that there could be new rounds of cutbacks. In fact, there had even been rumours that the entire Lahr plant would close, but they received a guarantee that it would remain open until at least 2008 (LZ, 9 June, 2005). Nonetheless, this was a huge loss for Lahr, and the feeling of insecurity remains strong.

In comparison to the rest of Germany, however, Baden-Württemberg is actually the state with the lowest level of unemployment. Simply because the rest of the country is worse off in this regard, however, does not mean that people in the region believe it will not eventually strike them equally hard. The unemployment level in Baden-Württemberg in May 2005 was $7 \%$. The German average at this time was $11.6 \%$, but there was an East/West split, unemployment being $18.9 \%$ and $9.7 \%$ in the two parts of the country respectively (LZ, 1 June, 2005 - See Figure 7.1). So despite the favourable conditions in comparison to the rest of Germany, there is still much instability. Over the last ten years in the Ortenaukreis, unemployment has ranged from as low as $4.5 \%$ to as high as $8.5 \%$, no small fluctuation (Statistisches Landesamt Baden-Württemberg, 2006). Lahr, however, was considerably worse off in comparison to the Ortenaukreis. Figure 7.2 shows umemployment in Stadt Lahr from 1995-2000. At this point in time Lahr stopped keeping this statistic (for reasons unknown) but in publications from 2004 and 2005 the Employment Department of Offenburg made estimations, also included in Figure 7.2. Simply from the statistics it is unclear how much this figure may have been affected by the reunification, but the west certainly did pump a lot of money into the East, not to mention the effect of all the former East Germans who moved to the West specifically to find work. In Lahr, the worsened situation could well 
reflect the residual effects of the withdrawal of the Canadians (although some of it would likely be a result of the Aussiedler population). It would certainly have given Lahrers a heightened feeling of insecurity that their town was facing tougher economic times than their surrounding region. This would certainly impact their spending and promote the belief that the employment market is unstable, promoting a desire to save in case of emergency or job loss.

Figure 7.1 : Unemployment Rates in the German States June 2005

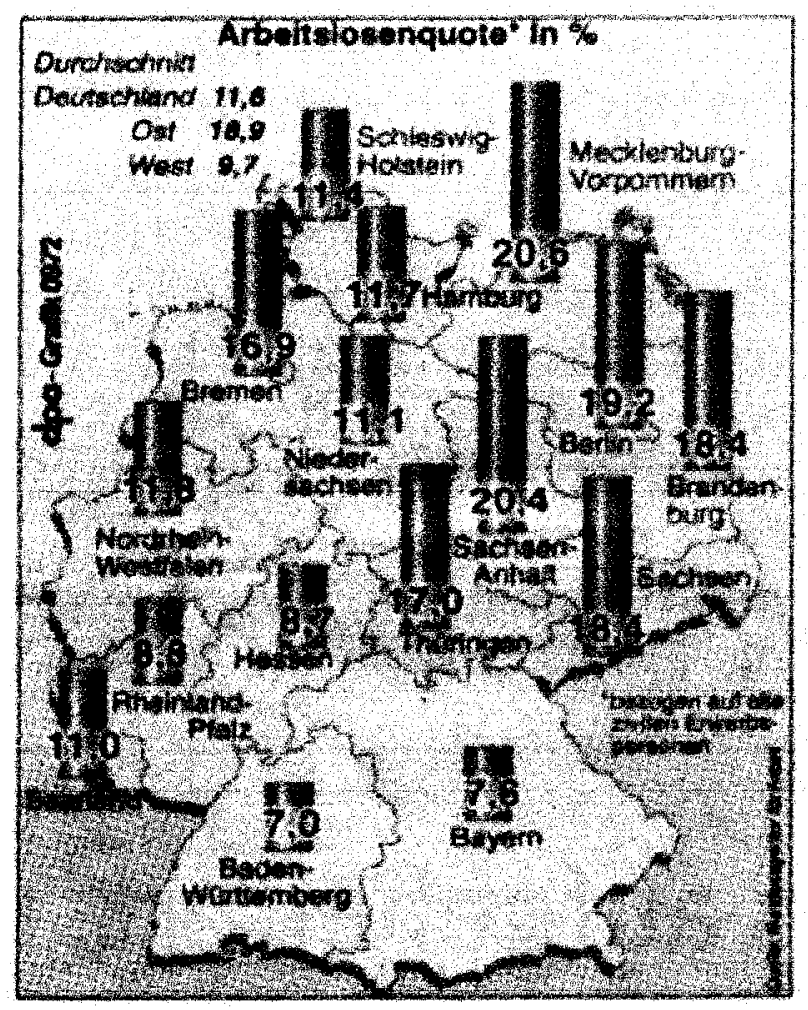

Source : "Arbeitsmarkt dümpelt dahin," in Lahrer Zeitung. 1 June, 2005. 
Figure 7.2 : Unemployment in Lahr

\begin{tabular}{|c|c|}
\hline Year & Unemployment (\%) \\
\hline 1995 & 13 \\
\hline 1996 & 13.4 \\
\hline 1997 & 14.5 \\
\hline 1998 & 12.5 \\
\hline 1999 & 11.5 \\
\hline 2000 & 9.5 \\
\hline 2004 & 12 \\
\hline 2005 & 11 \\
\hline
\end{tabular}

Source : Stadt Lahr. Wirtschaftsstandort Lahr - Daten und Fakten, 2004 and 2005.

The money that has been invested in the East has certainly not been for nought. Developments have been made, infrastructure improved, and some companies have made successful moves to the East. One thing that really struck me on a trip to the East, was the large amount of wind farms that were in this region - clearly a modern development for a forward thinking country. When I was in Berlin, a man even joked with me that they were thinking of changing the symbol of Berlin from the bear to a mole to adequately represent all the building and construction that was going on. Improvements are being made, however, the progress of the East being able to stand on its own is taking longer than expected. In 2019 the transfer payments are set to expire. What will happen to the East is uncertain. It will likely have to work on being able to support itself more independently, however, it is highly unlikely they will be completely abandoned by the West. Until then, however, the German economy will be hindered as a result of their high transfer payments. The German Institute 
for Economic Research stated that these payments are dragging down the country's economics. They warn that the "development in the new federal states could trigger a selffuelling recession" (Berg et al., 2005). Clearly the reunification of Germany, while a positive emotional and symbolic development, has become an economic challenge and only time will be able to tell whether Germany can improve the economics of their enlarged country and succeed in the same way that the former West Germany did.

Clearly reunification placed a strain on the German economy. In light of this, the conversion to the Euro could be seen as the proverbial straw that broke the camel's back.

One of the most widespread complaints amongst the German people when the topic of retail and shopping is brought up is that everything has simply become too expensive. As a result one cannot purchase as much as one has in the past, and the desire to save for a rainy day has increased. Naturally then, the amount of retail activity decreases. The culprit behind this complaint, that everything has increased in cost, according to consumers, is the conversion to the Euro as the currency in Germany. This belief is widespread amongst the populace, gaining the Euro the nickname, the Teuro (teuer being the German word for expensive) (Preisentwicklung, stern TV, 2006).

The currency conversion occurred across Europe on January $1^{\text {st }}, 2002$. This move was made to strengthen ties between the European Union countries, and to simplify economic dealings between the member countries. In order to prepare Germans for the conversion, during the year 2001, prices on goods in many stores were written twice, once in Deutsch Marks (DM), and once in Euros (€ - the exchange rate at the time of conversion was one Euro to two DM). This way, the consumer could familiarize themselves with the new 
currency and better understand the value of the number written on the price tag when the conversion took effect. It was hoped this would minimize any complications at the time of conversion, as consumers would be familiar with the Euro value of the goods they were purchasing.

However, this tactic does not appear to have worked. Almost immediately after the conversion to the Euro there was a public outcry that the stores had used the currency conversion to secretly increase prices so that the consumer would not notice the change in price, being still new to the Euro. Already on January $28^{\text {th }}, 2002$, there were massive Winter sales described with the specific intent of gaining back the business of angered consumers (BZ, 28 Jan, 2002). Even the speaker for the Primary German Retail Group (Hauptverbandes des deutschen Einzelhandlers), Hubertus Pellengahr, encouraged the consumers not to let the store owners get away with the increased prices, encouraging them to punish those stores (presumably through boycotting them), stating that some of the price increases bordered on profiteering. (BZ, $28 \mathrm{Jan}, 2002)$. So by January $28^{\text {th }}$, retailers were already trying to attract disgruntled consumers who must have drastically reduced purchasing in this short time to such a degree that sales were described as ranging from $20-70 \%$ off (BZ, 28 Jan, 2002). The fact that in less than one month after conversion there is an article speaking of counter measures to draw consumers back, must mean that there was, or was perceived to be, a quite noticeable, if not drastic, change in prices.

Naturally as soon as there was some outcry about higher prices, there came the counter argument. The very next day an article entitled "Many Factors Raise Prices" appeared in Die Badische Zeitung. One store owner stated that price increases occurring at 
the beginning of the year are nothing special, citing that many producers and large manufacturers recalculate their prices at this time and in most cases pass along higher prices to the individual stores (BZ, 29 Jan, 2002). The increased price of vegetables was blamed on bad weather in the southern countries, something which could have happened at any time (BZ, $23 \mathrm{Feb}, 2002$ ). It was also pointed out that the State increased some taxes at the beginning of the year (which ones are not listed, BZ, $23 \mathrm{Feb}, 2002$ ). One other logical reason for the increase was given by a butcher, who stated that the conversion to the Euro cost his business $18000 \mathrm{DM}$ amending scales, cash registers, and wages (BZ, $29 \mathrm{Jan}, 2002)$.

However, many specific examples of price increases were also given. Dog food was found to have increased in price by $9 \%$. Car washes increased $23.5 \%$ (this was blamed on new environmental rules). A Latté at the Cappuccino-Bar in Lahr cost in December 2001 3,50 DM. The cost on January 29, 2002 was listed at 2 Euros (At the time of conversion, one Euro was worth two Deutsch Marks). No explanation was given for this $12.5 \%$ increase in the cost (29 Jan, 2002). A 500 gram loaf of Bread used to cost 2.20 DM, but in January cost $1.30 €$, an increase of $16 \%$. Egg prices were also raised; before conversion a 10 pack cost 2.20 DM, and in January cost $1.30 €$, an increase of $9 \%$ (BZ, 23 Feb, 2002). Many examples of price increases are given, and it was clear that the consumers were not letting up in their anger. More articles surfaced, accusing and citing examples from new corners of the market that were exploiting the situation. On March $9^{\text {th }}$ an article stated that above all, Hairdressers, chemical cleaning products, movie theatres, restaurants, newspapers, magazines, beer, and certain food products used the conversion to hike prices. These findings were based on a study done by the Federal Bank involving 35000 product groups and 18000 prices. They 
found that $60 \%$ of the prices were raised. However they also discovered that $40 \%$ of the prices were lowered (BZ, 9 Mar, 2002).

While this may sound promising, naturally it all depends on what one purchases. As it turned out, the savings tended to be on items such as televisions and computers (although the general trend of electronics is to get cheaper over time, so this possibly had nothing to do with the conversion to the Euro), while increases on things like tomatoes, cucumbers, coffees, and buns. Unfortunately, the reality is that items such as buns, coffee, tomatoes and cucumbers are purchased on a daily basis. In contrast to this, items such as computers are purchased quite rarely in an individual's life. It appears the increases have come disproportionately on daily items, certainly making the Euro feel like a Teuro (BZ, 28 May, 2002).

By the $12^{\text {th }}$ of April things were looking terrible for the store owners. Hermann Frese, the President of the South Badisch Retail Store Owners Organization stated that "if something doesn't happen soon to change the current economic situation, many store owners will be forced to close down their stores" (BZ, $12 \mathrm{Apr}, 2002)$. Barely three and a half months into the Euro, and earnings had decreased so much that stores were on the verge of closing. Consumers were clearly sending a message, and no matter how many reports tried desperately to change their minds, consumers believed that prices were higher, and they were therefore not going shopping. Frese stated that overall profits in retail decreased in the first three months of the year by $3-6 \%$, but that some individual stores experienced decreases of up to $45 \%$ (BZ, $12 \mathrm{Apr}, 2002)$. Quite drastic indeed.

Two geographic trends were discovered at this time as well. The southern areas of 
Baden-Württemberg actually had an increase in sales, estimated to be benefiting from consumers from Switzerland, while the northern portions of the state were not well faring at all. Another discovery was made revealing that people were now going more often to big cities to do their shopping, presumably in an attempt to have more choice to search for cheaper prices. This is of course at the expense of the smaller cities in their surroundings, and the Ortenau, the region within which Lahr is situated, was specifically named as one particularly hard hit area as a result of this trend (BZ, $12 \mathrm{Apr}, 2002)$. One reason for this, particularly in the Lahr area, could be the topography of the land. The Black Forest lies directly behind Lahr, and once out of the town, the roads wind up and down the mountains, following the topography of the land. The head of the Lahrer Retail Promotion Organization (LRPO) stated that years ago, the people who lived on the other side of one mountain in particular - the Schönberg - would always drive to Lahr for their shopping. However, this has changed with the building of new, straight roads with high speed limits behind the mountain, creating a "all roads lead to Offenburg" situation, steering all the consumers in the Kinzigtal towards this larger city (Bickel, $31 \mathrm{Aug}, 2005$ ). Before the conversion it may have been fine to drive to Lahr through the mountain roads, however, if the hunt for better prices became paramount, it would be another, more attractive reason to go to Offenburg than simply a good road alone. In this case it would appear there are two factors working against Lahr gaining the patronage of the consumers in the valley behind the Schönberg.

By May of 2002, even the Chancellor at the time, Gerhard Schroeder, was getting into the debate. He stated that the government had relied on self regulation for the price conversions in the stores, and that was "taken advantage of" (BZ, 14 May, 2002). In June, the 
Finance Minister, Hans Eichel, stated that the price increases were primarily the doing of a few 'black sheep' in the retail world, which had lead to the reduced consumer activity in the first six months of the Euro conversion. In response, Pellengahr said that there could not be a hunt for these black sheep (clearly in complete contradiction of his earlier statement). He instead argued that the reduced consumer activity was a result of high unemployment, adding that whoever is concerned about the security of their job will simply not spend as much money (BZ, 3 June, 2002).

Despite Pellengahr's counter arguments, it appeared consumers took his earlier advice of punishing stores that raised prices. The Research Institute (Forschungsinstitut) conducted a survey, and found that $84 \%$ of consumers avoided going to the stores where they noticed price increases after the conversion to the Euro. $88 \%$ of consumers said they paid much more attention to prices compared to earlier in light of all the discussions and concerns in the media and elsewhere, resulting in a much more price-conscious consumer (BZ, 3 June, 2002). And clearly a price-conscious consumer, is also a more critical consumer. Alongside Germany, articles from The Economist indicate that French and Italian consumers are also complaining that the Euro has resulted in price increases. (Hold the Foie Gras, May 25, 2002, and Poorer yes. But by how much?, Jan. 11, 2003).

By the end of the year economists felt that they finally had the proof that the Euro was not a Teuro. Overall prices were said to have risen in average $1.3 \%$. This, in comparison to the inflation rate of 2001 at $2.5 \%$, meant that the rise in prices was actually cut in half. This, according to the experts, was the proof that the switch from Deutsch Marks to Euros did not influence prices in any way (BZ, $21 \mathrm{Dec}, 2002)$. However, this same article was again filled 
with examples of how many items did in fact become more expensive. For example, movie tickets became $4.6 \%$ more expensive, and motor oil and beer both increased $3.6 \%(\mathrm{BZ}, 21$ Dec, 2002). So while the overall article tried to suggest that things were not getting more expensive, there was again contradictory evidence to suggest that the consumer is right, that prices are rising. After all, this article did not mention what became cheaper. Hardly any examples are given of products that became cheaper after conversion. The one that keeps coming up is computers, which appear to have reduced in price by $18 \%$ (BZ, 3 July, 2002). But as mentioned earlier, technology has tended to get cheaper, so maybe this reduction is not due solely to the conversion but also to further advances in electronics. Another notable aspect of this is the large percentage of the decrease. Perhaps many other items increased in price by small percentages, and the few examples of decreases are quite drastic, therefore making a statistic such as inflation appear to result in a negligible increase, despite the fact that it is the daily items that have all increased. This would certainly give consumers the impression that everything has raised in price, since as mentioned earlier, it is not everyday one purchases a computer. However, this is just a theory. The fact is that one hears about how terrible the conversion to Euro was due to the high prices whether one asks about it or not; in overheard conversations between shoppers in a store; conversations with store employees and consumers; in discussions between friends at casual gatherings. It is simply everywhere, stated as fact, accepted by all. But how can there be such a discrepancy between what the consumers believe to be and what the experts believe?

In my own observations I would have to agree with the consumers on the Euro debate. I, personally, share the belief that prices have increased. For example, in a relatively 
inexpensive store, the cheapest pair of jeans for sale throughout the 7 month duration I was there, was 50 Euros. Consistently that was the cheapest I could find, not including special sales. Comparing with my most recent pre-Euro trips to Lahr this price is quite inflated. It would mean that the cheapest pair of jeans in the store at the time was $100 \mathrm{DM}$, which was certainly not the case. Another example, on a separate shopping trip with a friend, a woman in her mid-forties, the cheapest pair of capri pants we could find in a different store, also generally known to be of acceptable prices, was 60 Euros. My friend then stated "there is no way they would have dared to write $120 \mathrm{DM}$ on this price tag." I think this illustrates an important point about the Euro. I think it was very advantageous for store owners that Euro entered the market on a one to two ratio with the Deutsch Mark. This meant that numerically, all the price tags would show smaller numbers, enabling them to take advantage and perhaps increase the price. Had it been the other way around, had one Deutsch Mark been the equivalent of two Euros, I think store owners would not have had the same opportunity. Especially when it comes to small items. Many magazines that earlier cost $2 \mathrm{DM}$, now cost $2 €$, which, when a consumer simply looks at the top corner, does not sound like much, despite the fact that it is a doubling of the price. While clearly price increases can be expected with inflation, this clearly goes beyond what inflation would dictate.

Because the Euro is such a contested issue in Germany, I felt that I needed to somehow capture the prevailing feelings in a form that I could turn into data to use in this thesis. I decided that the most effective way to this was via a survey of consumers. This questionnaire was relatively short, containing only five questions, as I did not want to take up too much of the respondents' time and also because it is easier to get people to commit 
to short questionnaires as opposed to longer one. As mentioned in chapter 3 , the questionnaire was primarily conducted in the Lahrer Innenstadt and outside of the Arena. However, I did also ask some acquaintances to fill a few out as well. The questionnaire is included in Appendix C.

One question I asked was if the respondent could give any concrete examples of as close to the exact same product as possible, although I did not include any of the brand names in this paper. The examples are almost endless, however, I have simply chosen a few to illustrate this point:

"A winter jacket for $100 \mathrm{DM}$ was later priced at $89 € . "$

"A jar of pepper, where the old DM price was still printed on the label so the comparison could not be mistaken, cost DM 1.89 and was converted to $€ 1.69$."

"Eggs at the weekly market used to go for 16 pfennig, and then cost 12 cent."

"The daily newspaper has increased almost $100 \%$ in price."

I asked a some questions to specifically try and address what the experts were saying. This included a question about the articles that became cheaper after the conversion. However, consumers did not appear to quite agree with the experts on this one.

"Well groceries didn't increase in price too much...but nothing became cheaper."

"I don't know of any products that became cheaper through the Euro."

"Groceries on the whole did not increase in price as much as prices in other sectors, but aside from that, no."

"Electronic equipment became cheaper - computers, cameras, and cell phones, that type of stuff." 
Another question I felt was important to ask was whether prior to the conversion, retailers began slowly increasing their prices. This was something I had heard, although not all too often, and I thought this would be a good opportunity to settle what could just be a rumour. This would have bearing on the statistics, however, because if the prices were already raised in anticipation of the conversion in 2001 , then that would affect any statistics based on the calendar year as it would not include these price increases, and therefore not account for all Euro-based price increases. In response to this some people stated that they noticed prices for food increasing before the conversion. Bakeries took an extra load of criticism from many respondents. Buns, bread, pastries, cakes, etc., were all identified as having increased in price already in the summer of 2001, despite the fact that there is not increase in world wheat prices during this time (FAO, 2005). This was often stated as having been done in order to have a "rounder, nicer" number when it would be converted.

I also asked whether there were any advantages at all to the Euro replacing the Deutsch Mark. I felt these would be important to examine as there must be some benefits or else the conversion would never have happened. The most common answer to this question regarding travelling. Most people stated that when travelling you no longer needed to exchange currencies, which made things easier in many ways. First off no fees at the bank, but also one was better able to understand what the price meant in the foreign country, without always trying to calculate the exchange rate before deciding on whether to purchase a product or not.

The second most mentioned benefit of the Euro conversion was inter-European trade. It was described as a practical aspect because it is now much easier for big corporations to 
deal with foreign companies because their currency is now the same. It was also stated that this helps strengthen the ties of the European Union, making it a more powerful economic force that can truly rival the United States.

Another advantage stated was that at least it came at an exchange rate that was easy to compare with the Deutsch Mark. One Euro equals two Marks. Simple enough. That way they could easily compare the after conversion price with the currency they were familiar with, with only a simple calculation. However, many were of the opinion that the Euro had not earned praise of any sort.

My final question involved the previously mentioned statistic about the inflation rate in 2002 being lower than that of 2001, which experts believed proved that the Euro was not a Teuro. I simply asked for their reaction to this statement. Many respondents supported what I have hypothesized earlier on in this chapter about the more popular items having been made more expensive, while items that are not purchased on a daily basis may be cheaper, the impression is not there for that reason. A very typical response was "Statistically that may be correct, however, for the consumers it is a different picture. The statistics show the overall figures. Not everything included there is used by the average citizen. This way there is still a perceived increase in prices." One curious respondent, who questioned me quite intently on my personal background, upon hearing that I was most recently from Canada, compared the Euro conversion to the wind chill factor. The logic behind this being that there are two temperatures, one for the normal temperature (meant to represent the experts' findings), and one for the temperature with the wind (to represent the consumers' perceived price). They stated that essentially the only temperature is that including the wind chill because there is 
nowhere one can go where the wind is not blowing. His analogy was to illustrate that the consumer is hit harder by the conversion because the daily products are those that have increased, and therefore there is a felt price increase, just like there is a colder, felt temperature when the wind blows.

However, there were of course some people who were quite outraged at this suggestion. Clearly this was not their first encounter with such statements and they responded with answers displaying opinions that had likely been formed over the years since the conversion. For example one man declared that "You cannot believe the State dictated statements of the press and media. The $1.3 \%$ price increase is ridiculous. Statistics are falsified, distorted and manipulated to the benefit of the State. The truth looks very different."

A Swiss professor, Brachinger, conducted research on the notion of a felt inflation rate. He states that official state statistics are determined based on a representative and theoretical shopping cart whose goal is to act as an indicator for the stability of their currency. The flaw here is that the consumer does not really purchase in such a pattern, and so the felt inflation can be much different for the consumer and for the statistician. As a result of this, he added that the serious studies only provoke the consumer because they completely go against their personal experiences, and for the consumer, their experienced reality is the only one that counts and is real (Euro: "Korrekte Studien provozieren die Verbraucher, stern tv, 2006).

To combat this, Brachinger has developed statistics based on the felt inflation. This is based on a more realistic shopping cart of what people buy, and includes a higher 
importance on those items that are bought everyday, including items like buns and the daily newspaper, and less on items not bought everyday, such as a computer. Shown below is the graph he produced (Figure 7.3); green being the official rate of inflation, and yellow being the felt rate of inflation.

Figure 7.3 : Felt Inflation

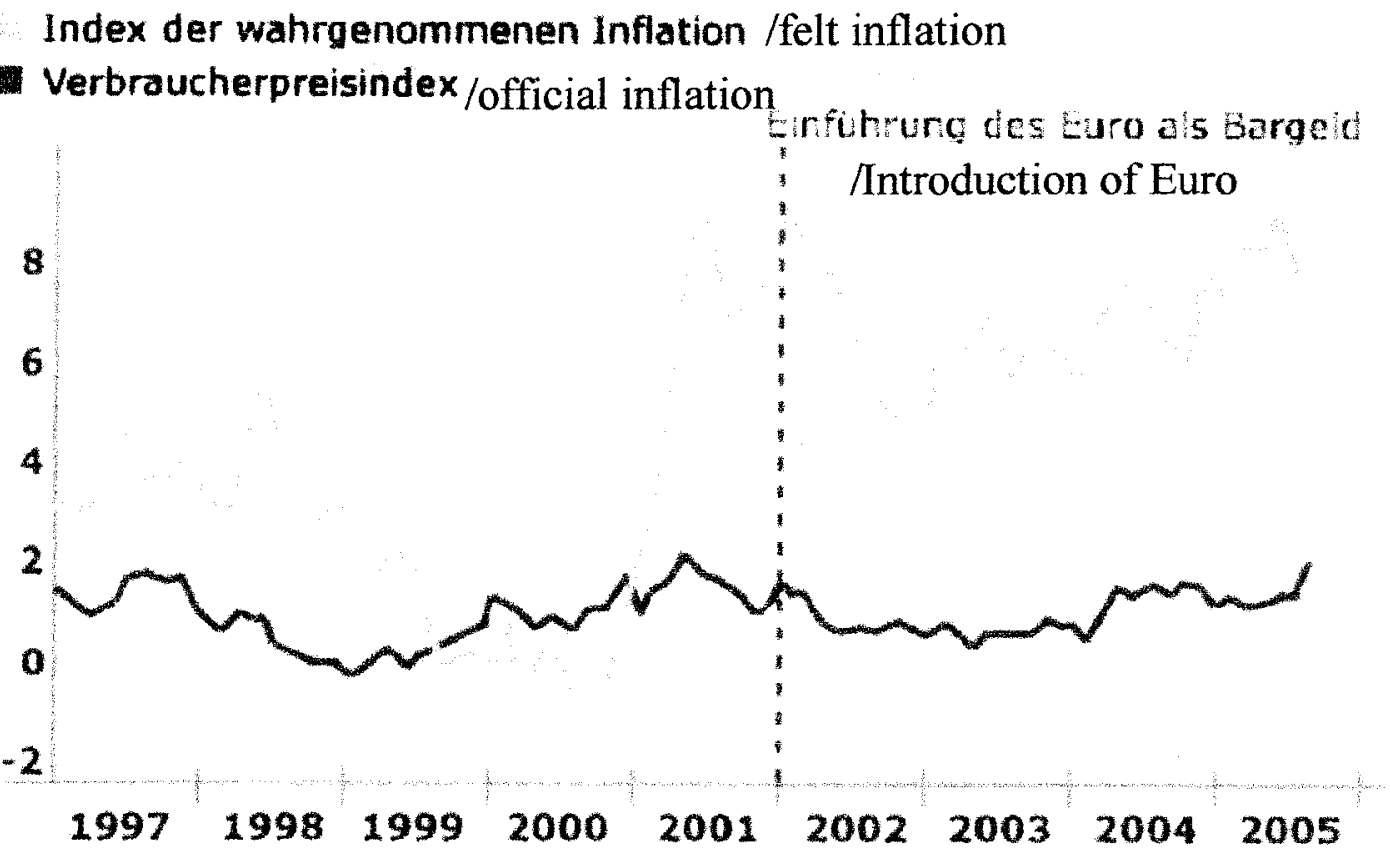

Source : "Euro : Korrekte Studien provozieren die Verbraucher," stern tv. Accessed at http://www.stern.de/tv/sterntv ; Internet, on January 26, 2006. Modified by author.

Brachinger's chart shows that already starting in 2001 , there was a huge increase in the felt inflation rate. Many people believe that stores marked up prices in this year to prepare for the Euro (although it may also have been done to cover the costs of conversion), and this index would definitely appear to back up some kind of a price increase. He also 
added that by December 2005, the felt inflation rate was at $9.6 \%$ - a huge increase. The inflation rate also soared to this number directly after the conversion to the Euro, perhaps explaining why so many people believe the Euro is responsible for increased prices (Euro, stern tv, 2006).

Clearly my own findings show that consumers believe that prices on the whole have increased, and the consumers demonstrate that they are skeptical about the statistics that are presented to them by the experts. It was brought to my attention that on January $11^{\text {th }}, 2006$, a television show, stern TV on Germany's network RTL, was broadcast with this topic, "Is the Euro a Teuro?" While I clearly could not view this show, I went to the website where they had a few articles based on this broadcast, including some consumer feedback. The introduction began by saying that four years after the introduction of the Euro, many consumers feel that there have been massive price increases. This is still the dominant view, the show explained. In their study, an institute of Price development (the name was not given) examined 284 groceries that were sold the most by comparing their current price to their price in 2001. They examined the prices from large supermarkets with at least 800 square metres (Preisentwicklung, stern TV, 2006).

The results of this show are described as surprising. Only $20.8 \%$ of the products increased in price more than the inflation rate, leaving $79.2 \%$ of products at either the same price or even cheaper (Preisentwicklung, stern TV, 2006). The information presented, however, states that there were clear price increases during 2001, which were in fact, higher than the increases which took place in 2002. In a detailed examination of the 2001 prices, they found that $52 \%$ of the products were more expensive than the prior year. Added to this, 
however, is that most of the price increases that occurred in the 2001-2002 time frame have been corrected due to increased competition in recent years (Preisentwicklung, stern TV, 2006). This may help identify why people feel that the Euro is a Teuro. First impressions certainly are lasting, and 2001 and 2002 showed increases in prices linked to the Euro (increases in 2001 are believed to have been made so that in 2002, even if the conversion was done properly, they would still have a mark up), which could explain why, despite some corrections, the perception is still out there that everything is more expensive. Also, this survey deals with groceries, and groceries was the only sector where consumers in my survey felt that the prices had not been terribly increased.

The website offered an opportunity for the audience to respond with their opinions. There were the usual examples of prices that had been increased, there were also some who again accused the stores of raising prices in 2001 to take advantage of the conversion, and the usual complaint that while prices in stores have been raised or converted incorrectly, their earnings had been converted correctly, essentially halved, and that just was not fair. An added point was brought up that was not mentioned in my survey, and that was that the big stores, especially those in large towns, are better able to lower their prices. Also many mentioned that while this may be true for groceries, it is not true for other sectors (Zuschauerreaktionen, stern TV, 2006). Again, this type of thinking would benefit larger towns, and be to the detriment of smaller towns such as Lahr, and has the possibility, and clearly has already begun to do so, of shifting much shopping from small towns towards larger ones in hopes of finding better prices.

The store owners in the Lahrer Innenstadt also feel that the conversion to the Euro has 
had an impact on consumer behaviour. Store 3 described customers as being much more price aware as a result of the change to the Euro. She added that you hear everywhere that the people believe everything was converted one to one, and she added her own example, a cucumber that used to cost 99 pfennig, now costs 99 Euro cents. There is something to it, she stated, and continued that as a result of this many consumers are having a harder time managing their finances, therefore creating a much more aware consumer as they are constantly on the search for the best price (Rödel, 29 Sept, 2005).

Store 2 built on this idea, elaborating that when you have less money you give it much more closely monitored out, or you simply designate certain amounts to certain necessities and do not deviate from the plan. She believes that the customer has not only become much more price aware, but at the same time they are more critical of what they buy. They would like low prices, but at the same time they want it to be of excellent quality. She stated that this really hits the small stores especially hard (Jeweller, 13 Oct, 2005).

She builds on this notion by bringing up the marketing slogan of a large electronics chain which states "Geiz ist Geil," meaning frugalness is cool. She stated that this saying is really an accurate one to describe the mentality of the consumers, and she says it is quite widespread (Jeweller, 13 Oct, 2005). Store 2 was not the only one to mention this slogan. The head of the LRPO also mentioned this as describing the attitudes of the consumers in a postEuro Germany. He believes that this "Geiz is Geil" slogan is absolutely terrible and essentially polluting the minds of the shoppers. Clearly as the private owner of a specialty store his emphasis and market niche is going to come from good quality products and a vast knowledge of his product. The problem for stores like his, he states, is that this "Geiz is Geil" 
slogan has resulted in a mass "price dumping" without compare, and points to 'discounters" as the prime culprits that make it difficult for him to compete (Bickel, $31 \mathrm{Aug}, 2005$ ).

The discounters primarily being referred to here are Aldi and Lidl. There are others, but these two are the most prominent and have multiple locations in and around Lahr. These discounters' primary merchandise is groceries, however, other products are also introduced which will be discussed shortly. Their competitive edge is that they have extremely low prices in comparison to other stores. The strategy to be as cost effective as possible is achieved through many cost cutting measures. For one, the store only offers about 700 different goods. These are considered to be the essential products, which are bought from independent producers at very good prices due to the discounters' size. In addition to this, no money is spent on attractive stores, floors, or lighting; ads always look the same because no marketing experts are employed; few retailing experts are employed - new ideas are tested at three stores, and if deemed a success, are copied in other stores; and there are no storage rooms, the goods being sold from the boxes on plain shelves. The average stores size is about 800 square metres, and for this space there are only 4-5 employees (Gerhard and Hahn, 2005). This devotion to keeping prices low is clearly appreciated by the customers, as Figure 7.4 demonstrates, it is the prime reason that people shop at Aldi, followed by best value and best special offers (and can likely be largely applied to other similar discounters, ie. Lidl). The additional products these discounters offer differ from week to week. Every week the discounters have huge sales in one special corner of the market other than food. When I was there they had a week of horseback riding equipment, bed sheets and covers, cycling gear, nordic walking gear, winter jackets, ski equipment, snorkelling, baby clothes, and many 
Figure 7.4 : Most important reasons for preferring Aldi to other stores

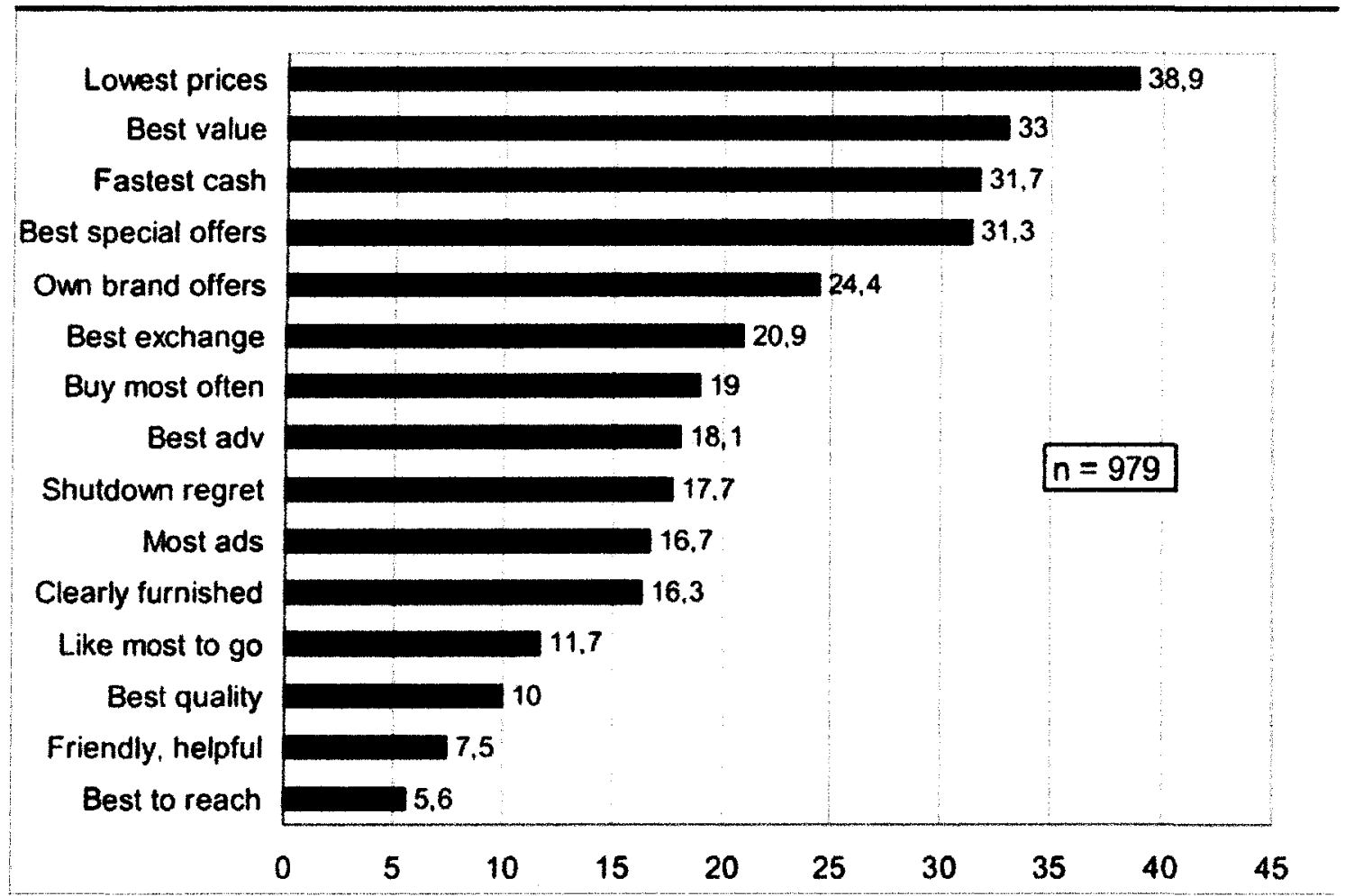

Source : Gerhard and Hahn, 2005, 23.

other specialty items. These specials are so popular that often consumers line up outside the store before it opens to buy them.

These discounters are located in open spaces away from the downtown core as they require more space than the Innenstadt can offer, and as a result of the wide gambit of products they offer, they are clearly a strong competitor for the Innenstadt. The head of the LRPO explained that these types of specials rival every single store there is, that everyone in any branch of retail feels it due to their wide spectrum of products. He added that these discounters belong to the largest German book sellers; that they have such a large impact it 
is hard to imagine. Eventually they will have an offer with cooking pots (he owns a dish store) or something else that just does not fit to them, and the people just go there. And one just has to be so careful because there was such a mix up and change of consumer patterns after the Euro because the belief was there, the Euro is a Teuro, so the thought process is 'why don't we just wait a bit and see if we can get it here for cheaper.' And that's how it is now in Germany; buy the cheapest, he continues. And that is bad, very bad. It takes away any creativity, and is actually very un-German because we are not exactly the cheapest producers. We produce quality, think of BMW or Mercedes, and so it does not fit, it is not logical. At some point in time one must think of their job, we produce quality, and someone has to buy the quality or it will not work (Bickel, 31 Aug, 2005).

After the Euro was introduced there definitely was a change in consumer patterns for the discounters. For Aldi specifically, although a similar trend likely occurred with other discounters, its turnover grew $15.7 \%$ in 2002 alone. This was as a result of their plan to actually reduce prices an average of $2 \%$ directly after the conversion to the Euro (Gerhard and Hahn, 2005). This plan clearly drew attention from consumers who felt that many retailers used the conversion to increase prices. In $2002,76.4 \%$ of all consumers in Germany shopped at Aldi (Gerhard and Hahn, 2005).

The former store owners 1 and 2, who together owned a store in the Innenstadt, from the perspective of consumers, had a discussion about this issue. 1 stated that when he can, he prefers to buy from stores in the Innenstadt because, as he describes it "we also had a store here, and we want to support those that are still around" (Himmelsbach, 5 Oct, 2005). Then he stated that many people go to the discounters on the periphery, and how those types of 
stores are really gaining in prominence, mentioning how they just built another new store in Lahr. 2, however, countered him by stating that it was necessary to go to these stores. "Everyone has to save these days," she stated. "There's nothing left but to go in such a store...nobody has money in their pocket anymore, like we said earlier, in comparison to before everything became more expensive. There was a one to one conversion for almost every item... and you have to see how you can get things done the best. Then you drive straight to the discounters, or?" (Fr. Himmelsbach, 5 Oct, 2005).

This leads to an interesting type of attitude that seems to prevail in the discounters. As mentioned earlier, in Innenstadt stores there was a lot of discussion of price increases and such. In the discounter stores, the mood is certainly different. Here it is more a "well it is not perfect, but where else will I get it for this price?' kind of mood. It is almost a type of resignation, that the consumer knows the situation is not optimal, but the price is the prime factor in the decision. This is, I believe, the reason the discounters are so popular since the conversion to the Euro.

Gerhard and Hahn's (2005) article states that German consumers have evolved into hybrid consumers. These consumers are described as not wanting to spend a lot of money on necessities such as food, but will buy an expensive or luxury good from time to time. This may have contributed to the change in perception regarding these discounter stores, which they describe as having "recently lost [their] image of being a store for the lower middle class and poor people" (Gerhard and Hahn, 2005, 18).

As mentioned earlier, due to the nature of the space that these discounters need to operate, the Innenstadt is not a viable option for them. Currently there is one of these 
discounter stores in the Innenstadt, but this branch truly does only sell food, likely as a result of the extremely small location. And even this branch, economic development officer 1 explained to me, will be moving out of the Innenstadt soon. The problem of space is a big one; he states that in the Innenstadt there are very many stores that only have spaces of 40 or 50 square metres, and that is a difficult space to make profitable. Also, a primary problem of these discounters is that their delivery trucks generally make the daily deliveries at five in the morning - no problem when delivering to a periphery location where the noise will not bother anyone. However, when dealing with their Innenstadt location, they drive over cobblestones, making such a racket that everyone complains so that they cannot deliver early anymore. They can only deliver at 7:30 and it is simply too expensive for the discounters to have the trucks sitting around for two and a half hours. That is why the last Innenstadt location will close, and they will simply continue to concentrate on the periphery (Beck, 17 Aug, 2005).

The questionnaire of stores in the Innenstadt included questions on the Euro to build on these ideas. One question specifically asked how the Euro conversion affected their businesses. $83 \%$ of respondents said it affected their businesses negatively. Of these $83 \%$, $26 \%$ say that it is getting better; that the time after conversion was by far the worst. Reasons why were not listed, but I hypothesize it either has to do with people simply getting used to the idea of the Euro and its perceived associated price increases, or prices were adjusted back to a more reasonable rate. Only $17 \%$ of respondents stated that the Euro was not a problem for their business. It is interesting to note that the stores which claimed that Euro had minimal impact are generally stores that have not been in their location for very long, many 
under 5 years. In these cases, where the store was not in its present location during the time of conversion, the respondent would state that there were no complaints by customers about the Euro prices, or that in other, longer standing branches no noticeable change was apparent. Two stores chose not to answer this question on account of not wanting to speak about their profit margin in any way (see Figure 7.5 for a summary of this questionnaire).

Figure 7.5 : Summary of Questionnaire Responses

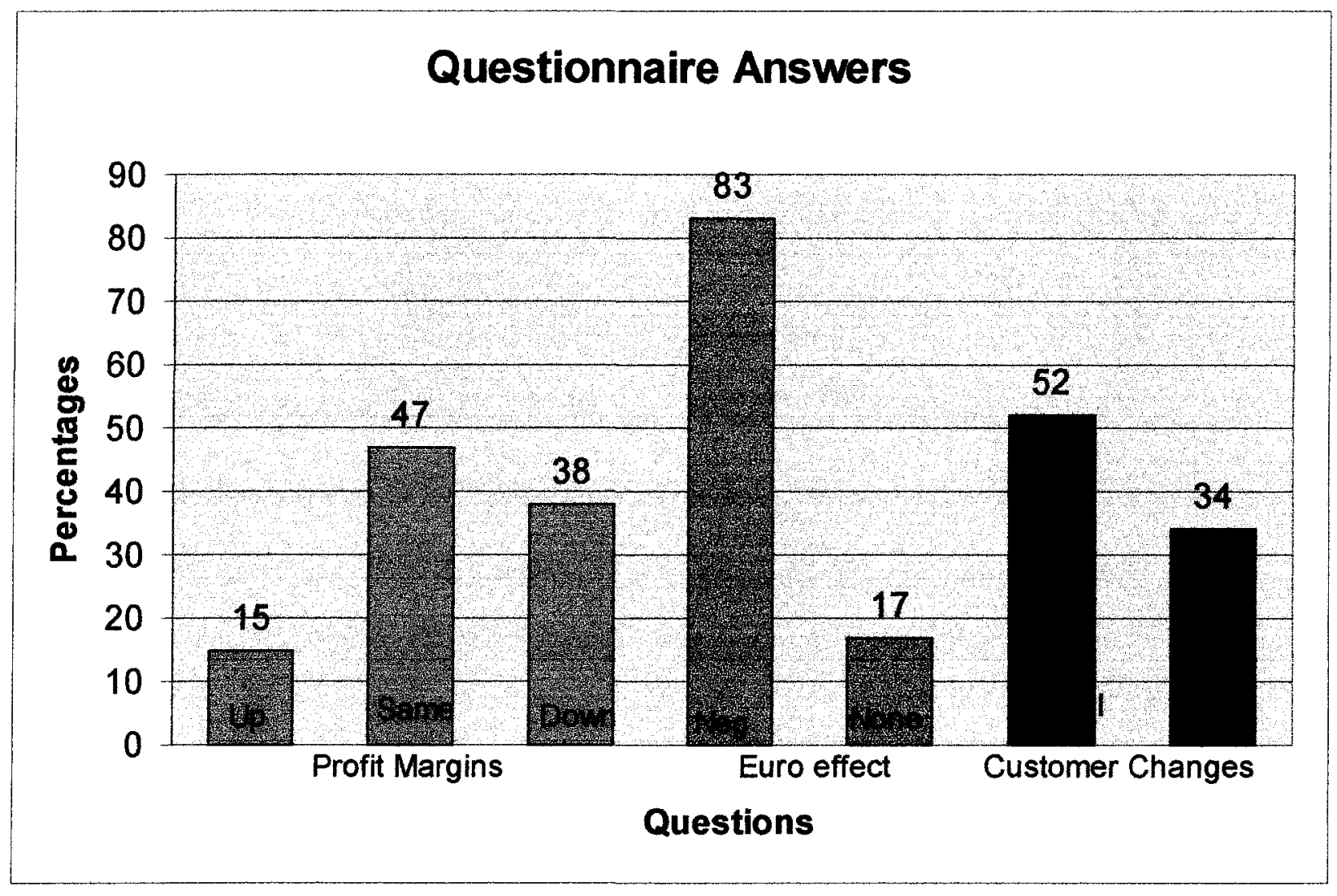

Source : Author's survey, 2005.

A related question, one that was mentioned in the previous chapter, regards the general profit margins of these stores over the last few years. In the previous chapter, only stores who had been in the Innenstadt during the time of the Canadians were included. 
However, in this examination, all of the stores' answers will be assessed. Out of the 47 stores who answered this question ( 2 again decided against it) only $15 \%$ stated that their profits had been increasing. This does not exactly characterize the Lahrer Innenstadt as a great location for business. $47 \%$ described their profits as remaining the same, and $38 \%$ said they were sinking. Again it is interesting to note that the long standing stores are the ones that have, for the most part, identified a decreasing profit margin. The ones that identified an increase are generally quite new to the area, which does appear logical as they would likely not have moved into an area where they did not expect to make any money. For example, it was noted that all the cell phone stores reported an increase in profits. The ones who claimed profits were staying the same were also generally skewed towards the younger stores. How much of this is directly attributable to the Euro is difficult to determine, however, from what I could sense while conducting the survey, the Euro did play a part. Again it should be noted that this question was asked before any Euro questions were introduced to attempt to keep any suggestions out of the survey.

The only store with whom I was granted a longer interview who stated that the Euro was not a problem was store owner 1 . He stated that the conversion was not a problem for him. He added that he changed his prices properly and therefore there was no noticeable difference because he did not sneak in a price hike (Spinner, 3 Nov, 2005). Although it is interesting to note that all of the store owners said that they adjusted their prices properly, yet in the same breath would state that everyone else did not, however, that they notice the price increases when they are consumers.

The final question that was related to the Euro in the questionnaire was that regarding 
customer changes. The respondents were asked to state whether there had been any significant changes in their customers over the last few years. It is important to note that this question was not led into by another Euro-related question, and comes before any other direct Euro questions. 5 respondents did not answer this question, but of the remaining respondents, $52 \%$ stated that their customers had become much more careful about what they buy, have less money, or are more price aware. $34 \%$ stated there was no change, and the rest had varying answers, including different nationalities, more younger/older customers, and so on. It does show that retail owners are noticing a much restrained public.

The final question of the questionnaire related to what the biggest competition was for the Innenstadt. Multiple answers were allowed, and the discounter stores, whose prominence was earlier linked to perceived price increases due to the Euro conversion, were mentioned as a main competitor by $30 \%$ of the respondents. So there is perceived to be some kind of a loss of downtown patronage as a result of these discounter stores on the periphery.

As it stands, Lahr is economically influenced by a multitude of non-local factors. Adopting a new currency and the reunification are national issues that all of Germany has to come to terms with. It does not appear that the European Union itself is a point of contention among Germans for after all, West Germany itself has been involved in such a union for many decades. However, it could be that the eastward expansion of the European Union has caused further concerns with regard to unemployment, as lower wage countries will be competing for jobs. Certainly the perceived increase in prices is affecting inner city retailers and benefiting outlying, larger establishments. 


\section{Chapter 8: Plans and Attempts to Revitalize the Lahrer Innenstadt}

Now that it has been shown that the Lahrer Innenstadt is experiencing difficulties attracting people, it seems appropriate to examine what measures stakeholders are taking to try and improve the situation. The stakeholders in this case are the Stadt Lahr municipal government and the Lahrer Retail Promotion Organization (LRPO).

The main attempt of the City of Lahr to revitalize the Innenstadt is through a plan that was commissioned called the Rahmenplan. According to Fr. Dalm, a city planning officer, it was primarily the Christian Democrat Faction that pushed for such a plan to be made, and so it was begun in 2001, and completed by November 2002. The concept of an overall plan, however, was developed earlier, and Stadt Lahr had been trying to improve the situation before these dates. Over this period of time the firm developed the plan through meetings with various stakeholders in order to determine what end result is desirable and methods to go about achieving this end result. The Rahmenplan has no concrete completion date, Stadt Lahr will simply implement as much of it as possible each year, as much as their budget will allow. As it currently stands, the state pays $40 \%$ of the Rahmenplan while the city pays the remaining $60 \%$ of the costs. It is hoped that it will all be implemented within approximately 15 years (Dalm, May 19, 2005).

The Rahmenplan's main concept is one of mixed use. It believes that if the Innenstadt offers the proper balance of living, culture and retail, then it will be able to regain its position of true centre and heart of the city. In 2000-2001 a start was made to this plan and the Bürger 
Buro was added in the City Hall buildings, and later the Kultur Buro was put on the ground level of the old Rathaus at the top of the Marktstrasse. This way there is a draw for the people through the entire city. The Bürger Buro is a place where citizens go to take care of their municipal requirements, such as notifying of changes in address, as well as a place to ask for assistance. The Kultur Buro is a place where people can inform themselves regarding all facets of life in Lahr and its surroundings, including bus schedules, concert schedules, tourist attractions and so on. It was hoped that this would start to pull people into town when they need to attend to their municipal responsibilities or would like information on cultural events in towns, and consequently, through the town as end points of the Marktstrasse, the main street through the inner city (Dalm, 19 May, 2005).

Another important part of the City's plan to make the Innenstadt more attractive is the ground surface. Fr. Dalm explained to me that the differences in stones that line the Innenstadt is problematic, uneven stones making the walk uncomfortable and women having an array of problems with their various heel styles. The city is consequently debating whether to make all the ground cover uniform in time, but at least to have the stones be of the best quality (naturally this depends on budget requirements). She explained that the portions in front of the old Rathaus at the top need to be changed, as well as those around the Kirchstrasse (a side street off the Marktstrasse), a project she was personally working on. However, she pointed out that because of the Innenstadt's charm as a historic centre, the ground cover would need to be carefully chosen in order to preserve this image, as well as be practical for walking (Dalm, 19 May, 2005).

Another point of emphasis in the Rahmenplan was the vision of Lahr as a "City of 
Squares." Lahr has many squares where either short term markets can be set up, festivals held, or simply used as meeting places with other citizens. One such square, the Schlossplatz, has already been remodelled a few years ago. The main Marktplatz had been redone in the 80 s already, and other squares are expected to be at least resurfaced in the coming years, as well as have other improvements such as better seating, lamps, and so on (Dalm, 19 May, 2005). The city of Lahr is certainly attempting to use these squares to the best of their ability. Almost every weekend there was some kind of attraction on a square in town, whether it be a car show, an open air presentation of Carmen, a mock 'Hamburger Fischmarkt', a fair, a futuristic truck, and so. These are simply examples of what I remember either seeing or reading about in the paper. In any case, Lahr certainly is attempting to make use of its squares to promote this idea of culture in the city to both its own residents as well as consumers from out of town.

As mentioned earlier the Rahmenplan emphasizes an idea of mixed uses in the Innenstadt through culture, living, and retail. To summarize these ideas, the Rahmenplan states that a one sided retail plan is not enough because it is more meaningful to develop a historic centre as a place to live. The types of people this plan are hoping to attract are the elderly and old, young people with kids, and two income, childless families; quite a wide spectrum. In order to achieve this it is recognized that they need to work on transit, attractive surroundings, buildings with proper accommodation for the elderly, retirement communities (although it is emphasized that these are not to be considered old age homes), playgrounds, youth centres, and some sort of a cultural life. New buildings will be built, but they will be in filled as opposed to building them in new areas, as well as renovate older buildings. Retail 
wise, Stadt Lahr would like to make certain that it is a safe investment to start a store in Lahr's downtown. The city of Lahr officials want the retail world to add to the experience of Lahr, and would like the retailers to work together to achieve this. They also state that they need a strong store to anchor the Northern portion of the Marktstrasse, following which they will attempt to get a circulation going, whereby one starts at the southern entrance of the core, walks North, and then Eastwards, eventually leading back to the Southern point (Bürgerinformation - Konversion und Stadtentwicklung. 2004, and Rahmenplan Innenstadt Lahr 2003). Hr. Albrecht, a city planning official, mentioned to me that they had an idea of what type of store they would like to act as anchor, stating that they were trying to get the large clothing store C\&A to move into this northern portion of the city to act as a magnet (Albrecht, 30 Aug, 2005).

Other points mentioned in the Rahmenplan include making the entrances into the city centre more visible and easily accessible (Rahmenplan, 2003). Fr. Dalm explained to me that some of these measures have already begun. For example, near the north western entrance a traffic light was replaced by a roundabout to keep the traffic flowing at a faster pace. In addition to this, again in the northern part of the inner core, a street that used to be only one way was changed and now accommodates traffic flow in both directions (Dalm, 19 May, 2005).

It was also mentioned that there be a better connection to the river, the Schutter, from the Innenstadt so that they can promote a 'city on the river' theme. When the Schlossplatz was being renovated, they also included here a little faux-stream down the side of the square, tying the water theme. The remnants of the canal that used to run through the centre currently 
runs beneath the Innenstadt. I do not believe they will make this prominent again, however, there are suggestions for a fountain in the Doler Platz to symbolize the canals (Rahmenplan. 2003).

Another key point in the Rahmenplan is the connection between the Innenstadt and the Arena. As mentioned in the previous chapter, the Grüne Wiese is too far away to even contemplate a connection, however, the chance is there with the Arena. If the Innenstadt could connect the two it would benefit greatly, essentially incorporating its competition within its own boundaries, and reducing the either/or mind set. The Rahmenplan acknowledges, however, that due to the historical growth structures of the town, a direct link between the two is not realistic. Instead, it proposes connecting the two via a series of stepping stones. The space between the Innenstadt and the Arena is currently uninteresting, and it proposes to use these primarily open spaces and bring in more life and culture to create the link. For example, a new hall for concerts, etc., is being proposed for one of the squares between the two locations, to replace one that already exists outside of the Innenstadt. More housing is also being proposed, and in the summer of 2005 one small apartment complex was completed in this space. Some of the current open spaces are expected to remain open spaces to make the walk more attractive (Rahmenplan, 2003).

Until this Rahmenplan is realized, however, the LRPO has its own plans to, in the short term, increase the patronage to the Innenstadt. Every Christmas they pay for the Innenstadt to be lit up in Christmas lights, an action which draws many people to the centre (Bickel, 31 Aug, 2005). A Christmas market is also set up for a few days, also described as a huge attraction for many people, including many from out of town, Christmas markets 
being a very popular tradition in Germany. During Easter flowers are also put up all over town, and Easter eggs as well, all decorated with a spring theme behind it (Fr. Himmelsbach, 5 Oct, 2005). Flowers are actually quite popular in Lahr, and are displayed in very beautiful and creative manners. In fact, in 2004, Lahr won the prize for "most blooming shopping mile" in all of Germany for its many creative displays year round (Bickel, 31 Aug, 2005).

The LRPO also realizes that stores that are not directly on the Marktstrasse are suffering more than those directly on the main street. In order to promote these side stores within the Innenstadt, the Organization has made signs at the mouths of these streets which state what stores, as well as other attractions, the shopper will find down the street. This encourages shoppers to turn into a side street when perhaps otherwise, they would not have gone that way (For an example, see Figure 8.1, Bickel, 31 Aug, 2005).

The city has also made an effort to make the issue of parking easier to deal with in the Innenstadt so that people will not view this as a reason not to shop there. As mentioned in the previous chapter, Lahr has two parking garages, however, the city is not responsible for running these and therefore cannot set the prices. But it does have control over all the other parking spaces, and here it has tried to make the situation easier. For example, all ground parking is free on weekdays after five in the afternoon, and Saturdays after noon (Parken in Lahr, 2005). The city has also created small parking lots in any amount of free space that there is in the Innenstadt, and has placed signs at all entrances of the core directing people to where they can find the parking. They have also printed pamphlets, which are available at various locations in the Innenstadt, which include maps of the various locations where parking is available, as well as explaining these new rules of parking, and providing 
Figure 8.1 : Example of sign to encourage more side street patronage

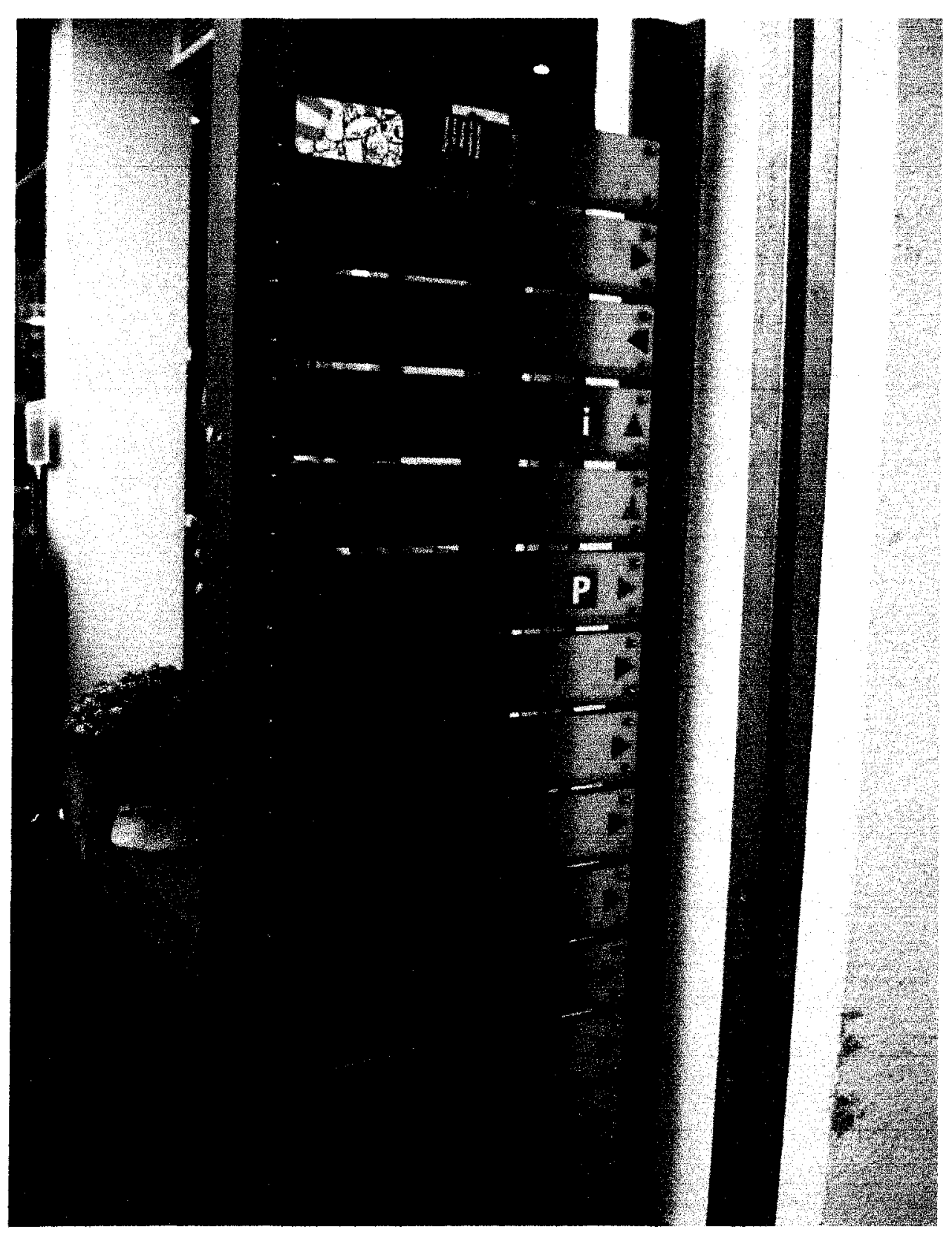

them with the prices, which in comparison with other towns, are not expensive, with $0.50 €$ buying the consumer anywhere from half and hour to an hour depending on where one parks (Parken in Lahr, 2005). 
The most successful plan to bring people into the Innenstadt is the Chrysanthemenzauber. This festival sees the historic core being covered in chrysanthemums, on buildings, in the squares, completely covering the core (Some examples can be seen below, Figures 8.2 and 8.3 ). This festival is a three week long event which takes place from the end of October to the middle of November to celebrate autumn. During this time the city is so full one can barely manoeuver the streets on evenings and weekends. In addition to the flowers, a ferris wheel is set up on the Town Hall square, along with other small rides for children. A little train takes people through all the side streets to see the different figures created out of flowers by various groups in Lahr. Stands are set up where the consumer can purchase anything from bratwursts to crepes to the famous chrysanthemums themselves. During these three weeks a special market comes in for one weekend, and then the town uses its quota for two Sundays when the stores are allowed to be open.

The Hr. Bickel adds that advertisements for the Chrysanthemenzauber are in papers, radios, flyers and signs all over Baden-Württemberg in particular, but even beyond. Alsace is also covered, as it is not far away and the idea actually came from Lahr's partner city in Dole, France (Bickel, 31 Aug, 2005). Bus loads of people come during this time, ranging from 20-30 buses per day come to Lahr over this three week period (Albrecht, 30 Aug, 2005). In total, more than 250000 people come every year - and this number is only increasing (Blum, 30 Aug, 2005). Clearly this means increased profits for all the retailers in the Innenstadt, and one notices immediately that everyone discusses this event with pride and joy. This is clearly one of Lahr's biggest success stories, if not the biggest, in the last 15 years. 
Figures 8.2 and 8.3 : Chrysanthemenzauber

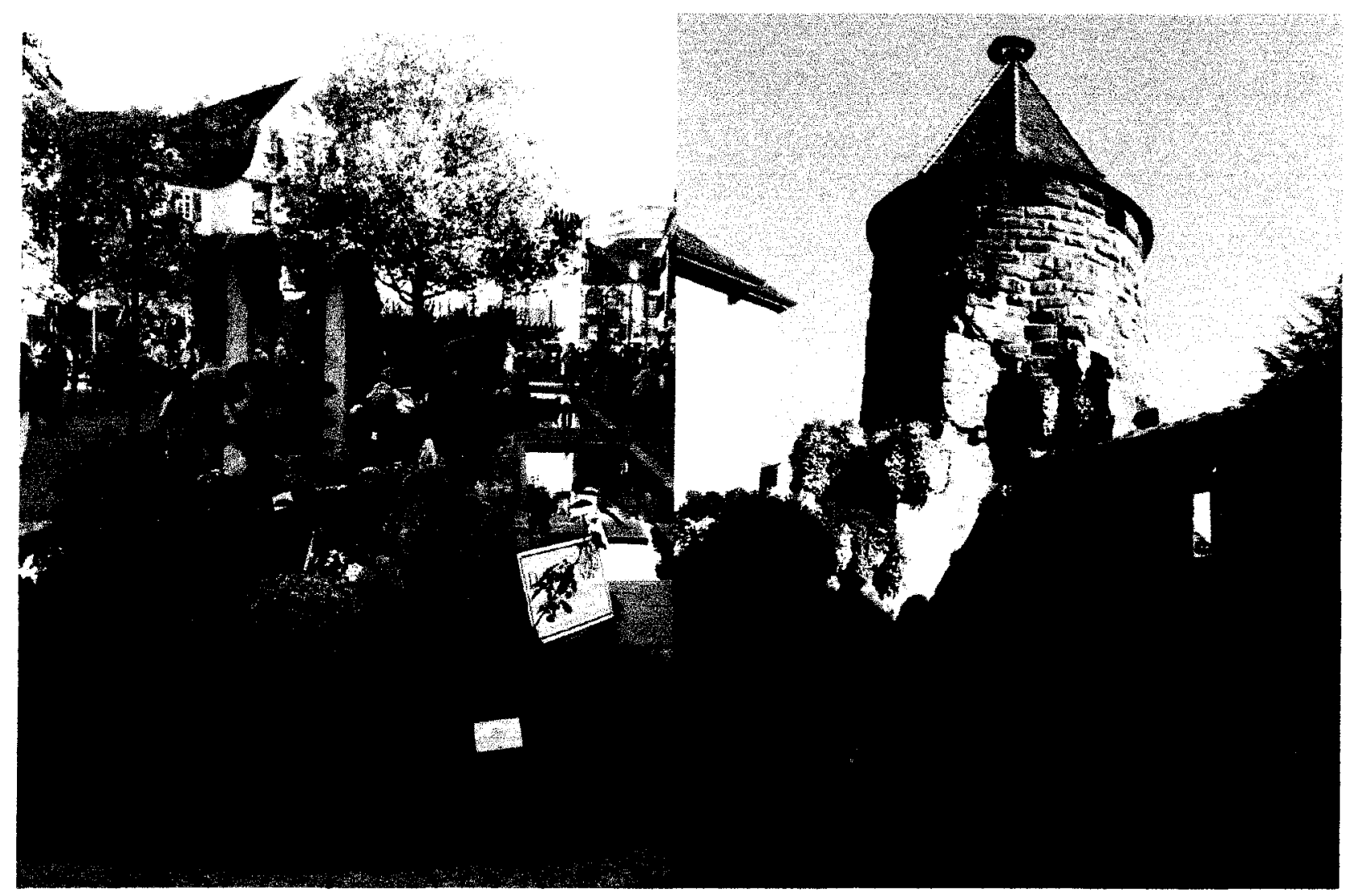

These initiatives are in place to promote increased patronage of the Innenstadt and address all of the factors mentioned in this thesis. The Rahmenplan is the most wide ranging initiative, with its mix of retail, living and culture to draw people towards the town centre. More people living in the Innenstadt would decrease the amount of people shopping outside centre town, be it at discounters or the Arena, all year round. Focussing on greater residential activity in the Innenstadt is likely the initiative that will have the greatest impact, and the greatest likelihood of filling the void left by the Canadian troops and their families. Clearly if more people live in the city centre, more people will shop in the city centre year round. Whether it can make up for losing thousands of consumers is difficult to determine. But it 
is unlikely that any initiative could replace the Canadians, and at least this works on creating more permanent consumers for the Innenstadt stores.

Having cultural events here also pulls people inwards for specific events, which might lead them to combine their trip with other things available in the Innenstadt, for example a coffee or some shopping needs. Improved retail certainly explains itself because better retail opportunities means that the Innenstadt would be a better magnet for attracting consumers.

In an attempt to gain insight into what the true strengths of the Innenstadt were, the questionnaire for store owners included a question about why they moved into the Innenstadt. The older stores answered that there was nowhere else to set up shop at the time, but the newer stores, answered to almost $100 \%$ that it was because there was a pedestrian zone. It seems that the stakeholders organizing the revitalization attempts truly do recognize this as the strength of the Innenstadt. Chrysanthemenzauber, the Christmas lights, and other such attractions are designed to take advantage of the pedestrian zone by offering attractions that can be examined and enjoyed in peace. They draw people into the centre to look at the decorations, helping to revitalize the area. This could not be enjoyed in the same way if cars were allowed in this space, and I believe that the stakeholders recognize this as the strength of the Innenstadt, and by building on this notion, they can likely encourage more and more people to come to the Innenstadt.

Again, it is likely such trips will encourage patrons to take part in what the Innenstadt has to offer while there, be it buying food or taking care of chores while in the area. If they enjoy the experience, it is more likely they will return, whether or not there is some other display going on or not. It is important to remember that as the town centre the Innenstadt 
offers more than simply retail opportunities, although that has been the focus of this thesis. The Innenstadt offers an experience, it is a place where one meets acquaintances, has meals or a coffee and cake, experiences cultural events, takes in holiday decorations, get some fresh air and exercise walking around, and enjoys the sights of an attractive and historical town centre. Any trip into the centre will remind a consumer of all the Innenstadt has to offer and if their combined experience was a good one, they will want to repeat it in the future.

The initiatives in parking have been made to make the experience more enjoyable as there have been complaints about difficulty finding parking. This initiative may be more targeted towards competing with the Arena and Grüne Wiese as plenty of available parking is one of their main draws. However, a good parking environment would encourage all automobile dependent consumers to patronize the Innenstadt more often, and so this is also a measure done to improve the situation year round.

Finally, the Chrysanthemenzauber is a time-specific initiative, but nonetheless a very successful one. While it does only occur over a three week period, these three weeks were instigated to help an entire year of decreasing sales. With over 250000 guests to the town, the retail sector experiences an enormous boost in sales over these weeks. Tourists are generally less frugal than daily shoppers, so the Euro issue would be minimized. Any boost in sales would help make up for the loss of the Canadians, for example, as well as any loss of customers to fringe retailing. This period is often described as the high point of Innenstadt retailing.

It is important to keep in mind, however, that the factors in this thesis are not necessarily factors for which replacements or equivalents can be found. Losing thousands of 
good customers with the withdrawal of the Canadians is not something for which a replacement can be found. The numbers were replenished as was possible at the time, but the Canadians were in a privileged position working on a foreign base. Such a factor is likely irreplaceable. The Euro conversion is also something that will simply take time to sort out. Retailers are trying to attract consumers back, but with high unemployment and then a conviction that prices have increased, it is difficult to encourage consumers to spend at the same levels as beforehand. Competition in the form of the Arena and the Grüne Wiese is a problem that many towns are faced with. Competition will always exist, and it is difficult for inner cities to compete when such developments have as many advantages as they do over inner city locations. These attempts by Lahr to revitalize the Innenstadt are their initiatives to bring consumers back despite the troubling factors that have arisen over the last 15 years. While it is likely impossible to duplicate situations of the late 1980s these initiatives do encourage people to visit the Innenstadt. The types of initiatives Lahr has developed appear to be based on formulas that have proven successful in other cities (ie. Chrysanthemenzauber from Dole, the mock Hamburger Fish Markt, increased transit). So the ideas are not unique, but it is their proven effectiveness that likely attracted Lahr to them. It could also be that there is a reluctance in Lahr to experiment because of possible failure, and the community therefore simply wishes to invest in ideas with proven success records. Hopefully, regardless of what draws them in, people will realize what makes the Innenstadt a special shopping experience and will be encouraged to return to the area at any time, to partake in many of its attributes, improving not only the retail aspect in the centre, but truly revitalizing the quality of the Innenstadt experience by bringing life back into the city. 


\section{Chapter 9: Conclusion}

This thesis has examined how the retail sector of the inner city of Lahr has been affected by various changes occurring in the town over the last 15 years. Examining the retail situation in a German city was seen as being very interesting because fringe or suburban retailing was not quite as established or widespread as in North America. Lahr in particular had faced some strong internal and external changes which made it a unique case study.

The first change that was examined was an external one. Lahr had been a garrison city for the last 100 years and when the Canadians decided to pull out, it ended this chapter in Lahr's history. The Canadians were stationed in Lahr for almost 30 years, and in this time had quite an impact on the town. As troops receiving extra pay for serving on foreign soil, they had a greater amount of disposable income, and the charming historic core proved to be the shopping destination of choice for many Canadian troops and their families. The fact that they left, coupled with the speed at which this occurred, left Lahrers generally unprepared for a life without the Canadians. As Lahr attempted to organize activities on the airfield, trying to make it a viable economic alternative, many Spätaussielders came to fill the vacant apartments. These people, however, did not have the same purchasing power as the Canadians, and as a result Lahr simply found itself having to accommodate more people in their town without having the additional revenue they had likely been hoping for. The retailers in the Innenstadt continued to suffer because the shopping patterns of the Spätaussielders directed them more towards discounters on the fringe as opposed to the more specialized stores of the Innenstadt. As a result of this, the retailers did not regain the 
purchasing power that had been taken away with the Canadians, despite the increase in population, and therefore, those that remain continue to deal with a loss of customers. However, it can be assumed that as the Aussiedlers continue to adapt to German culture, especially the younger generations, they will also adapt different spending habits more similar to the German patterns.

The monetary conversion from the Deutsch Mark to the Euro was another external factor that affected retailing in the Innenstadt, external in that it was decided upon outside of Lahr, but it also could be considered an internal factor because the German federal government decided upon it and so all German towns are affected. This factor is seen in conjunction with an overall poorer German economy over the past few years. Much money has been pumped into the East attempting to bring its quality of life on par with that of the former West Germany. Unfortunately, the conversion period is taking longer than expected, and the German federal government is continually financing the East without making much of an impact. Economic uncertainty is high in Germany, and the area where this hits most Germans is in the unemployment sector. Unemployment in Germany has soared to levels unheard of 20 years ago, for both the East and the West, however, particularly in the East. Uncertainty over job futures runs high in Germany, and as a result, spending is down. This, coupled with the conversion to the Euro, which most consumers believe brought with it an increase in prices as reported in many newspaper articles as well as confirmed in my questionnaire, has resulted in a changing attitude towards spending. There is more of an emphasis on buying what one needs, and fewer articles that one simply desires.

The spatial patterning of shopping is also changing. On a macro level, larger towns 
were drawing more consumers in the hope that with a greater selection, better prices could be found, leaving cities like Lahr with fewer consumers. Within Lahr itself, shifting is occurring from shopping in the inner city to shopping on the fringe where discounter stores are located that sell almost anything if one waits for the appropriate sale. This hurts the Innenstadt retailers who specialize in their field, put time and energy into knowing their product, and offer quality. This is therefore, often reflected in their prices as they are not mass producers, and also due to their inner city location, they have a smaller area to work with, and likely a higher rent than on the fringe. This puts the Innenstadt retailers at a disadvantage in comparison, and with the Euro conversion, this gulf is only increasing.

Internally, the Arena and the Grüne Wiese are also taking customers away from the Innenstadt. With offers such as free parking and set opening hours, many consumers simply find it more convenient and less stressful to shop at these locations. Coupled with the locally unique situation that Lahr has almost no grocery shopping opportunities in the Innenstadt (other cities in the region do), this makes the other two locations, with leading grocery stores, even more attractive. A majority of store owners in the Innenstadt stated that they consider these two areas their top competition, and believe they are syphoning customers away from the centre. With the Arena a connection could be possible, but stakeholders are finding it difficult to encourage shoppers to walk between the two locations. Bus connections to improve travelling between both sites and the Innenstadt have also been improved, but for the many consumers who wish to travel by car, the Innenstadt is simply at a disadvantage.

Finally, strategies that stakeholders are using in an attempt to increase the patronage of the Innenstadt were examined. The Rahmenplan was examined, and various methods to 
improve the Innenstadt from this planning agency were addressed. Unfortunately, due to budget constraints, many of these plans may not be able to be implemented for years to come. Strategies with more immediate results included the Christmas lighting, the Easter decorations, and the most successful strategy, the Chrysanthemenzauber. These all dramatically increased patronage during their times of operation. But clearly such festivals cannot be implemented on a daily basis, and therefore the Rahmenplan initiatives will become more important as they are implemented, because they will emphasize the quality of shopping in the Innenstadt.

This thesis is an important demonstration of how there are many different players involved in the success or failure of an inner city, regardless of how obvious they might seem upon first glance. Lahr's Innenstadt has been influenced by foreign governments, including the Canadian federal government, as well as other European Union governments to some extent, its own federal government, and its municipal government, as well the initiatives of developers and other retailers. All of these actors played a role in the development of the Innenstadt over the last 15 years. The other classic issue of inner cities is their historic construction, and the limited amount of space it allows for retail and for other modern amenities such as parking. The inner city retailers naturally also play a role, trying to improve the quality of their products, as this is often viewed as their primary niche. Various stakeholders try and improve the situation by coming up with new ideas that will attract people to the centre, multiple festivals and such. However, over the course of human history, the problem of attracting people to the centre is a relatively new one, and it is certainly interesting to contemplate what the future of our cities holds. Currently, especially in 
European cities, the centre is still an area of retail importance, but how this will all play out as more and more retail developments occur on the fringe is unknown.

For now it is evident that inner city retailing is threatened. Threatened by economic changes, threatened by fringe developments, and threatened by the very morphology that also makes it charming. How inner cities continue to develop will define how well they meet challenges in the future. What role will inner cities have in the evolving retail environment? What will become the new attractions and advantages to being in a central location? What types of initiatives can make a small, historic core become a more attractive retail choice than its large, modern, climate controlled counterparts? This could be very valuable information for other cities facing the same loss of the central functions of their inner cities. Are suburban, fringe developments the future? This promotes uncertainty regarding the entire future of cities, and the changing geographies of important locations within them. With an increasing proportion of people living in cities, such examinations are vital in understanding the development of how humans interact with their environment.

How Lahr specifically handles its problems will also be an interesting topic to revisit in the future. Perhaps once most of the Rahmenplan ideas have been implemented, it would be relevant to re-evaluate the situation here, determine which methods have proven to be successful in bringing shoppers back into the Innenstadt on a daily basis. In order for this to happen, however, it seems the city government will have to begin keeping better records of what is occurring in their city. The city of Lahr's lack of keeping statistics will not equip them with the information necessary to determine which methods are helpful, which are not, and evaluate how far Lahr has come since beginning the Rahmenplan. The debates in council 
regarding the airport developments and their overall slow handling of the Canadian troop withdrawal demonstrate that council did not truly have a sense of what kind of a challenge they faced. At some point in time, appropriate records will need to be kept in order to learn from past mistakes and move forward with the best course of action, based on what was proven successful in past years. Hopefully the council can address the revitalization of the Innenstadt in a much more successful manner that will not be hindered by a slow reaction or by misinformation. It seems that already the Rahmenplan is facing some of the same issues that the Canadian withdrawal demonstrated because it has taken so long to develop it, in addition to the fact that there is no deadline for when these changes are expected to be implemented. 15 years is stated as a rough goal, but essentially it will be decided upon year to year as budget constrictions become more clear. This does not place enough of a priority on the Rahmenplan, and as a result it could suffer from the same half-hazard reaction that the closing of the Canadian base seemed to garner insofar as it did not translate into quick, practical initiatives with successful results.

Perimeters larger than the Rahmenplan covers are also necessary to examine. With regard to shopping, how can Lahr pull consumers away from the big attractions in the area Offenburg, Strasbourg, and Freiburg? Lahr is conveniently located just off of the Autobahn, a definite advantage. However, it suffers from disadvantages as well. For example, the train station is not located downtown as it is in most other towns. If coming by train, that may very well be a deciding factor in whether to get off at Lahr, where one will have to continue by bus to the city centre, or simply stay on the train for one more stop, and be in downtown Offenburg. Initiatives in parking will help Lahr in relation to other towns, as consumers often 
complain that in the larger cities, especially Freiburg, it is extremely expensive to park. But it is clear that Lahr will have to continue to create initiatives to try and draw consumers away from the larger towns and towards themselves.

With tourism the situation is similar. Lahr is located in the Schwartzwald, a very picturesque and highly visited area of Germany. However, it is not an area that lacks in historic tourist towns. Freiburg is the unofficial capital of the Schwartzwald, and many of the tourists that visit this area stay in Freiburg. Lahr faces both advantages and disadvantages with regard to its location. The main disadvantage is that there are so many possible towns and cities to visit, it may be difficult to attract tourists to Lahr. However, the advantage is that Lahr is in a good location. One could easily stay in Lahr, and make day trips to the other attractions in the area. The overnight costs would be less than in a larger city like Freiburg, yet everything is still easily accessible. From Lahr one could easily reach the tourist attractions of Triberg, Gutach, and Freiburg. In addition to this, Lahr is only about 15 minutes away from the French border, so Alsatian trips would also be possible. If Lahr could market itself as a town with an excellent location, not too large to have high prices, yet not too small to have nothing to do at night, and a beautiful historic core, then it could likely capture a good portion of the Schwartzwald tourism market. The Kultur Buro in Lahr could easily help organize day trips for tourists with hotels booked here. It seems this would be a viable economic path for Lahr to follow, and would certainly be an interesting topic for further exploration. 


\section{Appendix A: Euro Questionnaire Euro Fragebogen}

1. Haben die Läden in Erwartung auf dem Euro die Preise vor January 2002 erhöht?

2. Koennen Sie ein paar Beispiele von Preiserhöhungen nennen? Z.B. Levis Jeans vorher $60 \mathrm{DM}$, jetzt 50 Euro, oder Salat $1 \mathrm{DM}$, jetzt 80 cents.

3. Gibt es irgendwelche Produkte die Billiger geworden sind seit der Umstellung?

4. Noch irgendwelche allgemeine Gedanken, Beschwärungen, oder Lob den Euro betreffend?

5. In einem Artikel aus der Badische Zeitung vom 21 Dezember, 2002, steht :

"Die Verbraucherpreise in Deutschland sind im ersten Jahr des Eurobargeldes im Durchschnitt um 1.3\% gestiegen. Damit hat sich der Preisauftreib 2002 gegenüber dem Vorjahr mit 2.5\% fast halbiert...Damit sehen sich die Experten bestätigt, dass die Bargeldumstellung von DM auf Euro keinen wesentlichen Einfluss auf die allgemeine Lebenshaltung hatte. Der Euro sein kein Teuro."

Was sagen sie zu diesen Zität? 


\section{Euro Questionnaire}

1. Did the stores, in expectation of the conversion to the Euro, increase prices in summer 2001?

2. Could you name some examples of price increases? For example, Levi Jeans that used to cost $60 \mathrm{DM}$ now cost $50 €$, or a head of lettuce, before $1 \mathrm{DM}$, now $0.80 €$.

3. Are there any products that became cheaper since the conversion to the Euro?

4. Do you have any other general thoughts, complaints, or praise regarding the Euro?

5. In an article in Die Badische Zeitung it states that

"The consumer prices in Germany have, in the first year of the Euro, on average increased $1.3 \%$. This means that inflation, in comparison to the previous year's increase of $2.5 \%$, have almost been halved. With this the experts believe they have proved that the currency conversion from the DM to the Euro has had no influence on the overall standard of living. The Euro is no Teuro."

What do you have to say about this quote? 


\section{Appendix B: Store Owner Survey}

1. Was für ein Geschäft haben Sie? Private besitzt / Kette.

2. Wie lange sind Sie schon in der Innenstadt?

Sind Sie vor 1992 eingezogen:

Waren die Kanadier ein großes Teil Thre Kundschaft? Ja/ Nein

Sind Ihren Umsätze in den letzten 13 Jahren: gestiegen / geblieben / gesunken?

Sind Sie nach 1992 eingezogen:

Ging Ihr Umsatz in den letzten Jahren: hoch / geblieben / runter?

3. Warum sind Sie in die Innenstadt gezogen?

4. Hat sich die Kundschaft über die letzte Jahren geändert? Ja / Nein.

Wenn Ja, wie?

5. Wie würden Sie Ihre Kundschaft beschreiben? (z.B. männlich/weiblich, alter, Lahrer/Touristen, etc.)

6. Wie hat sich der Umstellung auf den Euro auf Ihr Geschäft ausgewirkt?

7. Sind jetzt mehr oder weniger Leute in der Innenstadt als früher? mehr/ weniger.

8. Was, Thre Meinung nach, ist die größte Konkurrenz für die Innenstadt?

144 


\section{Store Owner Survey}

1. What kind of a store do you have? Privately owned / Chain

2. How long have you been located in the Innenstadt?

If you were here prior to 1992:

Were the Canadians a large portion of your customers? Yes/No

Have your profits in the last 15 years: risen/stayed the same/decreased?

If you moved in after 1992:

Have your profits in the last few years: rise/stayed the same/decreased?

3. Why did you choose to move into the Innenstadt?

4. Have the consumers changed in the last few years? Yes/No

If yes, how have they changed?

5. How would you describe your customers? For example, male/female, Lahrers/Tourists, etc.

6. How did the conversion to the Euro affect your business?

7. Are there now more or fewer people in the Innenstadt than in previous years? More/Fewer

8. In your opinion, what is the biggest competition for the Innenstadt? 


\section{Bibliography}

Albrecht, Gerhard. Interview conducted on $30^{\text {th }}$ of August, 2005.

Ashworth, G.J., and Tunbridge, J.E. 2000. The Tourist-Historic City - Retrospect and Prospect of Managing the Heritage City. Pergamon : Amsterdam.

Beck, Werner. Interview conducted $17^{\text {th }}$ of August, 2005.

Berg, Stefan, Winter, Steffen, and Wasserman, Adreas. "The Price of a Failed Reunification," in Der Spiegel Online, 36/2005, Sept 5, 2005. Accessed March 2, 2005 at http://www.spiegel.de/international/spiegel/0,1518,373639,00.htm; Internet.

Bickel, Thomas. Interview conduted on $31^{\text {st }}$ of August, 2005.

Blum, Walter. Interview conduted on $30^{\text {th }}$ of August, 2005.

Blume, Peter. 2000. Das Ahornblatt in Germany - Kanadishe Heeresstrietkräfte in Deutschland 1951-1993. Condo Verlag : Emmelshausen.

Bosshammer, Herwart. "Stadt will 599 Wohnungen für 28,7 Millionen Mark kaufen," in Lahrer Zeitung. 31 August, 1996.

Bosshammer, Herwart. "Lahr droht ein Finanzloch von zehn Millionen Mark," in Lahrer Zeitung. 10 November, 1993.

Bruce, David, Ollerhead, Jocelyn, Rowe, Jennifer, and Ashton, Bill. 1995. A Primer on Military Base Reuse in Canada. Rural and Small Town Programme : Sackville, NB.

Capps, Philippa. "Vignette 5 - The retail workplace geography of gender, space and power dynamics: A case study of a camping business in south-east England," in Qualitative Methodologies for Geographers, Melanie Limb and Claire Dwyer, eds. 2001. Arnold : London. pp. 291-293.

Cornforth, Trisha. Interview conduted on $5^{\text {th }}$ of October, 2005.

Cotterill, Pamela. "Interviewing Women - Issues of Friendship, Vulnerability, and Power," in Women's Studies Int. Forum, vol. 15, nos 5/6 (1992), pp. 593-606.

Dalm, Claudia. Interview conduted on $19^{\text {th }}$ of May, 2005.

Dietz, Werner. March $28^{\text {th }}, 1991$. Letter to state government. Stadtarchiv Lahr, Heizmann 24. 
Dietz, Werner. September $19^{\text {th }}$, 1991. Letter to Ministerpräsident Dr. Erwin Teufel, Staatsministarium. Stadtarchiv Lahr, Heizmann 24.

England, Kim. "Getting Personal : Reflexivity, Positionality, and Feminist Research," in Professional Geographer, vol. 46 (1994), pp. 80-89.

FAO. 2005. Food Outlook. Accessed March 22, 2006 at www.fao.org/giews/english/fo ; Internet.

Fischbach, Kristina. 2004. Ab in die Mitte. Heidelberg.

Frädrich, Michael. “Ängste,” in Lahrer Zeitung. 9 September, 2005.

Freeman, Alan. "What has become of Klein Kanada," in Globe and Mail. February 6, 1998.

Fuller, Duncan. "Part of the Action or "Going Native," in Area, vol. 31 (1999), pp. 221-227.

Gerhard, Ulrike, and Hahn, Barbara. 2005. "Wal-Mart and Aldi : Two retail giants in Germany," in GeoJournal, 2005, vol. 62, pp. 15-26.

Glassberg, Andrew D. "Intergovernmental Relations and Base Closing," in Publius, vol. 25, (1995), pp. 87-98.

Gordeeva, Tatyana. "The Reunification and its Aftermath." 2006. Accessed March 2, 2006 at http://www.germanculture.com.ua/library/facts/bl_reunification_aftermath.htm ; Internet.

Goren, Lilly and Lackenbauer, P. Whitney. 2000. Canadian-American Public Policy - The Comparative Politics of Military Base Closures. The Canadian American Center : Maine.

Hauser, Werner. $12^{\text {th }}$ October, 1990. Letter to Cities with a Military Presence. Stadtarchiv Lahr, Heizmann 24.

Heineberg, Heinz. 2001. Stadtgeographie.Schöningh : Paderborn.

Herden, Ralf. "Vor fast hundert Jahren haben sich die Stadtväter die Militärpräsenz erbettelt," in Mittelbadische Presse. 6 November, 1990.

Himmelsbach, Eugene. Interview conduted on $5^{\text {th }}$ of October, 2005.

Himmelsbach, Helga. Interview conducted on $5^{\text {th }}$ of October, 2005. 
Jeweller. Interview conduted on $13^{\text {th }}$ of October, 2005.

Jones, Ken, and Simmons, Jim. 1990. The Retail Environment. Routledge : London.

Jordan-Bychkov, Terry, and Domosh, Mona. 2001. The Human Mosaic - A Thematic Introduction to Cultural Geography. W.H. Freeman and Company : New York.

Kalman, Harold. "Crisis on Main Street," in Reviving Main Street, ed. Deryck Holdsworth. 1985. University of Toronto Press : Toronto.

Keiper, Achim und Maier, Stefan. "Grohe-Mitarbeiter auf den Barrikaden," in Lahrer Zeitung. 25 May, 2005.

Kohlmeyer, Bruno. "Land gewährt 40 Millionen Mark zinlose Derlehen," in Badische Zeitung. 10 February, 1994.

Kohlmeyer, Bruno "Tore auf heißt es heute im Arena-Einkaufspark," in Badische Zeitung. 24 May, 2000. \#1.

Kohlmeyer, Bruno. "Ein Einkaufsparadies für 40 Millionen Mark," in Badische Zeitung. 24 May, 2000. \#2.

Kohlmeyer, Bruno. "Zwei Lebensmittelgeschäfte schließen," in Badische Zeitung. 25 October, 2001.

Koster, Rhonda, and Randall, James E. "Indicators of community economic development through mural-based tourism, " in The Canadian Geographer, vol. 49, no. 1 (2005), pp. $42-60$.

Langelott, Victoria. "Riesenchance oder Riesenverlust für die Region?" in Lahrer Zeitung. 19 September, 1991.

Lederle, Achim. "1200 Arbeitsplätze sind machbar," in Lahrer Zeitung. 1 July, 1993.

Maier, Stefan. "Neue Landesbehörde soll in Lahr angesiedelt werden," in Lahrer Zeitung. 26 June, 1993.

Maier, Stefan. "Erste Mieter ziehen eim Februar ein," in Lahrer Zeitung. 11 November, 1993.

Maier, Stefan. "Roth-Händel droht Gefahr von der EU," in Lahrer Zeitung. 3 May, 2005.

Maier, Stefan. “Grohe baut in Lahr 384 Arbeitsplätze ab,” in Lahrer Zeitung. 9 June, 2005. 
Massey, Doreen. "Questions of Locality," in Geography, vol. 78, no. 2, (1993).

Mietzner, Thomas. Interview conduted on $8^{\text {th }}$ of September, 2005.

Möller, Thomas. "Pfiffigkeit und Anpassung," in Lahrer Zeitung. 6 Feburary, 1999.

Monheim, Rolf. "Fußgängerbereiche in deutschen Innenstädten, " in GR 52 (2000), H7-8, pp. 40-46.

Mullings, Beverly. "Insider or Outsider, Both or Neither: Some Dilemmas of Interviewing in a Cross-Cultural Setting," in Geoforum, 30 (1999), 337-350.

Newman, Gary. Interview conducted $13^{\text {th }}$ of February, 2006.

Oanda. 2006. Oanda - The Currency Site. Accessed April 8, 2006 at www.oanda.com; Internet.

Obertreis, Rolf. "Statistiker prangern Preistreiber an," in Badische Zeitung. 9 March, 2002.

Pesch und Partner. 2003. Rahmenplan Innenstadt Lahr. Stadt Lahr : Lahr.

Phillips, Roderick. 1996. Society, State and Nation in Twentieth Century Europe. Prentice Hall : New Jersey.

Picard, Martin, and Rohn, Jürgen. "Haungs : Also zivilen Flugplatz nutzen, Caroli : Es gibt bessere Möglichkeiten," in Lahrer Zeitung. 4/5 May, 1991.

Picard, Martin. "Kanadier lassen in Lahr letzte Hoffnung platzen," in Lahrer Zeitung. 26 February, 1992.

Popp, Monika. "Developing Shopping Centres in Inner-City Locations : Opportunity or Danger for Town Centres?" in Die Erde, vol. 135, is. 1, pp. 107-124.

RB-Deskart. 2005. Baden-Württemberg. Accessed March 27, 2006 at http://www.weltatlas.de; Internet.

Rieger, Josef. November $19^{\text {th }}, 1991$. Letter to Lahr Mayor Werner Dietz. Stadtarchiv Lahr, Heizmann 24.

Robertson, Kent. "Dissecting the Main Street Approach," in Public Management, vol. 85, no. $1,(\mathrm{Jan} / \mathrm{Feb} 2003)$, pp. 16-21.

Rödel. Interview conducted on $29^{\text {th }}$ September, 2005. 
Rohn, Jürgen. "Kanadier ziehen noch schneller ab - Verunsicherung und Endzeitstimmung in Lahr," in Lahrer Zeitung. 16 March, 1992.

Rose, Gillian. "Situating Knowledges : Positionality, Reflexivities and Other Tactics," in Progress in Human Geography, vol. 21, no. 3 (1997), pp. 305-320.

Rose, Ulrich. “Wer hilft, wenn die Soldaten gehen?" in Badische Zeitung. 21 October, 1991.

Seefeldt, Ulf. "Kanadier ziehen in vier Jahren aus Lahr ab," in Lahrer Zeitung. 18 September, 1991.

Siebold, Heinz. "Der Einzelhandel klagt," in Badische Zeitung. 12 April, 2002.

Smith, B.L. September $17^{\text {th }}$, 1991. Letter to Lahr Mayor Werner Dietz. Stadtarchiv Lahr, Heizmann 24.

Spinner, Manfred. Interview conducted $3^{\text {rd }}$ November, 2005.

Stadt Lahr. 2005. Accessed February 23, 2005 at http://www.lahr.de ; Internet.

Stadt Lahr. 2005. Parken in Lahr.

Stadt Lahr. 2004. Wirtschaftsstandort Lahr - Daten und Fakten 2004.

Stadt Lahr. 2005. Wirtschaftsstandort Lahr - Daten und Fakten 2005.

Statistisches Landesamt - Baden-Württemberg. Accessed March 3, 2006 at http://www.statistik.baden-wuerttemberg.de ; Internet.

Starr, Colin. Interview conducted on $25^{\text {th }}$ October, 2005.

Starr, Ulrike. Interview conducted on $25^{\text {th }}$ October, 2005.

Stegna, Gerda. April 7, 2006. Personal Correspondence.

stern TV. 2006. Euro: Korrekte Studien provozieren die Verbraucher. Accessed January $26^{\text {th }}, 2006$ at http://www.stern.de/tv/sterntv ; Internet.

stern TV. 2006. Preisentwicklung. Accessed January 26 th 2006 at http://www.stern.de/tv/sterntv; Internet.

stern TV. 2006. Zuschauerreaktionen. Accessed January $26^{\text {th }}, 2006$ at http://www. stern.de/tv/sterntv; Internet. 
Stone, Kenneth. 1995. Competing with the Retail Giants: How to Survive in the New Retail Landscape. John Wiley \& Sons Inc. : New York.

Warf, Barney. "The geopolitics/geoeconomics of military base closures in the USA," in Political Geography, vol. 16, no. 7 (1997), pp. 541-563.

Wolf, Diane. "Situating Feminist Dilemmas in Fieldwork," in Feminist Dilemmas in Fieldwork, ed. Diane Wolf. 1996. Westview Press : Boulder.

Wrigley, Neil and Lowe, Michelle, eds. 1996. Retailing, Consumption and Capital Towards the New Retail Geography. Longman Group Limited : London.

“853 Wohnungen für die Stadt," in Badische Zeitung. 6 November, 1991.

“1300 Kanadier ziehen 1992 aus Lahr ab,” in Lahrer Zeitung. 19 October, 1991.

“1900 Soldaten verlassen Lahr noch 1992,” in Lahrer Zeitung. 17 March, 1992.

"Altstadt besser angebunden," in Badische Zeitung. 7 December, 2004.

"Arbeitsmarkt dümpelt dahin," in Lahrer Zeitung. 1 June, 2005.

"Aufregung steigt schneller als Preise," in Badische Zeitung. 28 May, 2002.

"Aus dem $>$ Glockengumpen $<$ wird ein $>$ Kanadaring, $<$ " in Lahrer Zeitung. 19 May, 1993.

“Das Anspruchsdenken an den Staat ist zu groß," in Badische Zeitung. 24 July, 1993.

"Der Einzelhandel wirbt massiv um die Kunden," in Badische Zeitung. 28 January, 2002.

"Der Masterplan ist die Grundlage für die Konversion," in Badische Zeitung. 1 July, 1993.

"Die Kanadier gehen - was wird aus Lahr und dem Flugplatz?" in Lahrer Zeitung. 18 September, 1991.

"Die Stadt Lahr steht vor einer ungewissen Zukunft," in Lahrer Zeitung. 17 August, 1991.

"Die Stadt steht vor einem großen Problem," in Mittelbadische Presse. 11 June, 1996.

"Die Werbegemeinschaft rechnet mit Kaufkraftverlust von großen Ausmaß," in Lahrer Zeitung. 16 March, 1992. 
"Edeka Kohler geht in die Kaufhalle," in Badische Zeitung. 25 July, 2001.

"Euro ist kein Teuro," in Badische Zeitung. 21 December, 2002.

"German Reunification." 2006. Accessed March 2, 2006 at http://en.wikipedia.org/wiki/German_Reunification; Internet.

"Germany's Surprising Economy," in The Economist. Aug 20, 2005, vol. 376, no. 8440, p. 9.

"Fremde Heimat," in Badische Zeitung. 27 March, 1999.

"Handel spürt Käuferverdruss," in Badische Zeitung. 14 May, 2002.

"Heute Entscheidung über den Abzug der Kanadier aus Lahr?" in Lahrer Zeitung. 6 September, 1991.

"Hold the Foie Gras," in The Economist May 25" 2002 , vol. 363 , no. 8274, p. 55.

“Im Zweifel eher für die Arbeitsplätze," in Badische Zeitung. October 7, 1992.

"In Deutschland geht Angst um," in Lahrer Zeitung. 9 September, 2005.

"Infation sinkt wieder," in Badische Zeitung. 23 February, 2002.

"Jeder zweite Kunde aus dem Umland," in Badische Zeitung. 26 May, 2001.

"Klarer Aufruf zum Schulterschluss," in Badische Zeitung. 20 April, 2002.

"Kohlers Arena hold Edeka-Cup," in Badische Zeitung. 19 September, 2003.

"Kohler und Oviesse starten," in Badische Zeitung. 18 September, 2001.

"Länger offen im Herbst?" in Badische Zeitung. 18 February, 2003.

Lahr City Council Meeting - 22 April, 1991. Stadtarchiv Lahr, Heizmann 24.

Lahr City Council Meeting - 7 October, 1991. Stadtarchiv Lahr, Heizmann 24.

Lahr City Council Meeting - 16 ${ }^{\text {th }}$ December, 1991. Stadtarchiv Lahr, Heizmann 24.

"Lahr muß nach Abzug der Kanadier einen > Lastenausgleich < erhalten," in Lahrer Zeitung. 3 August, 1991. 
"Militärstrukturelle Veränderungen $>$ mit Augenmaß ohne Krisengeheul < aufarbeiten," in Lahrer Zeitung. $28^{\text {th }}$ June, 1991.

"Mulroney Landon Entscheidung über Truppenreduzierung in Kürze," in Lahrer Zeitung. $20^{\text {th }}$ of June, 1991.

"Oberbürgermeister Dietz : >Bis jetzt sind das alles nur Sandkastenspiele, $<$ in Lahrer Zeitung. 18 September, 1991.

Ortenaukreis. 2006. Accessed April 9, 2006 at www.ortenaukreis.de ; Internet.

"Our Hospital." 2006. Accessed April 4, 2006 at www.heartlahr.com/englisch/about/hospital.htm; Internet.

"Poorer yes. But by how much?" in The Economist Jan. 11, 2003, vol. 366, no. 8306, p. 42.

"Ready to Motor?" in The Economist, Aug 20, 2005, vol. 376, no. 8440, pp. 58-60.

"Rund 3500 Übernachtungen und 2,5 Millionen Umsatz," in Lahrer Zeitung. 6 February, 1996.

"Selbst in Bonn war man verwundert," in Lahrer Zeitung. 18 September, 1991.

"So oder So, wir haben genügend Aufgaben," in Lahrer Zeitung. 20 September, 1991.

"Teuro Vorwurf trifft nicht den Handel," in Badische Zeitung. 3 July, 2002.

“Verbraucher boykottieren Preistreiber," in Badische Zeitung. 3 June, 2002.

"Verlockende Käsevielfalt," in Badische Zeitung. 7 June, 2003.

"Viele Faktoren treiben die Preise," in Badische Zeitung. 29 January, 2002.

"Wie kann die stadt den Spagat schaffen?" in Badische Zeitung. 15 March, 2001.

Wegweister zu Ihrer Unterkunft - das Schuttertal. [No other information given] Map.

Wirtschaftsstandort Lahr - Daten und Fakten, 2005. 2005. Stadt Lahr : Lahr.

"Wohnungsvergabe bereitet Ärger - auf beiden Seiten," in Badische Zeitung. 28 January 1995. For when find European place: 